2002

\title{
Design and implementation of Web-based GIS for forest fragmentation analysis
}

Fei Wang

West Virginia University

Follow this and additional works at: https://researchrepository.wvu.edu/etd

\section{Recommended Citation}

Wang, Fei, "Design and implementation of Web-based GIS for forest fragmentation analysis" (2002). Graduate Theses, Dissertations, and Problem Reports. 887.

https://researchrepository.wvu.edu/etd/887 


\title{
Design and Implementation of Web-based GIS for Forest Fragmentation Analysis
}

\author{
Fei Wang \\ Masters Thesis submitted to the \\ Eberly College of Arts and Sciences \\ at West Virginia University \\ in partial fulfillment of the requirements \\ for the degree of \\ Master of Arts \\ in \\ Geography
}

M. Duane Nellis, Ph.D., Chair

Timothy Warner, Ph.D.

Trevor Harris, Ph.D.

Department of Geology and Geography

Morgantown, West Virginia

2002

Keywords: Forest Fragmentation, IMS, ArcIMS, Web GIS, HTML, Java. 


\section{ABSTRACT \\ Design and Implementation of Web-based GIS for Forest Fragmentation Analysis \\ Fei Wang}

The advantages and limitations of current web GIS software for forest fragmentation information and analysis functionality were investigated using Landsat Thematic Mapper data of 1987 to 1999 for a test site in northern West Virginia. ESRI's ArcIMS technology was used to build a Web-based forest fragmentation analysis system to query, represent, and analyze the status of forest fragmentation using landscape metrics. Both ArcIMS HTML and Java fragmentation analysis tools were constructed. The web GIS was evaluated with respect to accessibility, navigation, interactive cartographic functionality, and spatial analysis functionality. The current ArcIMS approach was found to offer only limited support for the spatial analysis functions required for fragmentation analysis. A variety of enhancements to the current web GIS software are recommended, including support for polygon-based spatial query, interactive representation and operation for raster data, and the integration of userside and server-side data for spatial analysis. 


\section{Acknowledgments}

Conducting this research is one of my most unforgettable and desirable experiences. It helped me to grow from a student to a professional scholar in the domain of geographic information technologies. The completing this research would have been impossible without the generous support and encouragement of many people. I will try my best to express my immense appreciation to these people, though I know that no words are enough to convey my deep gratitude towards each and everyone of them.

My deepest gratitude goes to my amiable and excellent advisor, Dr. M. Duane Nellis, for his funding on my three-year graduate study and providing me the opportunity to work on this interesting and challenging project. I appreciate his encouragement, patience, understanding and guidance to me throughout this research. His constructive criticism and advice have been my most important source of inspiration. Most especially, I would like to thank him for setting up meetings with me to share his knowledge, insight, perceptions, experiences and concerns, despite his very busy administrative work as Dean. It was my pleasure to work under his supervision. Without him, this thesis would not exist.

My most heartfelt thanks go to Dr. Timothy Warner, for his unreserved sharing of his expertise in almost every respect. His wise advice, insightful suggestions and discreet proofreading and refining to this hundred page thesis from the first draft to the final version helped significantly improve the quality of my work. I would also like to deeply thank him for his understanding and support throughout my studies, practice, and writing. The invaluable guidance, encouragement, and advice I got from him were over and beyond what any student could have expected.

In particular, Dr. M. Duane Nellis and Dr. Timothy Warner not only assisted me in many phases of this study but also taught me a variety of valuable research methods which have prepared me to conduct future investigation.

My sincere appreciation goes to Dr. Trevor Harris, who served as a member on my committee, for his tremendous support in doing this research. His valuable comments and advice, and his thoughtful and sincere questions and ideas made this thesis better. I also deeply appreciate his kind support of funding, hardware and software for my Web GIS study.

I would like to thank all of my friends who had helped me on this project. My thanks go to Janette Bennett, Duffy, Brendon Keleagetse, Sewelo, Xianfeng Chen, Xuan shi, and Kaunda, Nalishebo. My sincere appreciation also goes to Kurt Donaldson, Frank LaFone, Eric Hopkins, Nicole Edwards, Kevin Kuhn, and Scott Lamon in West Virginia GIS Technical Center. These friends and colleagues tirelessly provided knowledge, advice, and friendship to me over the years. They will not be forgotten.

I also owe special thanks to Dr. Ge Lin, Dr. Michael Strager and Dr.Haixiao Huang for sharing their wealthy knowledge of GIS and GAP analysis.

My appreciation also goes to Beth Michael, Randy Crowe, Donna Titus, Hope Stewart for their kind and instantaneous help. 
I am very grateful for my years at the department of geography and geology, in Elberly College of Arts and Science of West Virginia University. Many thank to all the teachers and students here.

A "thank you" also goes out to NASA for supplying the funding that made my masters research possible

My special thanks goes to Dr. David Lanter. As my current job supervisor, he took me out from busy development work and gave me the time to prepare and finish my thesis and thesis defense.

My greatest debt is to my Mom. I am proud for possessing her understanding, confidence, the steadfast support and unfailing love. My mother has encouraged my further education greatly. Her continuous encouragement and unflagging drive to me toward the pursuit of knowledge have always been a source of inspiration for me. Since I was a kid, she has showed me the spirit of learning, inquiry, and integrity. She also taught me how to behave like a scholar-with sincerity and humbleness. I cannot thank her enough for everything she did and still does for me. Only thing I can do is to do better.

My deepest appreciation and love also goes to Xiaomei Yu, my lovely girl, and Xuan Wang, my sister and her husband Xin Li, for their unconditional love and support, endless encouragement, and for always being there for me. 


\section{Table of Contents}

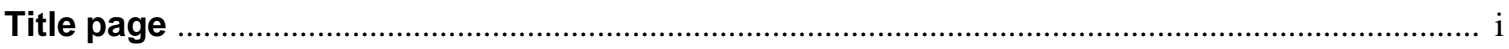

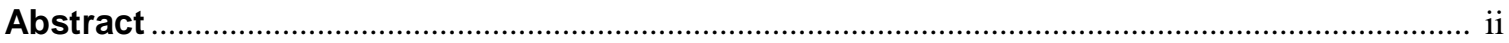

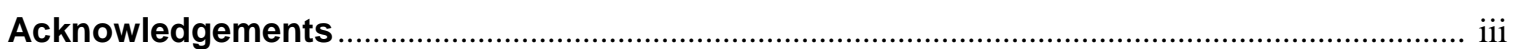

Table of Content

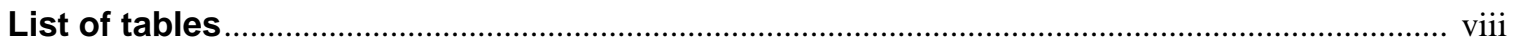

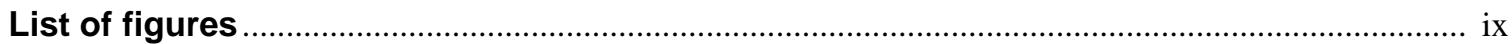

\section{Chapter 1: Introduction}

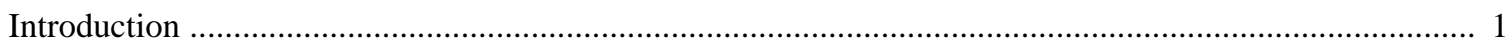

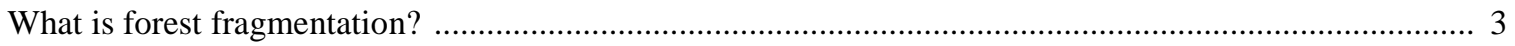

What are potential impacts of forest fragmentation? ............................................................................. 4

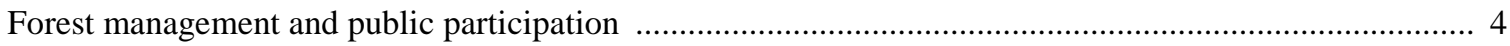

The new needs for geographic information technologies to improve the understanding of forest

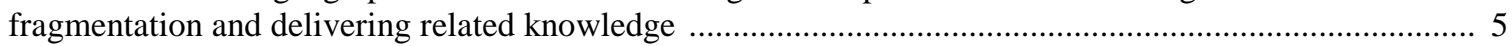

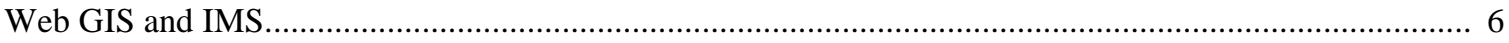

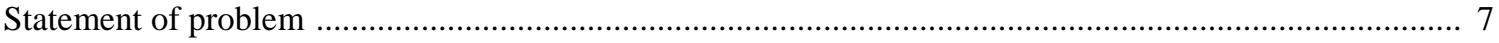

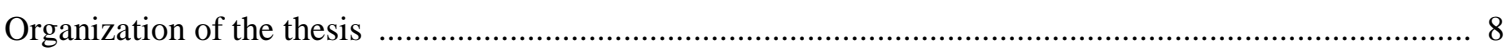

Chapter 2: Literature Review

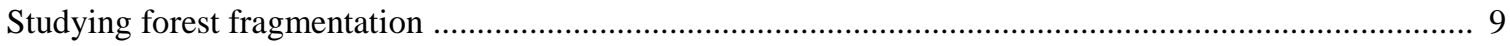

The origin and development of landscape scale forest fragmentation studies ................................. 10

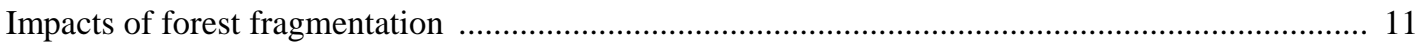

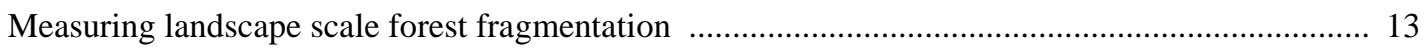

Remote sensing and forest fragmentation ………….................................................... 14

Forest fragmentation metrics ………………................................................................ 15

Tools for measuring forest fragmentation …………..................................................... 18

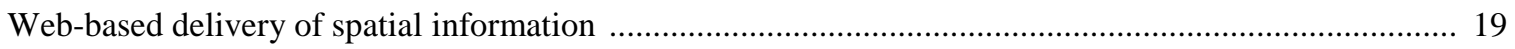

Basic architecture and components of Web-based information delivery ........................................ 19

Limitations of Web on delivering spatial Information .................................................................. 21

Web-based delivery methods of spatial information ...................................................................... 22 


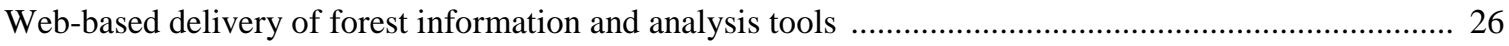

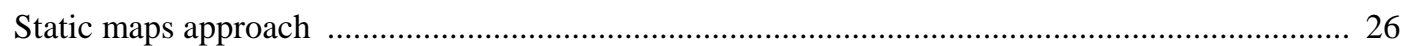

File Transfer Protocol (FTP) based forest data service .............................................................. 27

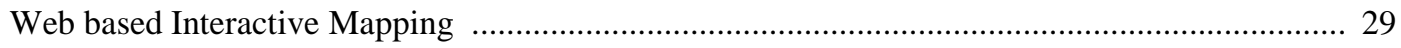

Web based information delivery for forest fragmentation .................................................... 34

\section{Chapter 3. Study Area}

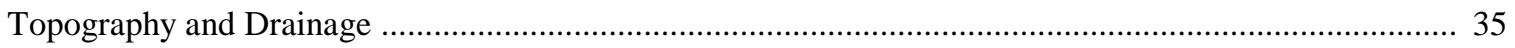

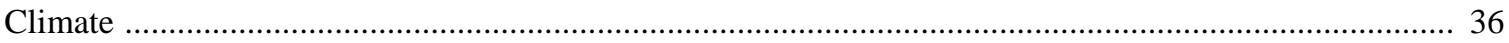

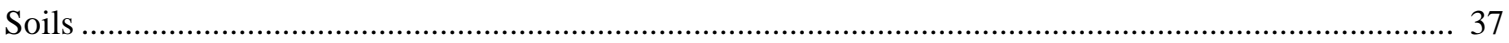

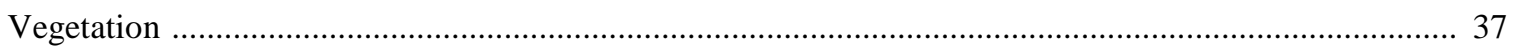

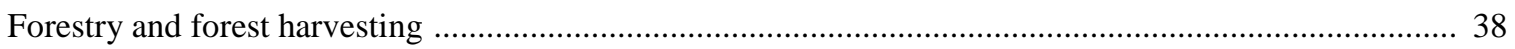

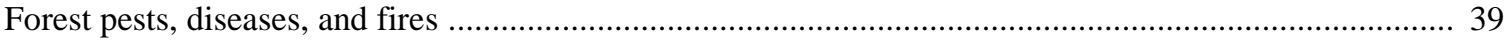

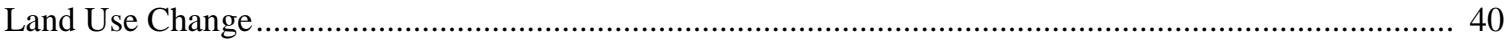

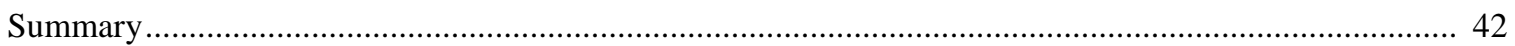

\section{Chapter 4 Methods}

Analyzing forest fragmentation on a standalone computing environment ……....................................... 43

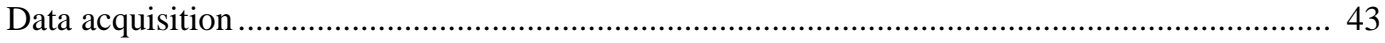

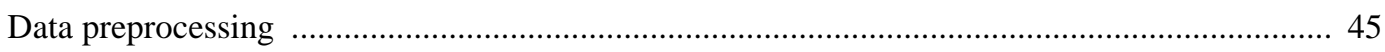

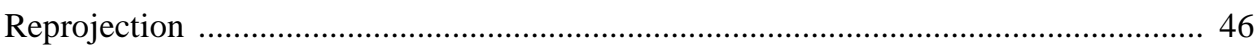

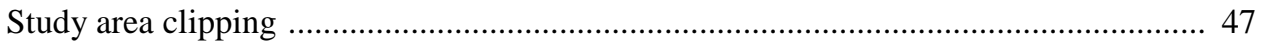

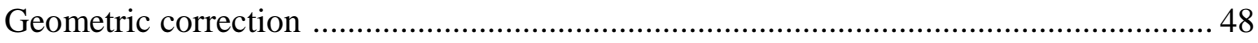

Land Cover/ Land Use Classification .................................................................................. 48

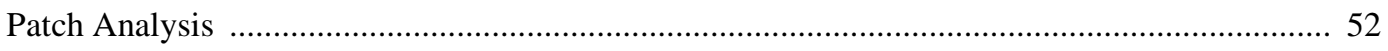

The design and implementation of Forest Fragmentation Analysis Web site with ArcIMS ..................... 55

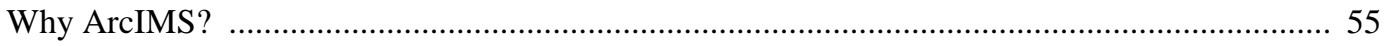

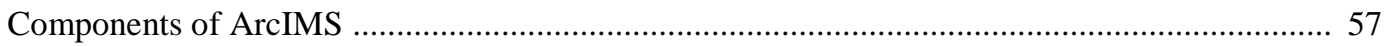

Communications among ArcIMS components via ArcXML .................................................... 59

General steps of designing and implementing a WebGIS website with ArcIMS ........................ 60 
Proposed Functions in Forest Fragmentation Analysis Web Site ............................................... 62

The Steps of implementing Forest Fragmentation Analysis web site ......................................... 63

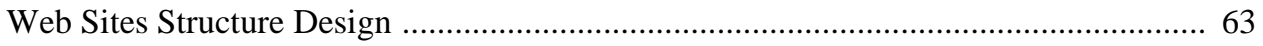

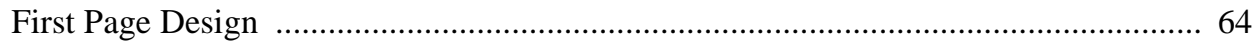

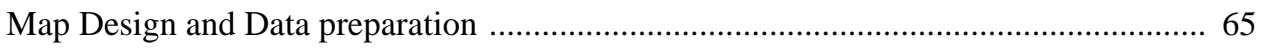

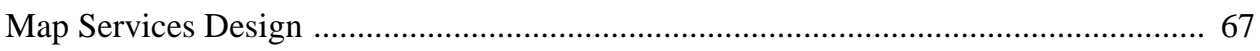

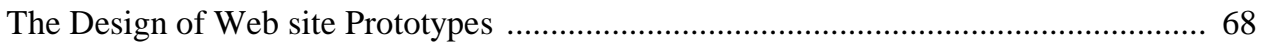

Customizations on interfaces and functionalities ....................................................... 73

\section{Chapter 5 Results and Discussions}

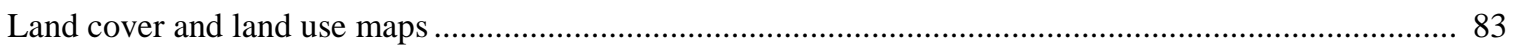

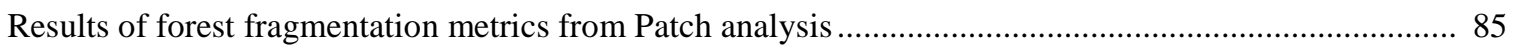

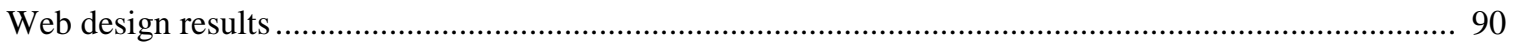

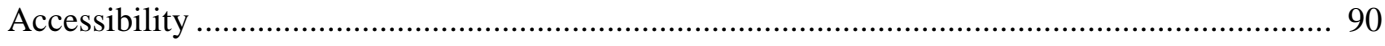

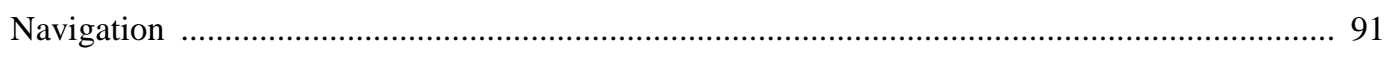

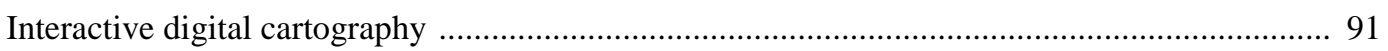

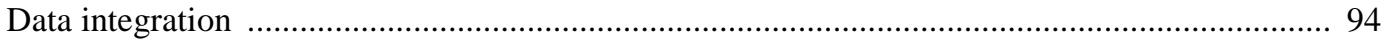

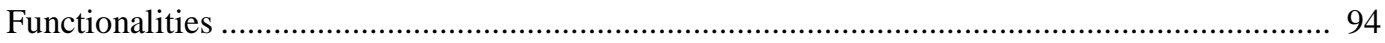

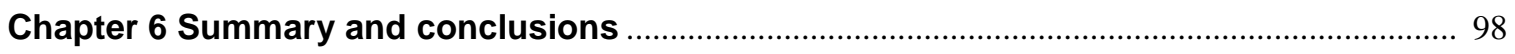

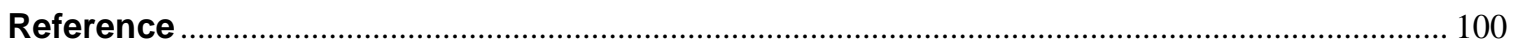




\section{List of Tables}

Table 3.1 Area of timberland and forest types in Monongalia and Preston Counties in 1989 (in thousands of acres)

Table 3.2 West Virginia forest land conversion from 1982 to 1997 (in thousands of acres)

Table 3.3 West Virginia urban land conversion from 1982 to 1997 (in thousands of acres)

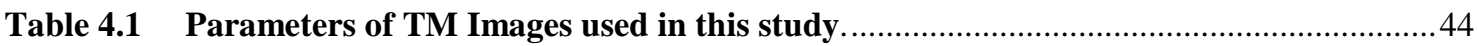

Table 4.2 Landsat5 TM Spectral and Spatial Resolution …..........................................................44

Table 4.3 Landsat7 Spectral and Spatial Resolution .................................................................. 44

Table 4.4 West Virginia Gap Land Cover Classification Schema ……….................................. 46

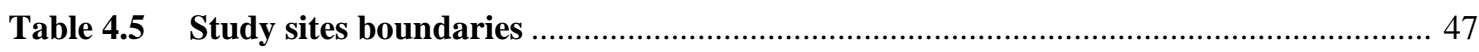

Table 4.6 The recoded Classification schema for TM image classification................................... 49

Table 4.7 MapServices in the Forest Fragmentation Analysis web sites ......................................68

Table 4.8 Web sites and their associated Viewer types and MapServices in WFFA system.

Table 4.9 JavaScript objects, related properties and methods for calculating forest fragmentation metrics

Table 5.1 Forest fragmentation metrics results derived

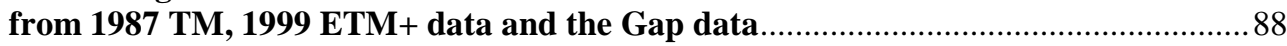

Table5.2 Household and population statistics for the eastern portion of Monongalia County and western Preston County for 1990 and 2000

Table 5.3 The implementation of forest fragmentation analysis functionalities 


\section{List of Figures}

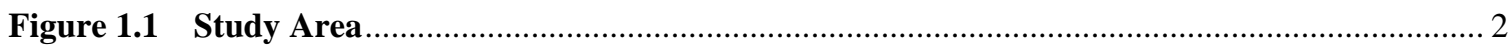

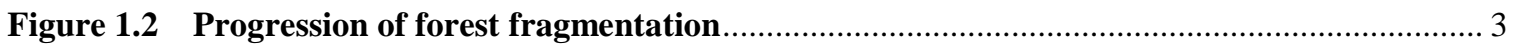

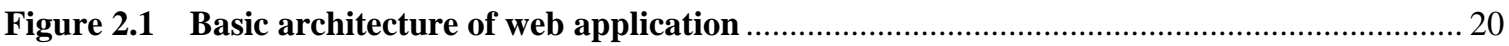

Figure 2.2 Example of an image maps: Pennsylvania Spatial data Access web site

Figure 2.3 Example of animation-based Web mapping: using

Macromedia Flash for interactive web mapping.

Figure 2.4 Web GIS example: Delaware 2000 Census Mapper

Figure 2.5 Web-based Static maps approach example 1: EPA Mid-Atlantic Integrated Assessment (MAIA) environmental Atlas.

Figure 2.6 Web-based Static maps approach example 2: forest fragmentation research web site

Figure 2.7 FTP based Forest Service land cover data service created by West

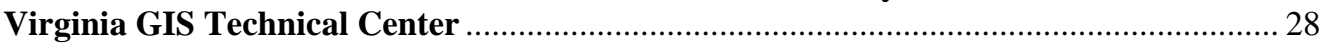

Figure 2.8 Web site of Global-Scale Patterns of Forest Fragmentation........................................... 29

Figure 2.9 USDA forest Service Forest Inventory Mapmaker ………………................................. 30

Figure 2.10 Sample results from USDA forest Service Forest Inventory Mapmaker.......................... 31

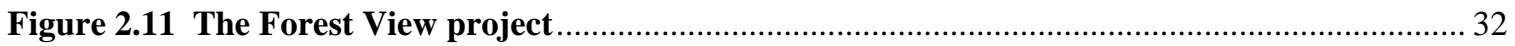

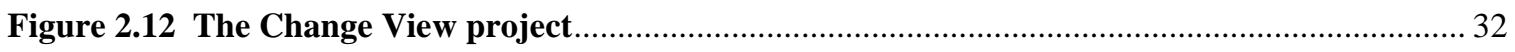

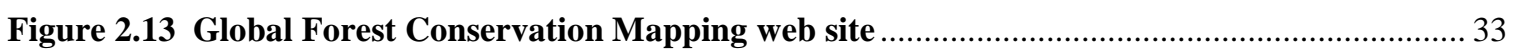

Figure 3.1 Three main forest management groups in the study area............................................. 35

Figure 4.1 Interface of ERDAS Imagine ${ }^{\circledR}$ Geometric Model …….................................................. 47 
Figure 4.2 Selected supervised classification signatures from the imagine signature editor

Figure 4.3 Spatial model for adding roads and power lines to the TM classification images

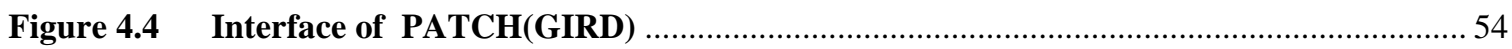

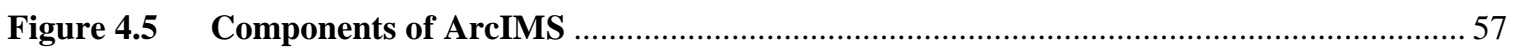

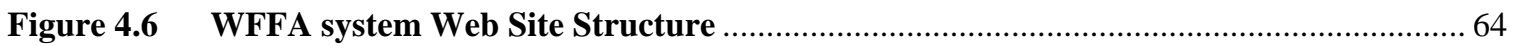

Figure 4.7 Interface for WFFA first page of the forest fragmentation Analysis web site

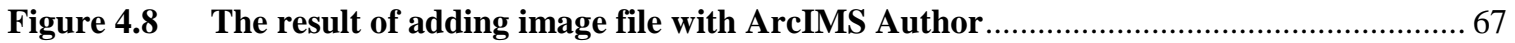

Figure 4.9 The result of displaying image file in the client side web browser ................................ 67

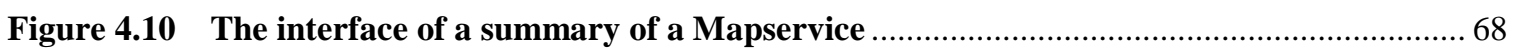

Figure 4.11 The interface for setting up the entry directory and title for the web site with ArcIMS

Figure 4.12 The interface for setting up MapService for the Web GIS application.

Figure 4.13 The interface for setting up the web site template......

Figure 4.14 The interface of setting up initial Map Extent with ArcIMS........................................ 70

Figure 4.15 The interface for setting up pre-defined interactive mapping functions

Figure 4.16 The interface for setting up the look of mapping elements, including the colors of the background, foreground and outlines of maps.....

Figure 4.17 Interface of setting up MapTips and Identify results …………................................. 73

Figure 4.18 Forest fragmentation viewer HTML Viewer interface................................................. 74

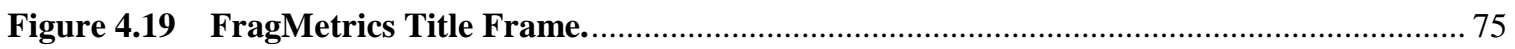

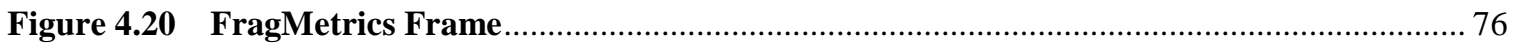

Figure 4.21 Forest fragmentation index results from a defined polygon ......................................... 77

Figure 4.22 ArcIMS justGetFeature Count function ...................................................................... 78

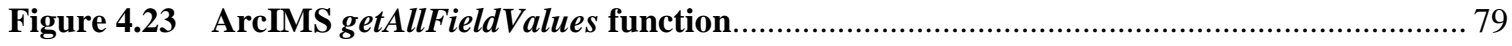




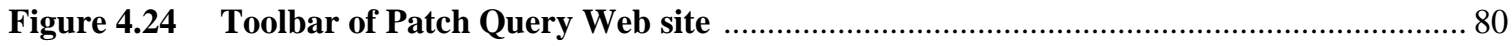

Figure 4.25 Program segment of calling the function queryPatchForm() ................................. 80

Figure 4.26 Interface of Inputting the size of Patch .......................................................... 81

Figure 4.27 Patch list of the size of patch >400000s sq.meters .......................................... 82

Figure 4.28 Patches which size >400000s sq.meters were shown in Map frame........................... 82

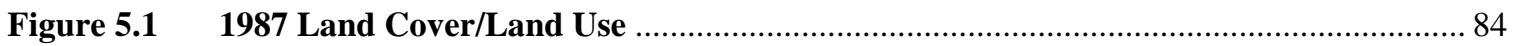

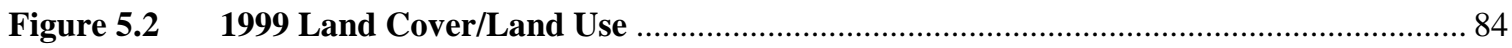

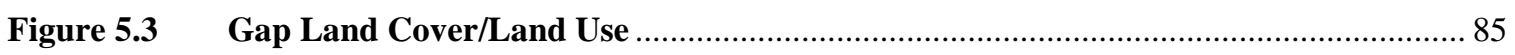

Figure 5.4 Overlay map of Gap theme and Landsat TM

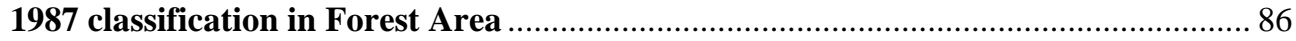

Figure 5.5 Overlay map of Gap theme and Landsat TM

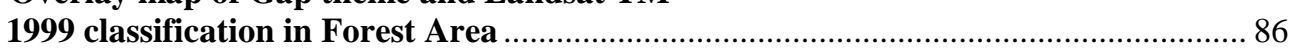

Figure 5.6 Overlay map of Gap theme and Landsat TM

1987 classification in Developed Area

Figure 5.7 Overlay map of Gap theme and Landsat TM

1999 classification in Developed Area

Figure 5.8 Semi-transparent rendering of Land classification map overlapping on a Landsat image .... 93

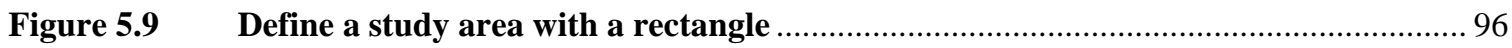

Figure 5.10 The result of defining a study area with the rectangle selection tool. 


\section{Chapter 1: Introduction}

\section{Introduction}

Forest fragmentation has complex effects on the local environment and economy of many areas in the eastern United States (Saunders et al. 1991, Hill et al. 1998, Weakland 2000). Changes in social and economic factors drive general land use change and forest fragmentation. Improving the understanding of forest fragmentation is becoming an increasing concern to Federal and State agencies and non-governmental organizations which are involved in natural resource management and associated policymaking.

West Virginia has more than 4.78 million hectares (11.8 million acres) of forested land (USDA Forest Service Northeastern Station 2000). Forest resources are central to the West Virginia economy, environment, recreation, and for ecological diversity. However, human activities, including introduced forest fires, timber harvesting, road construction, and home and service-sector development (particularly, recreational development and logging on private lands) are placing an ever-increasing strain on the West Virginia regional forest ecosystem (DeMeo1999). Since at least 1988, the U.S. Department of Agriculture (USDA) Forest Service has been interested in potential forest fragmentation stress in this area (DeGraaf and Williams 1988). A survey between 1982 and 1997 found that forested land in West Virginia increased by 68,351 hectares (168,900 acres). However, the total area of conversions was much larger. It was found that 128,810 hectares $(318,300$ acres $)$ of forest was converted to other uses, including 72,160 hectares $(178,300$ acres) lost to urban development, and there was an increase of nearly 242,810 hectares $(600,000$ acres $)$ of forest land from conversions of crop and pasture land (USDA Natural Resources Conservation Service, 1997). These conversions have had implications for forest fragmentation in this region and raise important questions such as how to monitor forest fragmentation dynamics at the landscape scale, what is the relationship between social and economic factors and forest fragmentation, and what are the possible effects on local wildlife habitat and biodiversity? Related to these questions is the interest in improving the understanding of the problem of forest 
fragmentation in West Virginia. In addition, in West Virginia, more than 90 percent of forestland is privately owned (USDA Forest Service Northeastern Station, 2000). The parcelization of land ownership may increase the complexity of forest management at the landscape scale (Riemann and Tillman 1999). Significant efforts are being made to help private landowners apply environmental and economic resource management principles to benefit themselves, future landowners, and the public. For example, the USDA sponsors the Forest Stewardship Program (USDA Forest Service, 2001c). Most of these programs have a geographic context. Therefore, studying ways to improve pubic access to this kind of spatial information and knowledge is necessary.

In order to understand better the problem of forest fragmentation in West Virginia and find potential Internet-based spatial information solutions to improve the forest fragmentation analysis and knowledge delivery, a case study was chosen. The study site is in northern West Virginia, and covers Central and Eastern Monongalia County and Western Preston County (Figure1.1).

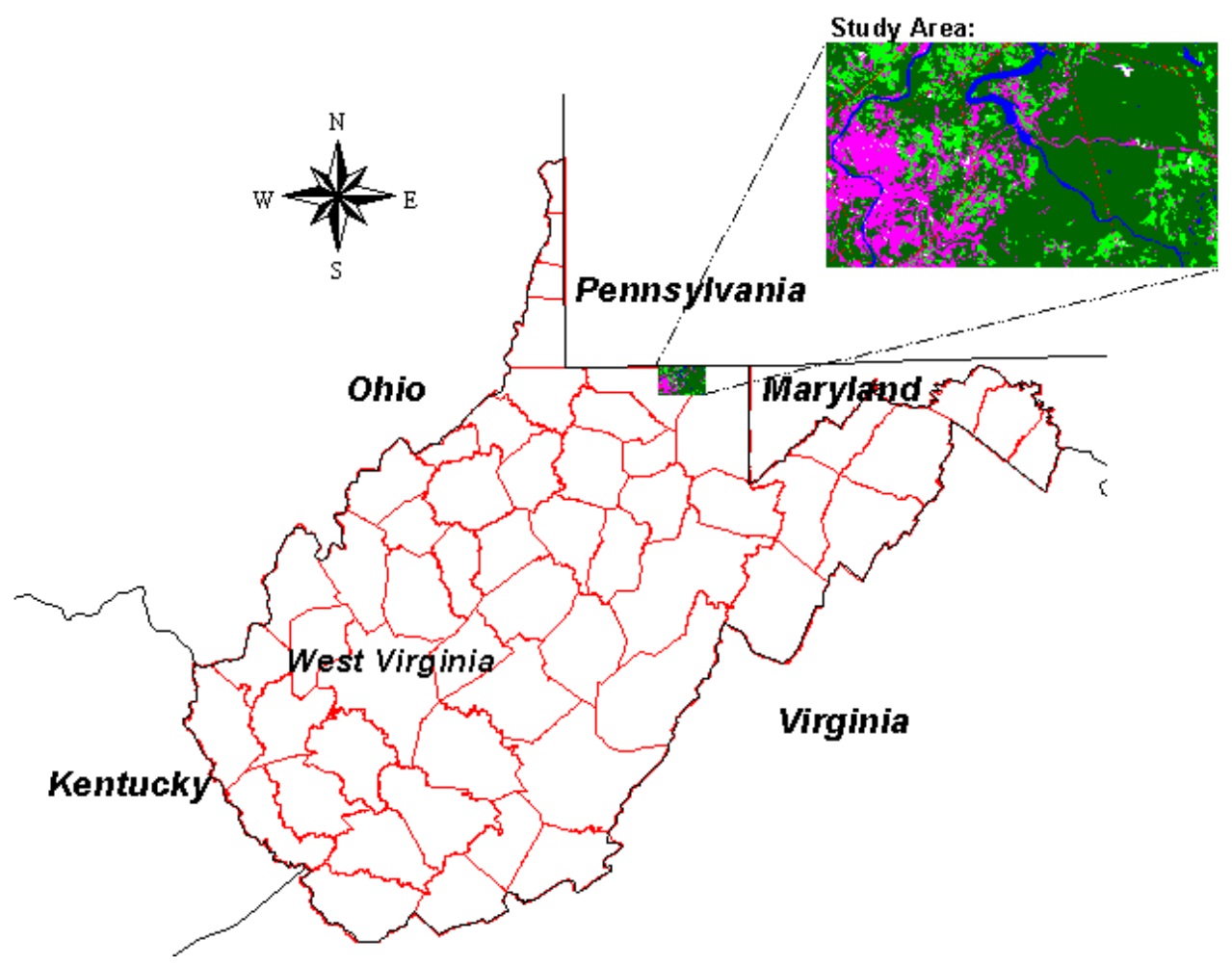

Figure 1.1 Study Area. 


\section{What is forest fragmentation?}

Fragmentation is the process of dissecting large and contiguous areas of similar native vegetation types into smaller units separated by different vegetation types and/or areas of intensive human activity (Saunders et al. 1991). As such, forest fragmentation is a process by which large expanses of forest are increasingly divided into smaller, discontinuous units. With the progress of fragmentation, a naturally patchy forest is transformed into a fragmented forest, then to a number of forest fragments, and finally a single insular forest patch (Harris and Silva-Lopez 1992) (Figure 1.2).

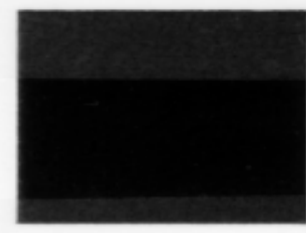

forested

landscape

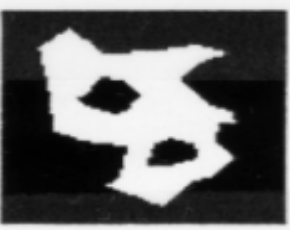

fragmented forest

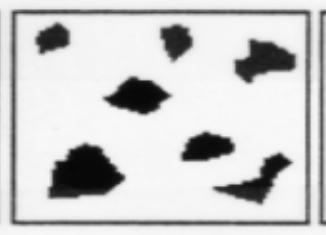

forest fragments

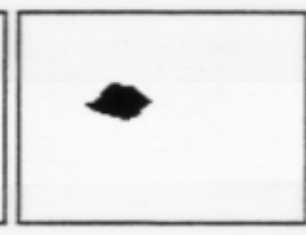

insular forest patch

Figure 1.2 Progression of forest fragmentation (from Harris and Silva-Lopez 1992).

The causes of forest fragmentation are varied and complex. Fragmentation may result from natural events such as forest pests, forest fires, or may occur from dynamic interactions between the natural landscape and society's ever-increasing demands on the land, creating a mosaic of the natural and human-modified environments (Gardner et al. 1999, Tyrrell and Dunning 2000). Forest fragmentation may result from permanent land use conversion, such as from forest to agricultural fields, or result from temporary land cover change, such as the disruption of mature forests by timber harvesting (Weakland 2000).

In addition, forest fragmentation is sensitive to the spatial scale (Lord 1990). For example, fragmentation apparent at a large spatial scale may sometimes be considered as non-fragmented at a smaller scale. Forest fragmentation is also sensitive to, and influenced by, the land cover classification system employed. Different classifications will give a different picture of the same region's fragmentation. 


\section{What are the potential impacts of forest fragmentation?}

Even though some research has shown forest fragmentation has had little impact on specific species in high density forest areas or even positive effects on some edgesensitive species in West Virginia (Demeo 1999, Weakland 2000), most research has shown that forest fragmentation can have negative, and even irreversible effects on biodiversity and forest health. In particular, forest fragmentation associated with development may reduce the sustainability of the regional ecosystem. Habitat for certain wide-ranging species, such as large mammals and migrant birds, can be destroyed permanently. Edge environments create pathways for invasive nuisance species, domestic predators, and disease vectors, making forests much more difficult to manage (Tyrrell and Dunning 2000).

Forest fragmentation may also be detrimental to human health, recreational opportunities, and economic well-being. Forest fragmentation may change the distribution of market and nonmarket benefits and costs from the landscape. Continued fragmentation can lead to a loss of aesthetic values, recreation, forest-based employment, and harvested forest products (Hill et al.1998).

\section{Forest management and public participation}

Many conservationists believe that reserves of public lands do not constitute sufficient habitat to conserve biodiversity effectively and that private landowners need to be included in conservation efforts (Hansen et al. 1991, 1000 Friends of Wisconsin and The Land Use Institute 2001). Not only are foresters required to consider the ecological, socioeconomic and institutional policy dimensions of forested landscapes when developing management plans, ideally, private landowners will also participate in planning the future of the larger forested landscape, of which they own a small part (1000 Friends of Wisconsin and The Land Use Institute 2001).

The dispersal of forest ownership may cause forest parcelization, or a trend toward dividing land up into smaller acreage parcels. When previously large forest tracts are divided into smaller ones, it is rare that the various new landowners will have the same forest management goals. Therefore, the chances for management and protection of 
this forest tract decrease. It has been shown that forest management practices on private lands can influnce the dynamics of forest fragmentation, and then have an impact on specific species (Weakland 2000). However, a vast majority of society has a limited understanding of forest fragmentation as a sustainable forest development issue. It will be necessary to take steps to increase public awareness and education, as well as provide access to information detailing considerations associated with forest fragmentation.

West Virginia loggers in recent years have cut about twice as much timber as they did 10 years ago according to a state Division of Forestry study (The Charleston Gazette Online 2001). This increase in forest harvesting is expected to continue. The attitudes and actions of private forestland owners will likely guide the future of logging in West Virginia (Weakland 2000). The relationships between such forest harvesting activities and the future of West Virginia forests is not being addressed because of "the lack of public involvement" and "the lack of an open-ended and broad-based planning process that will address it", according to the Charleston Gazette Online (2001).

\section{The new needs for geographic information technologies to improve the understanding of forest fragmentation and delivering related knowledge.}

Geographic information sciences and technologies, such as remote sensing and Geographic Information System (GIS), have been widely applied for forest fragmentation analysis (Johnsson 1995, Jorge and Garcia 1997, Roberts et al. 2000). However, most of these applications focused on integrating spatial data, establishing spatial information models and representing the spatial knowledge based on stand-alone platforms or a Local Area Network (LAN) based architecture. These traditional approaches have limited capabilities to provide public access to geographic knowledge and to represent geographic phenomena with distributed spatial data.

These limitations could constrain the value of GIS and remote sensing for fragmentation research. The causes and effects of forest fragmentation are varied and complex. Collaborative research on many levels of both public and private sectors may provide creative solutions to help us understand forest fragmentation (Tyrrell and Dunning 2000). Moreover, researchers studying forest fragmentation need spatial data 
from many different disciplines, sources, media, and institutions. Combining data from such diverse sources will require new approaches to integrate distributed spatial data for representation, analysis and query.

Different management practices of private forest owners may have direct effects on forest fragmentation. It is therefore necessary to take steps to increase public awareness of forest fragmentation. This will require public access to collect and synthesize various forest data, such as the existing status of forest cover, ownership, spatial requirements for maintaining species habitat, the potential effects of individual actions, landscape scale patterns and so on. The powerful spatial data representation and analysis abilities supported by GIS have increased people's understanding of spatial phenomena. However, the public still has limited access to GIS functionality. Therefore, there is a need to find potential methods to enhance the public's access to these functionalities.

\section{Web GIS and IMS}

Internet technology can improve the accessibility and utility of spatial information through its potential to deliver GIS data efficiently, and to manage and operate distributed spatial databases. A GIS running on Internet protocols is called an Internet GIS. The Internet GISs which run on the World Wide Web (WWW) environment are called Web GISs.

A Web GIS has two parts. The first part is the client side interface which runs in a web browser, and sends the user's requests to a server. The second part is a Web GIS server, or Internet mapping server (IMS), which serves mapping and spatial analysis functions. These server-side functions are always called map services (ESRI 2001). Building a GIS based on the Web provides a potential approach for establishing spatial models with distributed spatial data and services, and for adding new forms of data such as hyperlinks and multimedia into geographic information representation. A Web GIS can also provide multiple views for the same geographic phenomena.

Compared with a traditional stand-alone GIS, Web GIS has many advantages. First, a Web GIS provides access to spatial information and data without burdening end 
users with complicated and expensive software. Second, Web GIS is particularly powerful for a distributed, multi-site organization. Third, it is particularly powerful for communicating with the public. Fourth, people can specify their unique areas of interest and then see the information described in a map. In addition, users also can click on a map feature or area and see selected database information about that particular map item. They thus have access to an easy way to navigate through large quantities of information. Fifth, using very simple user interfaces, users can view dynamically-constructed maps that reflect the current state of the information (Intergraph 2001). These advantages may enhance community participation in geographic-related planning and policy-making.

\section{Statement of problem}

This study has two main objectives: (1) to develop an understanding of the current status of forest fragmentation and its changes from 1987 to 1999 in a study area in northern West Virginia, and (2) to assess Internet Mapping Server (IMS) and Web GIS as new approaches to improve forest fragmentation information analysis, representation and delivery through a case study.

For the first objective, the main approach will draw upon a classified recent Landsat Thematic Mapper image combined with previously classified Gap Analysis Program (GAP) data to identify changes of landscape-scale forest fragmentation in the study area. The regional perspective of fragmentation gained from satellite imagery will aid policy makers, managers, and researchers.

For the second objective, the basic question is methodological. Specially, I will investigate whether ArcIMS can be used for delivering forest fragmentation information and to support selected essential forest fragmentation analysis functions such as a userdefined region metrics calculation and disturbance analysis. In addition, the limitations of existing ArcIMS HTML and Java approaches for supporting forest fragmentation information delivery and analysis will be investigated. 


\section{Organization of the thesis}

This thesis consists of six chapters. Following the Introduction, the Literature Review summarizes previous work on forest fragmentation analysis and Internet GIS technologies. The third chapter gives a detailed introduction to the study area as it relates to the general topography, drainage, climate, soil, forests and forestry, land cover and land use change. The fourth chapter, Methods, outlines the specific procedures that were developed for forest fragmentation analysis with Landsat TM data on a stand-alone platform and in a Web-based environment. After that, in Chapter Five, Results and Analysis, the spatial pattern of forest fragmentation of the study area is presented, and the Web GIS HTML and Java approaches for delivering the above information and analysis capabilities are compared. Finally, in Chapter Six, the Summary and Conclusion are presented. The capabilities and limitations of current ArcIMS approaches for supporting forest fragmentation analysis are identified and potential future research suggested. 


\section{Chapter 2. Literature review}

"The natural world is interconnected, therefore, interdependent."

This literature review focuses on three topics: forest fragmentation, Web-based spatial information delivery, and Web-based forest information delivery. In the first section, the current status of landscape-scale forest fragmentation studies and methods for measuring changes of forest fragmentation at landscape scale will be reviewed. Where possible, examples will be given of forest fragmentation studies in West Virginia. The limitations of stand-alone forest fragmentation analysis and representation approaches will be critiqued. In the second section, Web-based spatial information delivery approaches will be introduced. In the third section, approaches to the delivery of forest information and analysis tools in a Web environment will be reviewed. The concepts and methods of Web-based GIS will be introduced as a powerful new approach, which may improve interactivity and accessibility of forest information and associated analysis tools.

\section{Studying Forest fragmentation}

Traditionally, forest management has focused on forest stands ranging in scale from individual trees to a few hectares or even a few square kilometers. It has become increasingly apparent that stands cannot be managed wisely and efficiently in isolation. Forest management must take into account the small scale (Sachs et al. 1998). More and more research is addressing the spatial modeling of forests at the landscape scale (Mladenoff and Baker 1999). Forest fragmentation is one of the main concerns in landscape level forest management.

Lord (1990) presents a detailed review of scale and the spatial concept of fragmentation. He states that fragmentation could occur at different scale, with varying impacts on organisms. In his opinion, (1) at a finer scale of fragmentation, "ecosystem functioning is more likely to be disrupted"; (2) at a given scale, more complex systems are more likely to be disrupted by fragmentation than simpler systems; (3) "The finer the scale of fragmentation, the smaller the organism that is adversely affected"; and, (4) a 
finer scale fragmentation analysis may be used for studying organisms with a limited range of mobility, whereas coarser scales are more suitable for very mobile organisms.

\section{1) The origin and development of landscape scale forest fragmentation studies}

The study of forest fragmentation at landscape scale originates from forest research in landscape ecology and conservation biology. Studies in those two fields had discovered two important principles. First, habitat fragmentation in forests may lead to the loss of species and result in an impact on the biodiversity (Verboom and Van Apeldoorn 1990, Kruess and Tscharntke 1994, Donovan et al. 1995). Kozakiewicz (1993) in his study on the effects of habitat isolation on small mammal populations and communities, found that movements of individuals between habitat patches are critical to support the existence of species in patchy, heterogeneous landscapes and "Key habitats" play a crucial role for population existence in the dynamics of species needs and resource

supply. Kozakiewicz (1993) second finding was that edge habitats could be considered to be a distinct community. "Create as much 'edge' as possible" had been included in standard habitat management (Harris 1984) because "wildlife is a product of the place where two habitats meets" (Yoakum and Dasmann 1971). Recent research has supported the concept of the special role of edges. Berry (2001) in his study on edge effects on forest birds, found that there was a significantly higher number of species and individuals in forest edges than in nearby forest interior sites.

Increasing the amount of habitat fragmentation and edge habitats are two direct consequences of forest fragmentation (Rolstad 1991, Esseen and Renhorn 1998). Researchers have focused on forest fragmentation and its consequences, including impacts on biodiversity, and the productivity and sustainability of forests.

Previous forest fragmentation studies have five main areas of focus: (1) assessing the status of forest fragmentation and identifying the extent and location of forest fragmentation (O'Neill et al. 1988, Turner 1990, Turner and Gardner 1991, Ripple 1994, Johnsson 1995, Wickham et al. 1997, Tinker et al. 1998, Roberts et al. 2000, Saura and Martinez-Millan 2001, Mid-Atlantic Regional Earth Science Application Center 2001); (2) modeling changes of forest fragmentation, predicting the fragmentation trend 
(Burnham 1973, Muller and Middleton 1994, Sachs et al. 1998, Hsu 2000); (3) identifying the impacts of forest fragmentation on specific species (Lynch and Whigham 1984, Rolstad 1991, Matthysen 1995, Rudis 1995, Russ 2000, Hewison et al. 2001); (4) exploring the causes of forest fragmentation (Reed 1996); and (5) developing forest fragmentation analysis and representation tools (Vogelmann 1995, Theobald 1998, Lefsky et al. 2001).

\section{2) Impacts of forest fragmentation}

Saura and Martinez-Millan (2001), in their research on the sensitivity of landscape pattern metrics to map spatial extent, state that landscape spatial configuration influences ecological processes such as biodiversity and animal population dispersal and abundance. Landscape spatial configuration of forest fragmentation usually refers to two aspects: the absolute quantity of fragmented patches and the dispersion pattern of these patches. A great deal of research on landscape level forest fragmentation has investigated the consequences of forest fragmentation for biodiversity, species population, forest health, and forest productivity, and especially the impacts on specific birds or animals. It has been found that increased fragmentation may, in the long run, decrease species richness. For example, for birds and mammals that depend on habitats in interior forest or late-successional stands, clear-cuts and roads can result in a quantitative and qualitative reduction in suitable habitat (Andren 1994, Vogelmann 1995). However, this result conflicts with the result of Berry (2001)'s study. The potential reason may come from the different reaction of different species to forest fragmentation.

It is very difficult to identify all the species that are affected by forest fragmentation. There are three main reasons for this. First, different species prefer different landscape patterns, and it is unlikely that any single measure of fragmentation is relevant in all situations (USGS Biological Resources Division 1999). The species that prefer edge habitats may benefit from an increase of forest fragmentation, but other species may decrease as a consequence of a more fragmented forest. Second, to predict the effects of landscape modification, models of species reproduction need to incorporate variation in the animal-landscape relationship due to behavioral plasticity (Hewison et al. 2001). Third, forest species' biological characteristics such as populations and 
biodiversity are affected by many other social or biological factors besides forest fragmentation. For example, through studying the complex and species-specific impacts of forest fragmentation on bird populations, Lynch and Whigham (1984) found that although forest fragmentation adversely affects some bird species, structural and floristic characteristics of the forest can be more significant than patch size and isolation for some bird species. Distinguishing forest fragmentation impacts from other factors is very complex, and until now has not received much attention.

Recent research has addressed the relationship between species diversity and productivity in the Appalachian forest, as well as the relationship between harvesting and regeneration strategies and maintaining species diversity (Miller and Smith 1991, Miller and Kochenderfer 1998). It has been shown that choosing suitable harvesting and regeneration strategies has direct consequences for species diversity. Maintaining species diversity is the key to sustaining production of desired benefits in central Appalachian forests.

At present, the impacts of forest fragmentation in West Virginia have not been widely studied. Two exceptions are DeMeo (1999) and Weakland (2000). Weakland (2000) found that forest fragmentation caused by timber harvesting is not having shortterm deleterious impacts on most songbirds. DeMeo's (1999) study found that fragmentation effects in West Virginia forest were evident but only up to $25 \mathrm{~m}$ from edges. Beyond this distance, DeMeo found only an ambiguous relationship of nest survival to distance from the edge.

Even though within the scientific community there is no strong consensus on understanding the specific mechanisms by which fragmentation changes forests and reduces their habitat value, it is relatively well established that decreases in forest cover and increases in fragmentation will result in negative ecosystem effects (Mid-Atlantic Regional Earth Science Application Center, 2001). It has been suggested that the landscape can be managed under the assumption that if a landscape is maintained within the limits of natural variability, then most native species will be managed adequately (Tinker et al. 1998). 


\section{3) Measuring landscape-scale forest fragmentation}

In order to maintain the integrity of forest ecosystems while continuing to provide for sustainable forest development, an essential requirement is to assess quantitatively the forest fragmentation status at the landscape scale and to identify its extent, location, amounts and spatial pattern.

There are many different ways to measure forest fragmentation, because there are a variety of features that can be interpreted as subdividing a forest, and different scales at which the various definitions can be applied (McGarigal and Marks 1994, Riiters et al 1995, Mertens and Lambin 1997, Nielsen and Paracchini 2000). Nielsen and Paracchini (2000) in their study on remote sensing-based estimates of structural diversity and sustainability for forest ecology assert that there cannot be a single measure that quantifies fragmentation, because fragmentation is so complex and may have many manifestations. Thus it is necessary to use various combinations of measures. USGS Biological Resources Division (1999) in their Nation's Ecosystem research point out that calculating the effects of a road or a power line in fragmenting a forest is related with whether the edges of these features are considered as patch boundaries. Even more complex is whether to regard patches of different age classes as boundaries.

In most studies, forest fragmentation is usually measured in one of three ways: the absolute amounts of fragmented patches, the spatial disperse pattern of those patches, and the associated changes (Turner 1990, Hsu 2000). The first two approaches can usually be implemented with various landscape metrics, the last approach requests a linking of landscape metrics models such as regression and logit models (Alig 1986, Dale et al. 1993, Hsu 2000) for spatial trend prediction.

The spatial units for fragmentation analysis are commonly user-defined independent study units such as terrain facets, watersheds or management units (Johnsson 1995). Alternatively, continuous units such as a 3x3 pixel window are sometimes used in raster data.

Mathematical graphics have also been used as a framework for exploring the spatial structure and configuration of ecosystem components (Cantwell and Forman 1993, Anderson and Danielson 1997). Analysis of forest fragmentation using spatial 
autocorrelation, graphs and GIS can help us understand the connectedness or disconnectedness of forests, and assess the extent of fragmentation of forests introduced by natural and man-made features and disturbance (Roberts et al. 2000).

Forest fragmentation analyses require information on land cover and land use. The information could be stored in vector or raster structures. Most landscape-scale forest fragmentation studies have been raster-based, because of the importance of classified remotely sensed data in providing land cover information (Wickham et al, 1997, Saura and Martinez-Millan 2001).

Nevertheless, these remain a significant need for increased work on the integration of RS, GIS and landscape ecology metrics for modeling, monitoring and assessment of ecosystems space (Ripple et al. 1991, Vogelmann 1995, Frohn 1998).

\section{Remote Sensing and forest fragmentation}

In landscape-scale forest fragmentation analysis, capturing consistent and complete land-cover and land use data in a large area is an essential requirement. "Consistent" means that there must be no spatial pattern to the random and systematic error. "Complete" means that the data cover the entire area rather than provide a sampling of it (Sachs et al. 1998). Satellite imagery is an excellent tool for gathering consistent and complete spatial data for large areas for the purpose of measuring landscape patterns (Saura and Martinez-Millan 2001).

The special advantages of satellite imaging for landscape pattern analysis has been widely discussed in many studies. Johnston et al. (1997) found satellite remote sensing to be "an inexpensive tool" for forest management. Scott et al. (1993) and Sharma and Palni (2000) demonstrated that satellite remote sensing could be used successfully to identify the frequency, boundaries, and sizes and shapes of various landscape components.

Digital imagery obtained from multi-temporal satellite remote sensors including NOAA-9, SPOT (Rasch 1994), Landsat MSS (Vogelmann 1995, Sachs et al. 1998) Landsat TM (Ripple 1994), and IRS (Sharma and Palni 2000) have been successfully used to map land-cover and associate changes for forest fragmentation analysis at different spatial resolution (Fang 1990, Chavez and MacKinnon 1994). 
The most popular sensor in the United States for regional or local landscape-scale forest fragmentation analysis, as well general forest studies is Landsat TM (Chalifoux et al. 1998). For example, Stenback and Congalton(1990) used Landsat TM for mapping forest understory. Sader (1995) investigated the spatial characteristics of forest clearing and vegetation regrowth with multi-date Landsat TM imagery. Tinker et al. (1998) used $\mathrm{TM}$ in an analysis of forest fragmentation by clearcuts and roads in a Wyoming forest.

Most current national land cover and land use databases are also derived from Landsat TM data. For example, the Multi-Resolution Land Characteristics (MRLC) maps are derived from 1992 era Thematic Mapper (TM) images, and portray about 20 land cover classes nationwide at 30 meter resolution in a consistent way (USGS Biological Resources Division 1992), USGS national GAP database (USGS Biological Resources Division 2000) used Landsat TM images, MRLC datasets, and National Land Cover Data (NLCD). Those data have become important data sources for forest fragmentation analysis (West Virginia GIS technical Center 2001, Mid-Atlantic Regional Earth Science Application Center 2001). In West Virginia, a GAP land cover database and West Virginia Forest Fragmentation maps are available at three brand scales at 7 hectare, 66 hectare and 590 hectare (West Virginia GIS technical Center 2001).

Landsat TM can be used to understand complex forest fragmentation phenomena. Lefsky et al.(2001) in their recent study asserted that multitemporal TM is a cheaper and less complex alternative to either hyperspatial or hyperspectral sensors.

There are, however, some drawbacks to use Landsat TM data for forest mapping. Tinker et al. (1998) raise a concern that Landsat data can provide only limited differentiation of successional stage. In addition, Tinker et al. (1998) point out that classified Landsat data are typically 'noisy', with many single-pixel patches that may represent important landscape components. That is usually ignored in fragmentation analyses.

\section{Forest fragmentation metrics}

Landscape metrics have been defined as quantitative indices to describe structures and patterns of a landscape (O'Neill et al. 1988) that are assumed to be related to the suitability of that landscape as habitat for plants and animals (Nielsen and Paracchini 
2000). Research has indicated that forest fragmentation metrics have three basic characteristics: sensitivity, diversity and correlativity.

Sensitivity means that the values of landscape metrics are sensitive to the changes of spatial elements such as spatial scale, land classification, and spatial data processing methods. Different metrics have varying sensitivity to different spatial elements. In ecology, spatial scale is associated with both extent and grain (Forman and Godron 1986, Turner 1989, Wiens 1989, O’Neill et al. 1998). Grain is the size of the individual units of observation, and is often described as the spatial resolution of the data. In a raster based forest fragmentation analysis, the grain is limited by the pixel size. Spatial extent is the total area of an investigation or the area included within the landscape boundary (Saura and Martinez-Millan 2001). The extent and grain are important parameters for a particular study, and should be chosen to represent the scale of the ecological phenomenon or organism under study. The spatial grain has been shown to greatly influence the derived values of the metrics (Wickham and Riitters 1995, Frohn 1998). Saura and Martinez-Millan's (2001) study have shown that Edge Density is the most robust metric in the presence of variations in map spatial extent. In contrast, Mean Shape Index and Perimeter Area Fractal Dimension were found to be by far the most sensitive metrics to spatial extent. Wickham et al. (1997) show that fragmentation metrics are also sensitive to differences in land-cover composition and land-cover misclassification. Tinker et al. (1998) found that fragmentation metrics are sensitive to spatial resolution, the way spatial data are filtered or otherwise processed, and the classification schema. Therefore, he argued that comparison of absolute landscape values of metrics is appropriate only within a single study area. Unless the same data sources and data processing are used, it is unlikely that index values can be compared directly (Tinker et al. 1998).

Diversity means that there are many landscape metrics used for describing landscape structure and pattern of forest fragmentation. For example, the forest fragmentation index (FI) (Johnsson 1995) was developed as one of several objective measures of pattern complexity for thematic maps. When using the FI as a measure of landscape complexity, it must be kept in mind that the choice of classes, the degree of detail and accuracy of the land classification is of great importance for how well the 
results will correspond to the actual landscape complexity on the ground (Johnsson 1995). The Matheron index, a commonly used index for studies that focus on forest/nonforest interfaces, measures the 'openness' of the land cover type of interest as a function of the length of the edges of the landscape elements (Nielsen and Paracchini 2000). It has been used as a metric (Mayaux and Lambin, 1995 and 1997) to describe the fragmentation of forest covers observed in Landsat TM and NOAA AVHRR images (Nielsen and Paracchini 2000). Additional metrics commonly used include measures of size, shape, spatial distribution, density of patches, patch abundance, dominance, contagion, and fractal dimensions (USGS Biological Resources Division 1999). In recent years, new metrics have been promoted. For example, Frohn (1998) has shown that the number of patches per unit area (PPU) and the square of the patches $(\mathrm{SqP})$ describe landscape structure and transformation better than contagion and fractal dimension metrics, because the formers are less sensitive to the scale of observation. PPU measures the degree of fragmentation of patches on a landscape and SqP measures the shape complexity of patches on a landscape

Correlativity means that many metrics of landscape structure are highly correlated. Tinker et al. (1998) used principal component analysis to show that many metrics of landscape structure are highly correlated. It is possible to monitor landscape conditions by focusing on a few key metrics such as patch core area, patch size and number, edge density, and patch shape (Vogelmann 1995, Tinker et al. 1998). Sachs et al. (1998) found through factor analysis that most variation in 85 maps of land use and cover could be explained by five univariate metrics of average perimeter/area ratio, contagion, standardized patch shape, patch perimeter-area scaling, and number of attribute classes.

Due to the above three characteristics (sensitivity, diversity and correlativity), no single index could define or describe directly all pattern or structures of a forest fragmentation at landscape scale. Instead various combinations of measures are being used (Riiters et al 1995, Mertens and Lambin 1997; Nielsen and Paracchini 2000). In this study, the metrics of the landscape structure used to qualify fragmentation were those suggested by Jorge et al. (1997): (1) Patch size (calculated from the average patch area and average patch perimeter);(2) Patch abundance (patch density and percentage of 
landscape area occupied by patches); (3) Patch shape (measured in three ways: perimeterarea ratio, fractal dimension (D), shape diversity index (SI)) and, (4) Edge effect (patch edge-centre distance).

In general, accurate quantitative comparisons of forest fragmentation among large areas or among different temporal periods require that the data and analysis be uniform. This means that the data must be derived from the same sources, have the same resolution, be filtered or otherwise processed in the same way, and that the patches be defined using the same level of classification of cover types, successional stage/age classes or other criteria (Tinker et al. 1998). Therefore, comparison of absolute landscape values of metrics is appropriate only when the same data sources and data processing used on a specific spatial and temporal domain (Tinker et al. 1998).

\section{Tools for Measuring forest fragmentation}

There is a wide range of software tools available for quantifying fragmentation. Specialized software is required for specific, complex metrics, or for exploratory data analysis (Theobald 1998). The tools for measuring forest fragmentation always link directly or indirectly with GIS. Two common tools used in the United States are FRAGSTATS (McGarigal and Marks 1995) Patch Analyst (Rempel et al. 1999, Rempel 2000). FRAGSTATS, which was used to quantify the landscape pattern in this project, calculates a set of pattern metrics for each patch within a landscape, each cover class within a landscape, and the entire landscape (Tinker et al. 1998). Patch Analyst also uses FRAGSTATS as the base for calculating fragmentation metrics, but it runs on ArcView Spatial Analyst extension.

The main challenges to utilizing existing forest fragmentation measurement tools include: (1) refining the approaches that use these landscape metrics to reflect a biological basis (Theobald 1998); and (2) improving the access to forest fragmentation measurements tools. 


\section{Web-based delivery of spatial information}

Spatial information and technologies have been applied widely in natural resource management, environment assessment, land use planning and other many fields (Mallawaarachchi et al. 1996 Peters and Nichols 1998; Ranta et.al. 1998; He et. al., 2000; Fournier et. al. 2000). The diverse range of spatial information and GIS applications has shown that spatial information and GIS functionalities are potentially useful to almost everyone. However, traditionally, spatial information was published through hardcopy such as paper maps. Even with the advent of digital data, information is normally limited to single computer or network. Consequently, the improvement of accessibility of geographic information and functionalities is a basic research question in GIS (Mark 1999). Two aspects of accessibility that need to be addressed are how to access distributed, multi-format, multi-theme spatial data effectively, and how to access related processing, modeling and analysis tools.

The appearance of the Internet and World Wide Web (most often called the Web) technology has changed the way many institutions provide spatial information. The Internet is a vast collection of open standards supporting data communication and representation. The Web is a subset of Internet protocols. It is mainly based on a handful of technical interoperability standards such as the Hypertext Transfer Protocol (HTTP) and the Hypertext Markup Language (HTML) (W3Schools, 2001). Standard web browsers such as Microsoft Internet Explorer and Netscape Navigator can be used easily to access information published on the Web, and distributed around the world.

\section{Basic architecture and components of Web-based information delivery}

Information on the Web is delivered through a Client/Server architecture (Figure 2.1), with documents called Web pages. Web pages are stored on Web server computers. Computers reading the Web pages are called Web clients. A Web client may consist of a Web browser and other optional client side components such as cookies and plug-ins. A Web browser fetches a Web page from a server by a request. A request is a standard HTTP request containing a page address. When the request is accepted by the Web 
server, the Web services on the Web server may response with the requested Web pages directly, or call a server-side scripting program to create dynamic Web pages and send them back the client. All Web pages contain instructions on how they should be displayed, which are interpreted by the browser. The display instructions are usually specified by Web protocols.

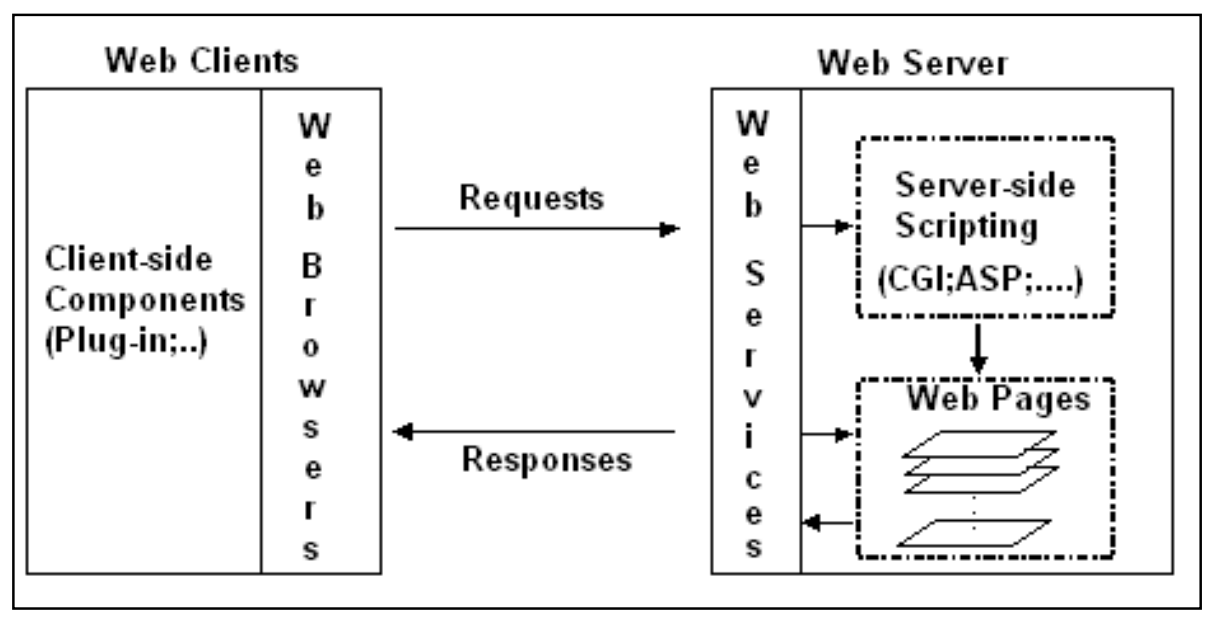

Figure 2.1 Basic architecture of web application

Web browsers can support many data types including text strings, URL, and images in formats such as JPEG and TIFF. These kinds of data types that may be supported depend on the protocol and client side components of end users. The basic data formats supported by Web browsers are defined in the HTML specification, which is the most common display protocol (World Wide Web Consortium 2001). HTML stands for Hyper Text Markup Language. An HTML file is a text file containing predefined markup tags. The markup tags tell the Web browser how to display the page. Web browsers with support for different versions of HTML specifications have different sets of data formats. There are three approaches to implementing new specific data types for display and manipulation on the Web: (1) add new data type processing protocols; (2) add a Web browser Plug-in, which is a smaller "add-on" computer program working in conjunction with the Web browser; and (3) add middleware to convert the new data type to a basic Web data type.

Due to the weakness of HTML on supporting diverse data, XML was created. XML stands for Extensible Markup Language. XML is a markup language much like HTML, but XML tags are not predefined. The user of XML can create new tags. XML 
uses a Document Type Definition (DTD) to describe the data. XML with a DTD is designed to be self-descriptive. XML is used to both describe and carry the data.

There are many Web programming languages such as Java, Perl, JavaScript and VBScript. Common Gate Interface (CGI), ActiveX Server Page (ASP) and Java Server Page(JSP) are server side programming approaches, which use Web programming languages to create Web application logics, carry out calculations and data processing, and also create dynamic Web pages.

The integration of HTML, Web Programming languages and Server side programming, provides essential tools for building a Web-based application Graphic User Interface (GUI) and logics, which are important for enhancing the interactivity of Web applications.

\section{Limitations of Web on delivering spatial Information}

Even though the Web has been used widely for delivering information, there still are technical limitations that have to be overcome in order to utilize the Web to deliver spatial information.

(1) Limitations due to hardware and speed of the Internet.

The size of spatial data sets is almost always large, and spatial data processing almost always takes a long time, even when the application is running on a local computer. Therefore, delivering spatial data requires high-performance hardware and Network communication. However, the current speed of Web servers and the Internet bandwidth are still not satisfactory for integrating, processing, displaying and transporting large size spatial data sets. Data compression technology and wideband technologies may have potential to overcome these limitations.

(2) Limitations associated with Web-supported spatial data formats

Two basic data structures for spatial data are vector and raster format. On the Web, raster data generally are modeled with JPEG, TIFF, GIF or other web image formats. However these web images have no "projection" and "layer" concepts, so we cannot use them directly to represent geo-referenced multi-band remote sensing imagery. Moreover, vector data have not been supported in the existing standard commercial web 
browsers. Therefore, in order to deliver vector data, it is necessary to convert information to web supported raster images.

(3) Limitations on Web-supported spatial data operation

The delivery of spatial information requires that end users not only access spatial data, but also carry out basic operations such as spatial query, spatial processing and analysis. However, existing Web browsers have no direct support for such operations. Instead, the end users have to utilize other Web-embedded programs such as JavaApplets and DHTML, or user-defined XML to input spatial requests.

\section{Web-based delivery methods of spatial information}

Currently, spatial information on the Web is always delivered in one of four approaches: static maps, FTP integrated with a spatial data search engine, interactive mapping and Web-based GIS (usually called Web GIS).

Static maps use Web supported images such as JPEG and TIFF to represent maps. FTP refers to File Transportation Protocol, which is a protocol supporting downloading and uploading files on the Internet. The FTP approach can be combined with spatial data search engines to help spatial data users find and retrieve specific data. In order to display or analyze the downloaded files, the user must have the appropriate specialized software.

Compared with the former two approaches, Web-based interactive and Web GIS are more flexible and powerful for spatial information delivery. Even though the terms interactive mapping and Web GIS have been used widely, they still do not have a common accepted definition. Generally, however, it is understood that interactive Web Mapping is an essential part of Web GIS, and Web GIS is a way to implement Web mapping.

Besides the Web GIS approach, interactive Web mapping can also be implemented with image maps, Web-based animation, and HTML Form-based interactive mapping.

Image maps are images in Web pages that include hot regions or hotspots. An image map in a Web page has three components, an image, a set of map, and an HTML host entry. The image is a normal Web image, typically stored in the GIF or JPEG 
format. The map is a graphic boundary description of the mapped regions within the image. The host entry is HTML code that positions the image within the Web page and designates the image as having map functionality (Automata 2001). The end user can read the map in browser directly. However, the end user cannot navigate the map or query any information. There is no interactivity between maps and end users. For example, the Pennsylvania Spatial data Access web site (Pennsylvania spatial data access 2001) allows users to select a county on a map, and access the county's spatial information (Figure 2.2).

Animation-based Web mapping uses Web page author tools to create maps. For example, Macromedia Flash allows users to zoom in out of a map, to link maps with other multimedia information, or create hyperlinks, and even query information from specific geographic feature. For example, the web site http://www.hotelabbazia.com/mapofgrado.htm allows users to zoom in out the map used to help users locate a hotel (Figure 2.3).

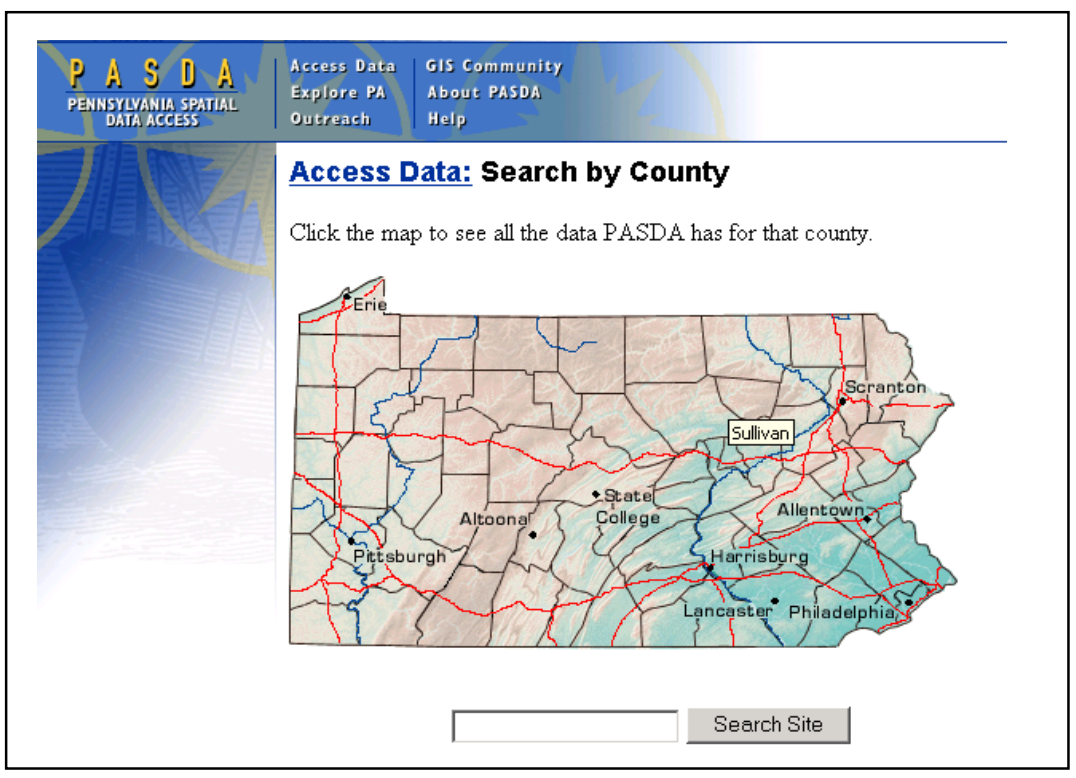

Figure 2.2 Example of an image maps: Pennsylvania Spatial data Access web site. (http://www.pasda.psu.edu/access/county.shtml) 


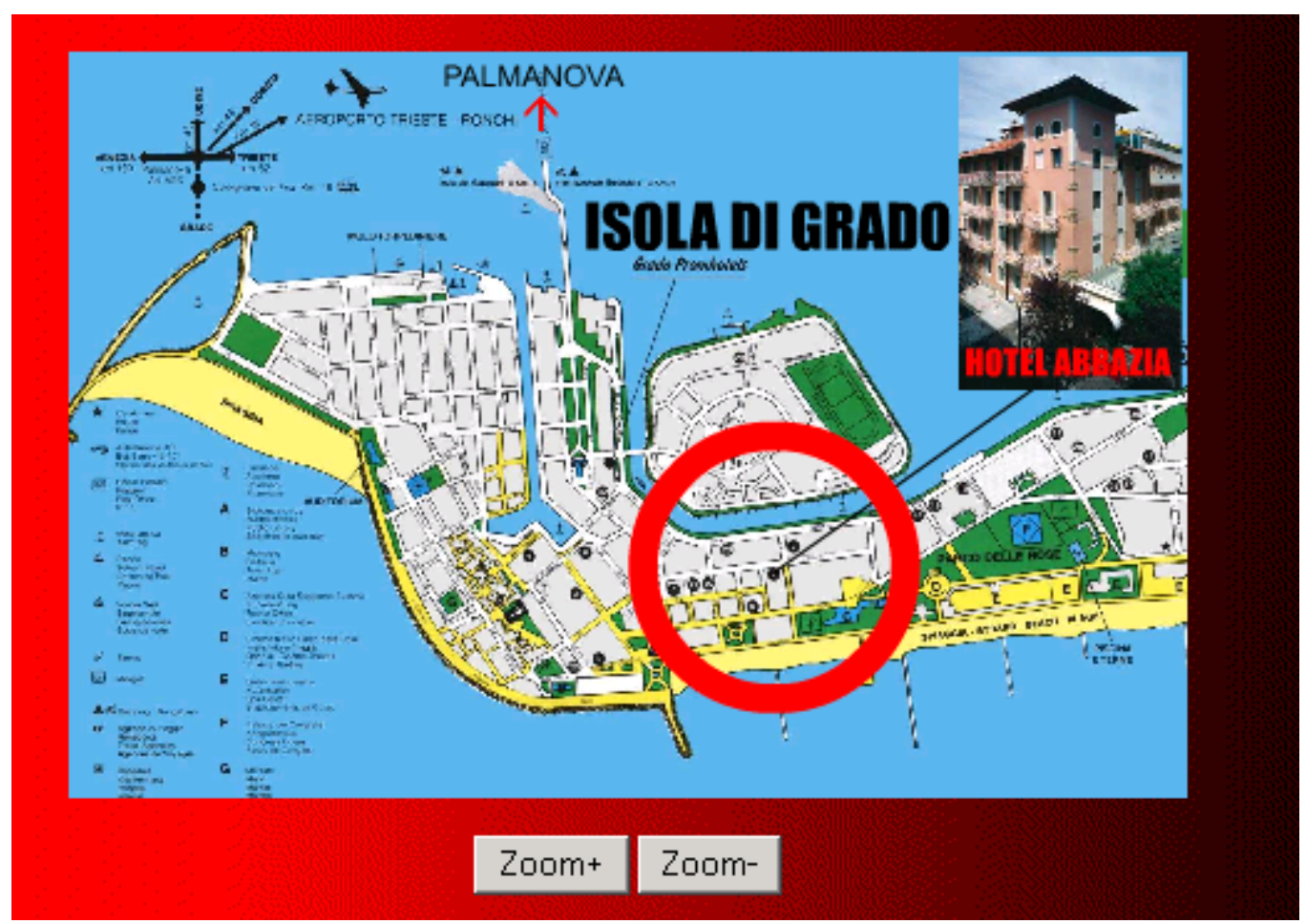

Figure 2.3 Example of animation-based Web mapping: using Macromedia Flash for interactive web mapping (http://www.hotel-abbazia.com/mapofgrado.htm)

HTML Form-based interactive mapping uses HTML forms as the interface entering mapping parameters such as boundary coordinates, projection, geographic area and features, which are then interpreted by the Mapping server to draw the final maps.

GIS based on Internet protocols is called Internet GIS. An Internet GIS running on standard World Wide Web (WWW) browsers is referred to as Web GIS. Web GIS is an implementation of GIS on the Web. Typically, a Web GIS application uses a Graphic User Interface (GUI) as the application interface. Spatial data can be displayed, queried, navigated, manipulated and output in a Web GIS. For example, with ESRI ArcIMS, Delaware 2000 Census Mapper provides the public with comprehensive web based dynamic mapping services (Figure 2.4). An ideal Web GIS would provide all the 
functionalities that are included in a traditional GIS.

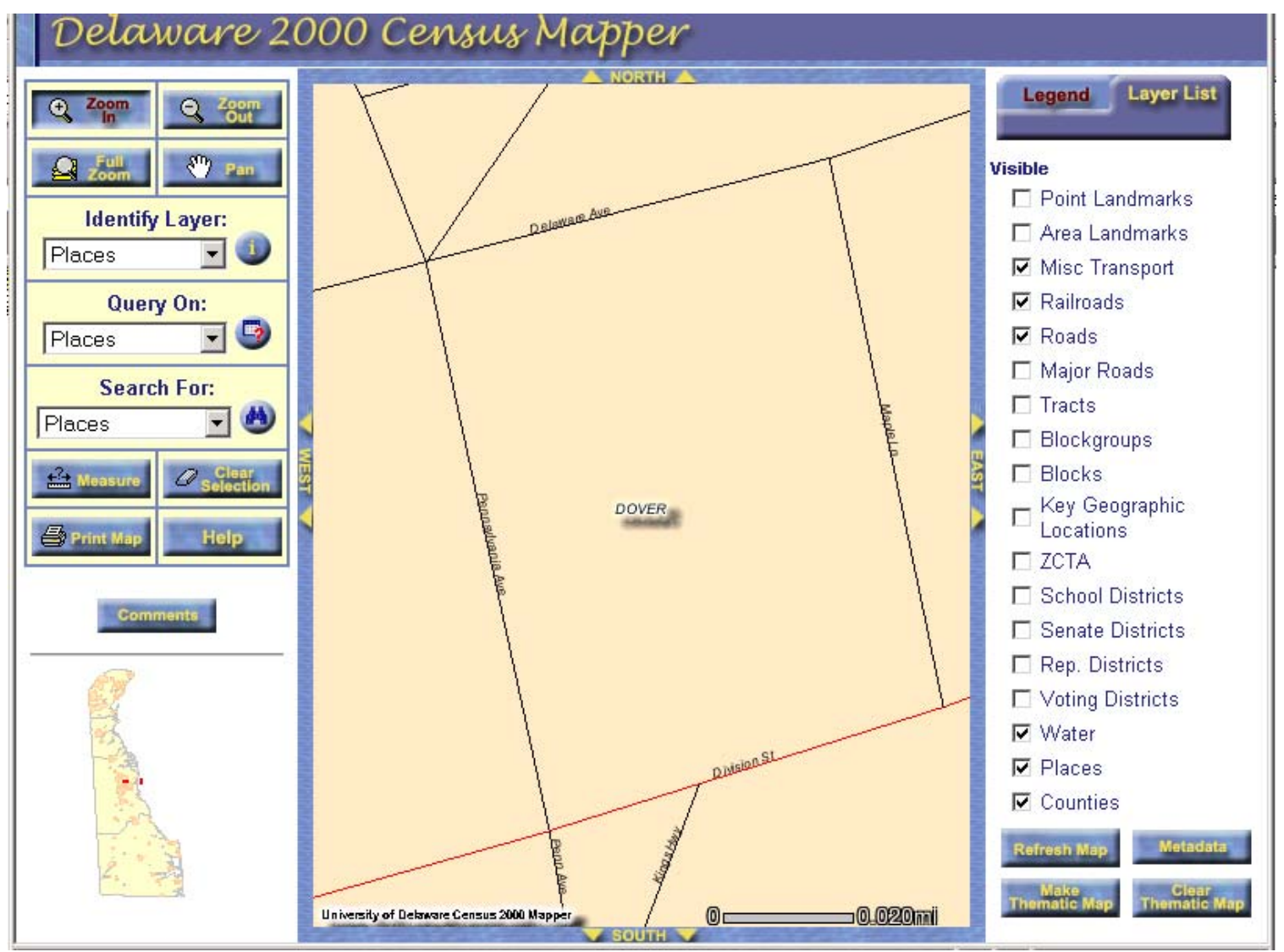

Figure 2.4 Web GIS example: Delaware 2000 Census Mapper. [http://128.175.8.149/census/censusmapper]

Internet GIS is a rapidly evolving field. There are general trends from static maps to dynamic and real-time interactive mapping, from data delivery to function delivery, from central spatial data service to distributed service, from simple data format to multiformat data integration, and from $2 \mathrm{D}$ to $3 \mathrm{D}$ visualization. 


\section{Web-based delivery of forest information and analysis tools}

In the United States, forest information systems have been developed for over 20 years by federal and state forest managing agencies, academic research groups, and forest product companies (Fried 2000). In these systems, spatial features are important information components. However, the limited technical support for delivering spatial information to potential users, and for integration of spatial data among distributed agencies, has constrained efforts to build a consistent and accessible forest information system. Web technologies offer the potential to overcome these constraints, and consequently a great deal of spatial forest information has recently been published on the Web.

As discussed in the previous section, there are four approaches for delivering spatial information. Examples of these approaches applied to forest spatial information will be discussed in more detail below.

\section{Static map approach}

The static maps approach is a relatively simple way to deliver forest related maps, and consequently is mainly used for illustration purposes. The EPA Mid-Atlantic Integrated Assessment (MAIA) environmental atlas (Figure 2.5) is an example that combines a forest fragmentation index map, charts, and textual explanation to describe the status of forest fragmentation status in the mid-Atlantic region (US Environmental Protection Agency 2000). Another example of the static map approach is the College of Agriculture \& Natural Resources, University of Connecticut forest fragmentation research web site (Figure 2.6) which demonstrates a comparison of land cover maps, satellite images, and forest fragmentation maps (University of Connecticut, College of Agriculture \& Natural Resources 2001). 


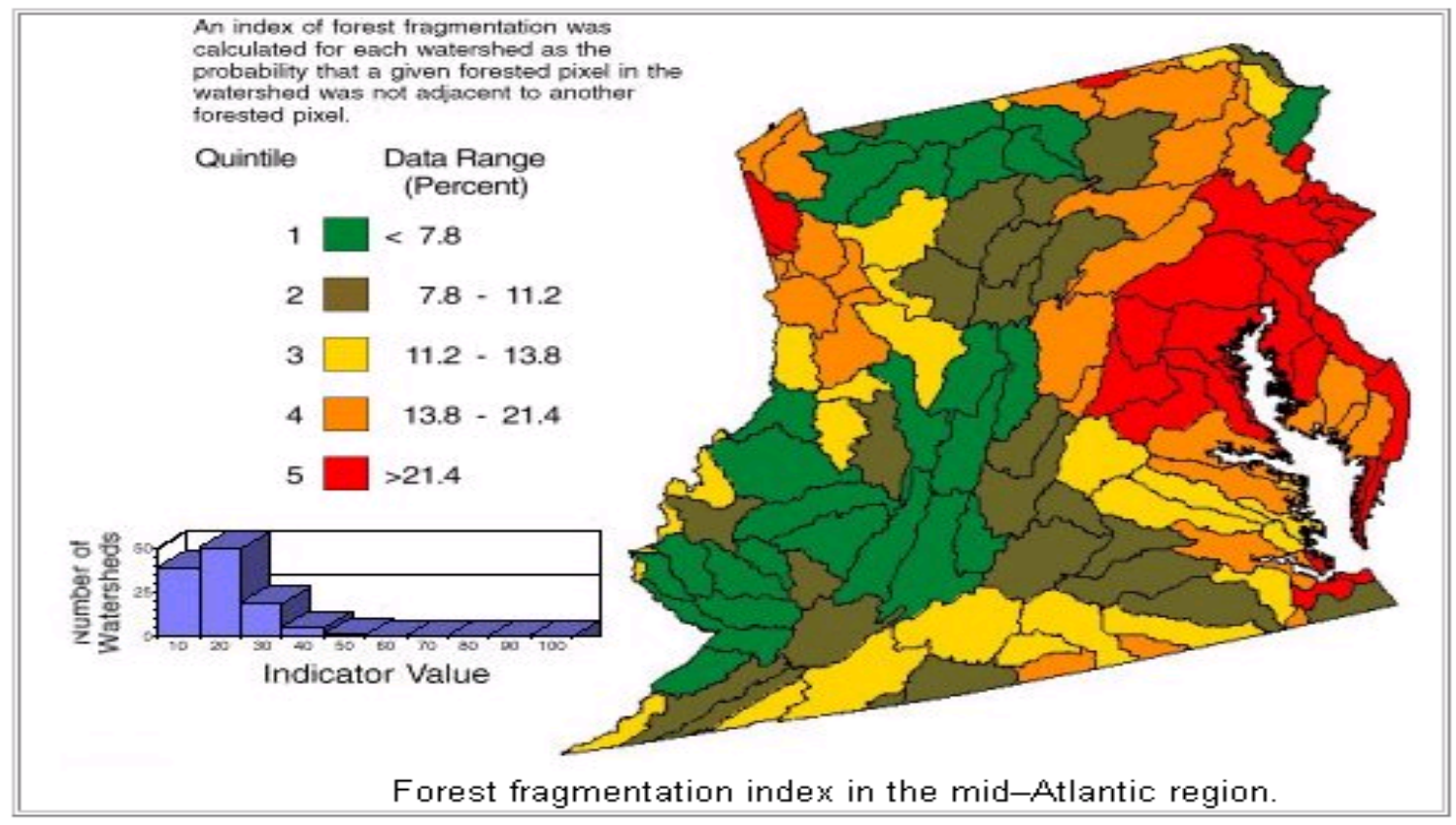

Figure 2.5 Web-based Static maps approach example 1: EPA Mid-Atlantic Integrated Assessment (MAIA) environmental Atlas. (http://resac.uconn.edu/research/forest_frag/index.html)

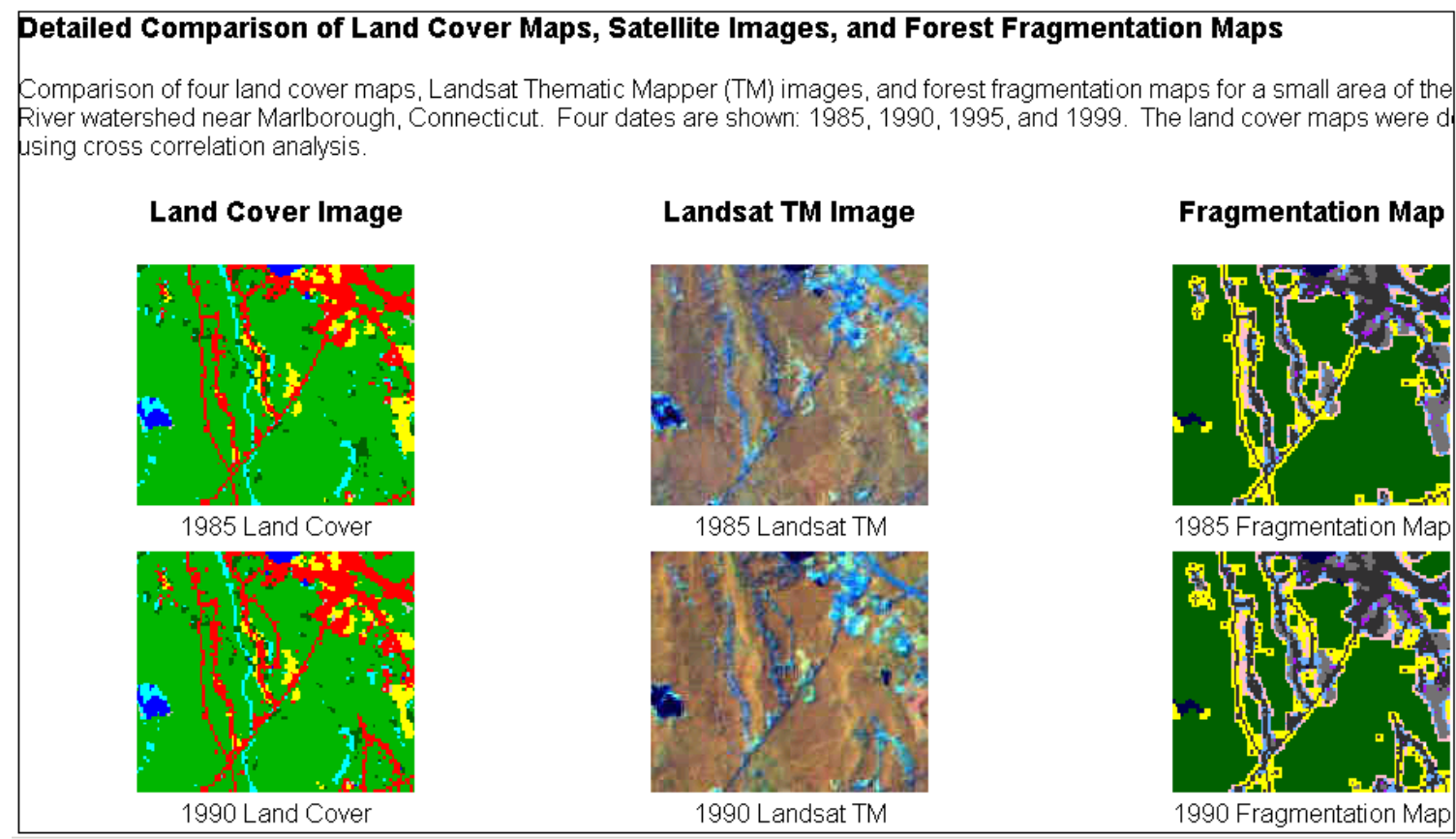

Figure 2.6 Web-based Static maps approach example 2: forest fragmentation research web site. (http://resac.uconn.edu/research/forest_frag/index.html)

\section{File Transfer Protocol (FTP)-based forest data service}

With the FTP-based data service, users can click on hyperlinks of the data sets listed in a Web browser in order to download data. The FTP services can be integrated with spatial data search engines to support end user queries for spatial data sets. For 
example, on the web site of the West Virginia GIS Technical Center (Figure 2.7), the user can use a "search" function to query spatial data, view the metadata of the associated dataset, and then use FTP services to download the data.

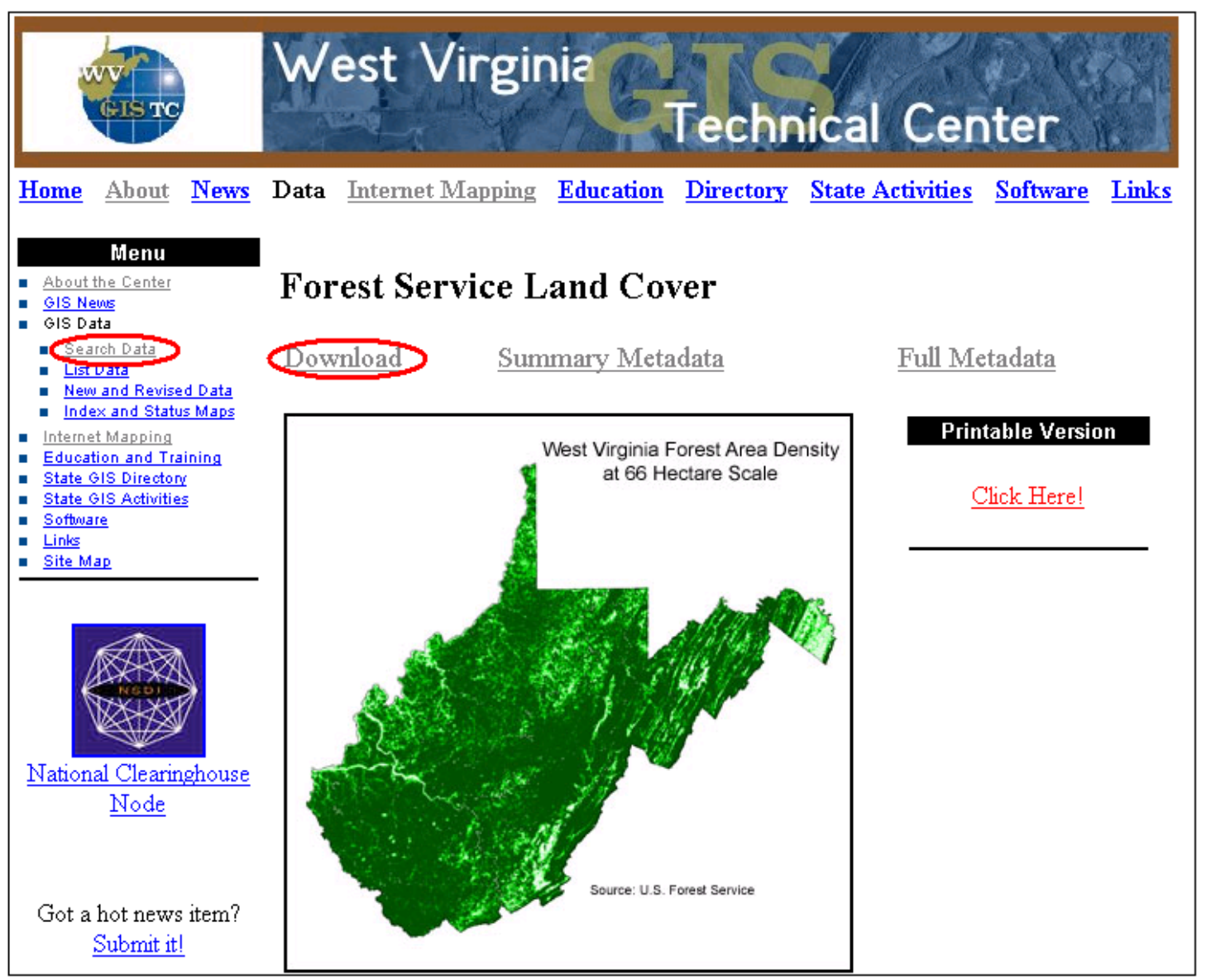

Figure 2.7 FTP based Forest Service land cover data service created by West Virginia GIS Technical Center (wvgis.wvu.edu).

The Static map approach and FTP based spatial data services have been widely utilized for delivering spatial forest information. For example, the web site of GlobalScale Patterns of Forest Fragmentation (Figure 2.8), which includes a summary global forest Fragmentation Index Map, allows users to download a large size TIFF file via FTP (Riitters et al. 2000). 


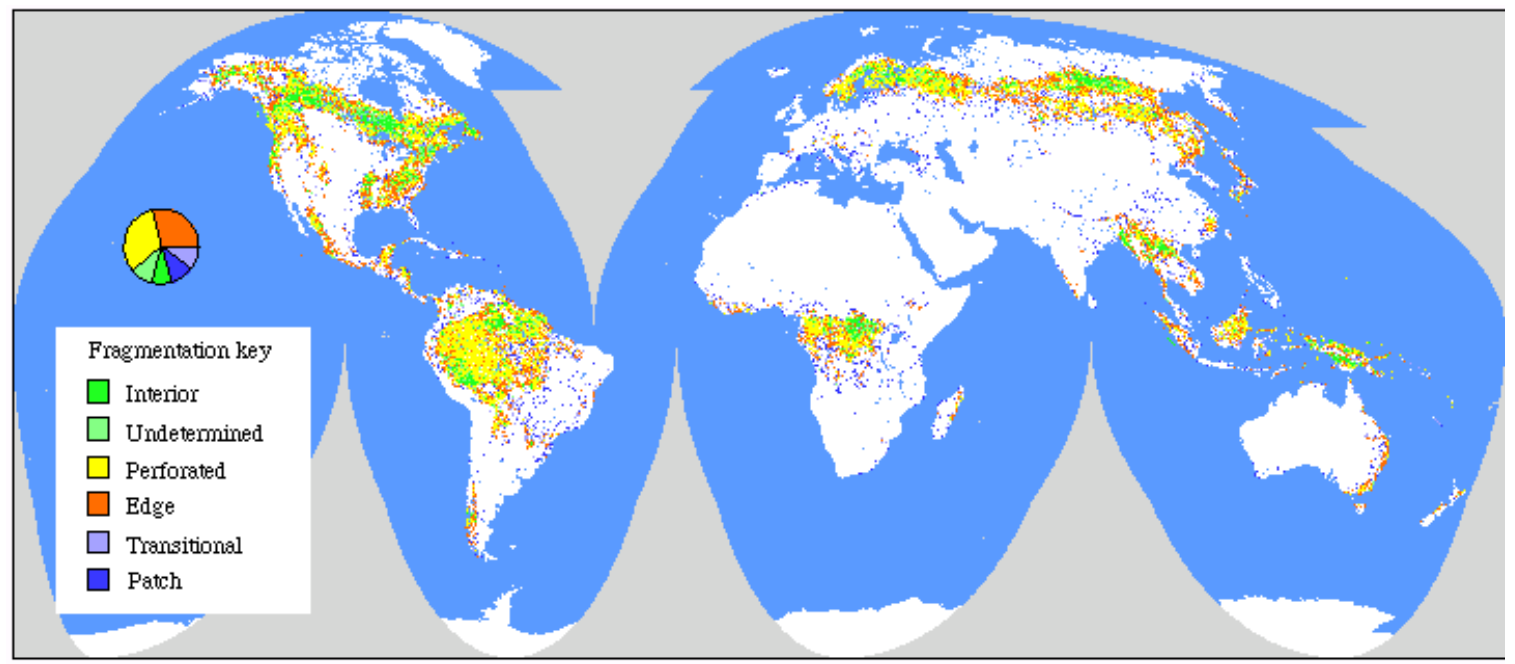

Figure 2.8 Web site of Global-Scale Patterns of Forest Fragmentation (http://139.142.203.66/pub/ www/Journal/vol4/iss2/art3).

\section{Web-based Interactive Mapping}

Neither the Static Map nor the FTP approach give end users are interactive or allow the ability to navigate, query, and analyze forest spatial data on the Web. The FTP approach requires the end users to install GIS software on their local computers to read and process data. In order to provide web-based interactivity and reduce the cost of using spatial forest information, Web-based mapping technologies have been introduced into spatial forest information delivery.

The main approaches used in interactive forest mapping are HTML form-based interactive mapping and Web-based GIS. The HTML form-based interactive mapping approach was used in implementing the USDA forest Service Forest Inventory Mapmaker (Figure 2.9) (USDA Forest Service 2001d). End users were asked to input their query parameters or add local forest data in HTML forms, and then the system creates a static map (Figure 2.10). 


\section{Forest Inventory Mapmaker Version 1.0}

\section{Geographic Area of Interest (page 1 of 4) Session $\mathrm{D}=63026211$}

\section{Reporting Units}

- English Units (acres, cubic feet, pounds)

- Metric Units (hectares, cubic meters, kilograms)

\section{Retrieval Type}

You may choose the way in which the FLA Retrieval System will select data from the database. The options are state/count you must enter the latitude and longitude of point center in decimal degrees (The latitude and longitude of Duluth, for examp. 92.12 decimal degrees west) and the circle radius in miles if you are using English units or kilometers if you are using metric longitude of a particular county, city or zip code through the Census Bureau U.S. Census Bureau Gazetteer.

- $\odot$ State/County

- $C$ Circle (also produces link to plot file on page 4 of 4 for uploading (using ADD TABLE) into ArcView TM
- Latitude : Decimal Degrees North
- Longitude: Decimal Degrees West
- Radius:
(in miles if reporting in English units or in kilometers if reporting in metric units)

\section{West Virginia 1989 cucle 1 \\ - No Selection \\ All Counties \\ O Specific Counties (You must choose one or more of the following counties)}

\begin{tabular}{|l}
54001 Borbour \\
54003 Berkeley \\
54005 Boone \\
54007 Braxton \\
54009 Brooke
\end{tabular}

Figure 2.9 USDA forest Service Forest Inventory Mapmaker (http://www.ncrs.fs.fed.us/4801 /FIADB/index.htm). 


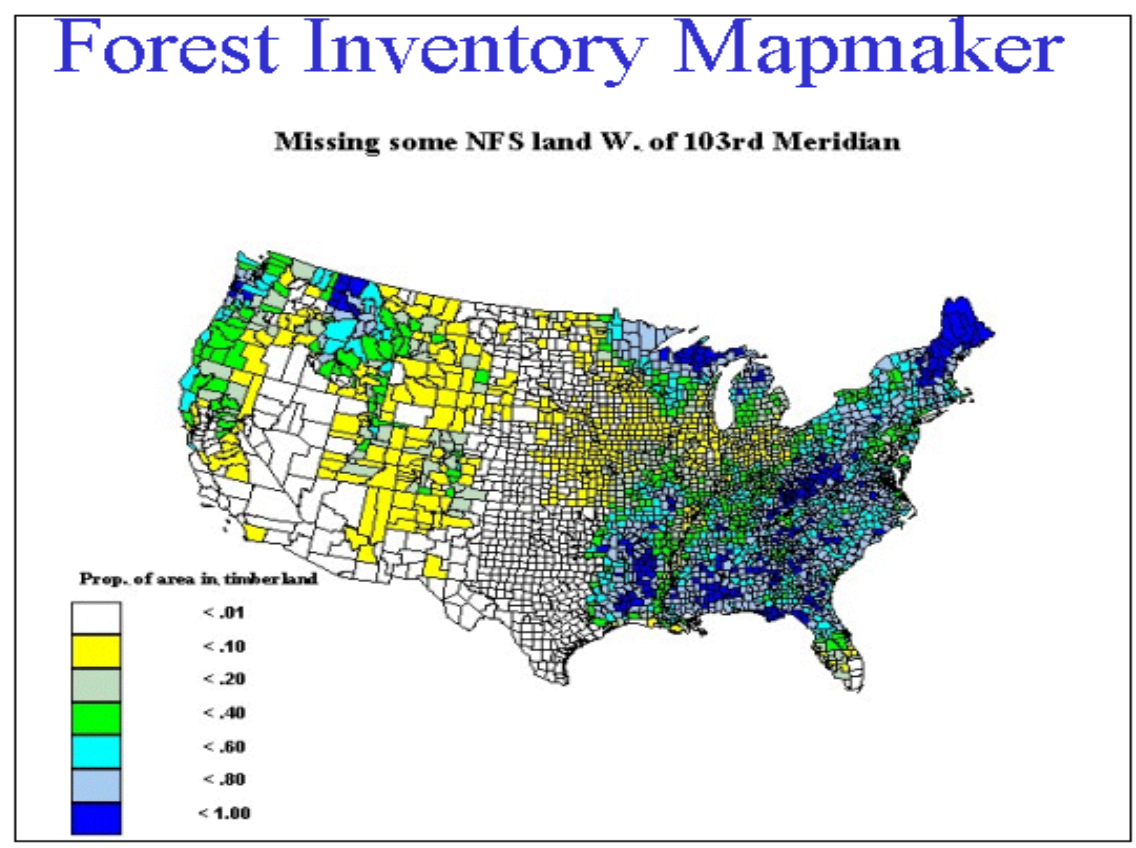

Figure 2.10 Sample results from the USDA forest Service Forest Inventory Mapmaker (http://www.ncrs.fs.fed.us/4801/FIADB/index.htm).

Compared with other web-based spatial information delivery approaches, a Web GIS gives the end user maximum interactive ability and the potential for integrating an interoperable distributed spatial data set. Web GIS is becoming a key way to deliver spatial forest information.

Forest information has been delivered using different Web GIS approaches including open source approaches and commercial Web GIS approaches. The Fornet Showcase project (http://www.ra.dnr.state.mn.us) developed by the Minnesota Department of Natural Resources (2001) used open source technology based Mapserver (http://mapserver.gis.umn.edu) to provide many of the advantages of Web GIS user options to create forest thematic map dynamically (Figure 2.11 and Figure 2.12). This Web site illustrates multiple layers of vector data and raster data that can be integrated in the Web browser. End users can change the scale, and pan across the map. The map legend is created automatically based on the current layers. 


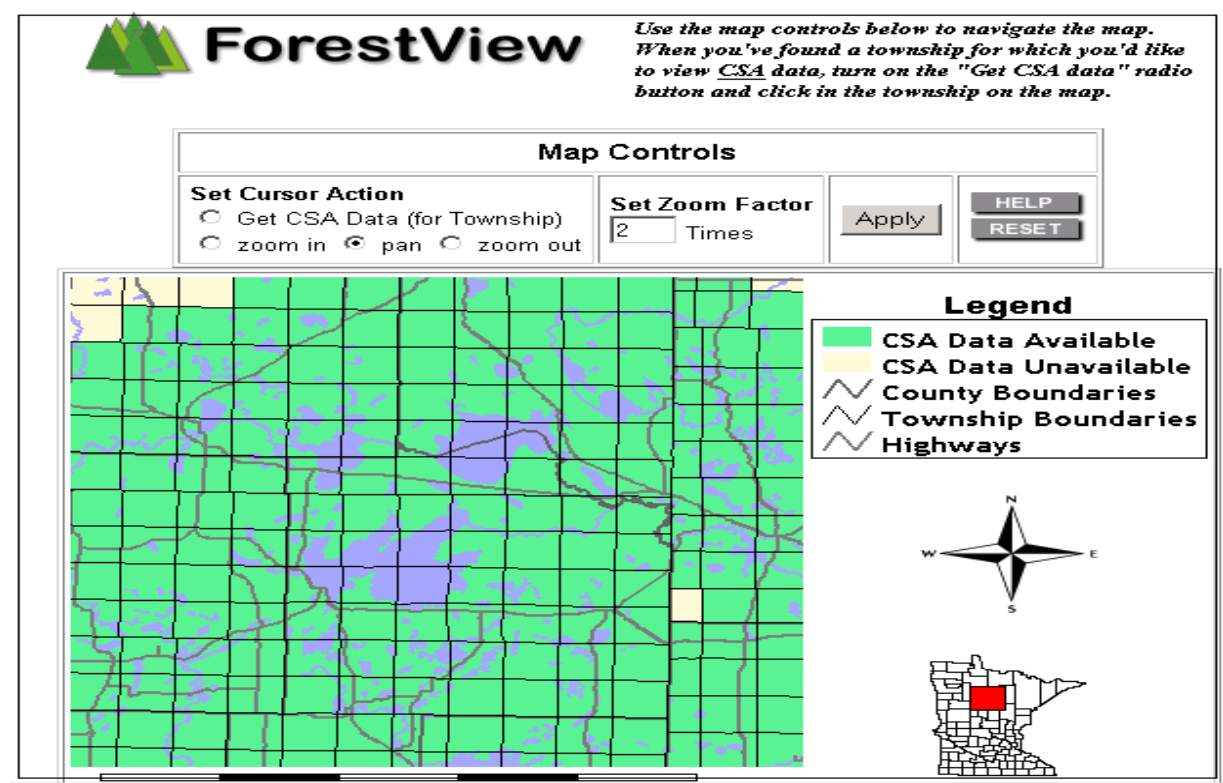

Figure 2.11 The Forest View project (Minnesota Department of Natural Resources 2001)

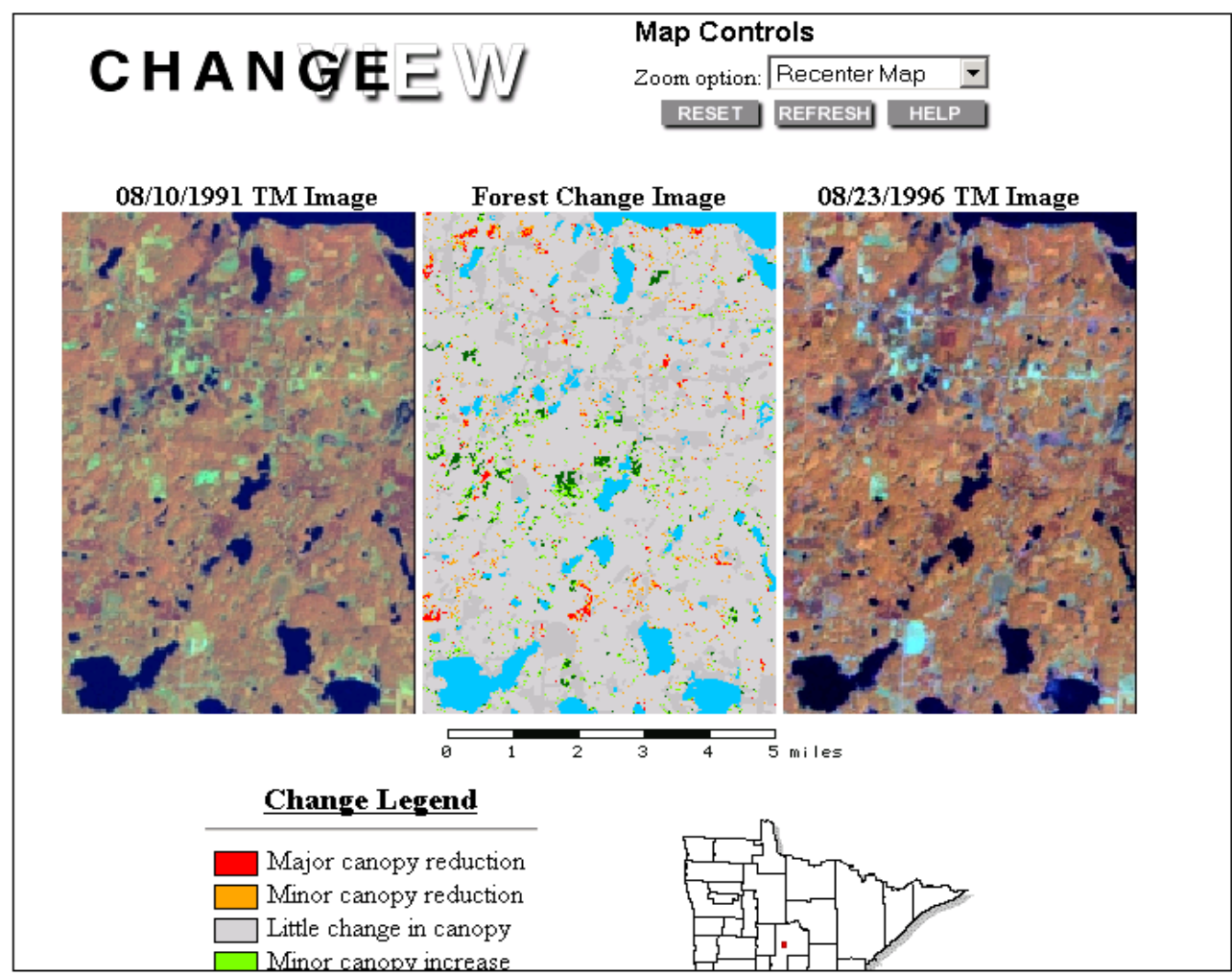

Figure 2.12 The Change View project (Minnesota Department of Natural Resources 2001)

Using an open source approach can provide flexibility to the Web GIS developer for customizing the Web GIS application, however this is at the cost of extensive 
development time. The alternative way is to use a commercial Web GIS server such as ArcView IMS, Map Object IMS, Autodesk MapGuide, which work in conjunction with Web development technologies such as HTML, ASP and JavaScript, to develop a Webbased forest GIS. An example of a web site built on the ESRI ArcIMS commercial Internet Mapping server is that of Global Forest Conservation Mapping (Figure 2.13) (Forests.org Inc. 2001).

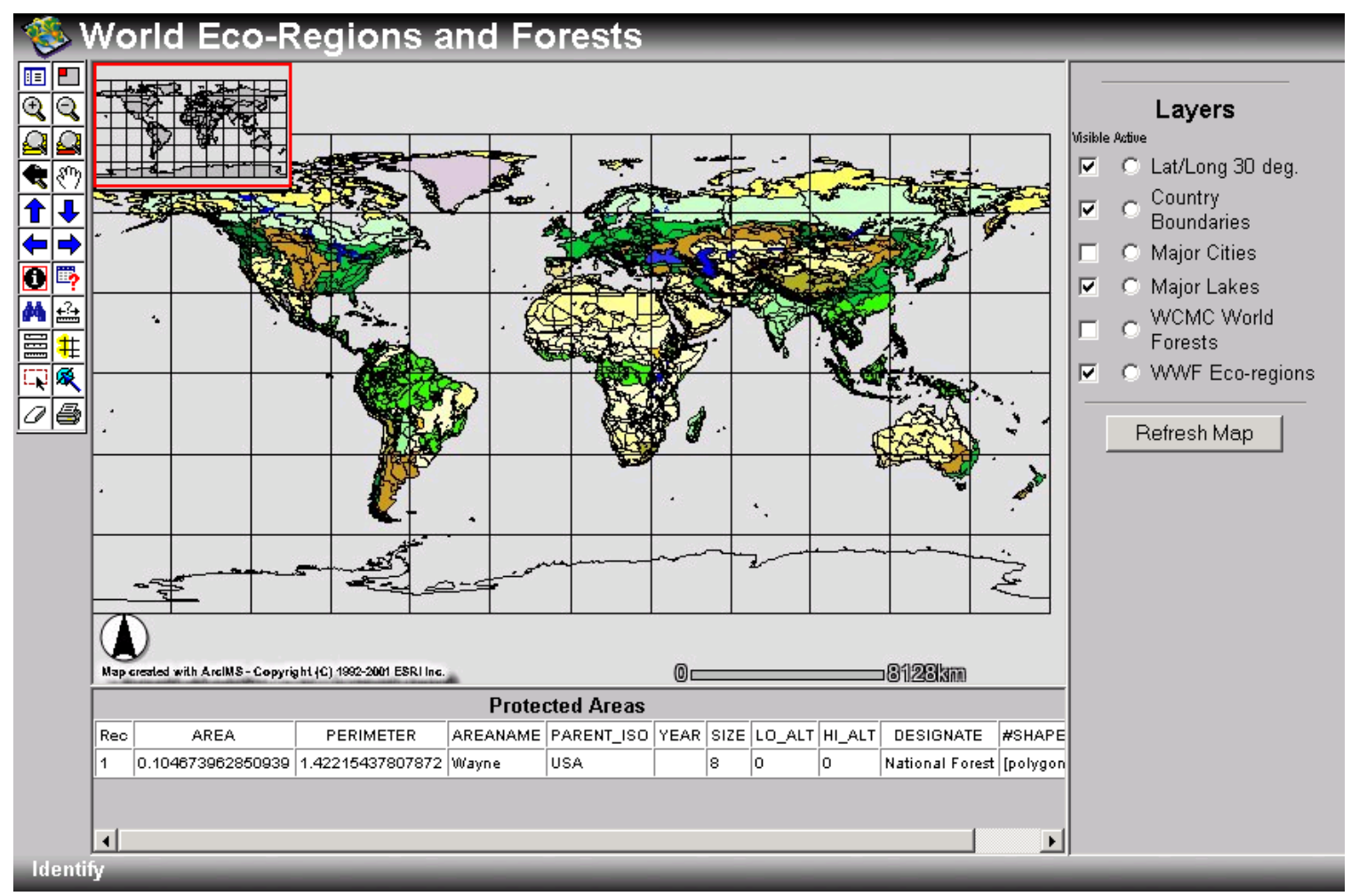

Figure 2.13 Global Forest Conservation Mapping web site (http://forests.org/maps/makemap.htm).

The commercial Web GIS server based websites usually support similar map navigation functions. The main differences between commercial Web GIS approaches are the efficiency of delivering spatial data, requirements for the client browser, the ability to integrate spatial data, support for interactive cartography, and the ability to implement spatial query and analysis.

Compared with other spatial forest information delivery approaches, most existing forest Web GIS system are clearly superior with regards to map navigation, data integration and spatial information query, but web sites with spatial analysis ability and distributed data integration are still rare. 


\section{Web based information delivery for forest fragmentation}

Even though there are more researchers addressing forest fragmentation

(University of Connecticut, College of Agriculture \& Natural Resources 2001, Reed et al. 1996), and some forest fragmentation web sites have been built, forest fragmentation information is always delivered in static text, graph, tables and images or FTP approaches. No comprehensive literature has been found addressing web-based forest fragmentation analysis.

The main source of forest fragmentation data for the state of West Virginia found on the Web is the West Virginia Forest Fragmentation Grid Map at a 30 meter resolution and 7, 66, and 590 hectare scales. These datasets are accessible on the web site of West Virginia GIS Technical Center (http://wvgis.wvu.edu) via FTP approaches. 


\section{Chapter 3. Study Area}

The study site for this research is located in northern West Virginia. The total area is 32646 ha (80670 acres). There are three main forest management groups in the study area (Figure 3.1): the West Virginia University Forest, 762 ha (1883 acres); Coopers Rock State Forest, 5516 ha (13631 acres); and Snake Hill Wildlife Management Area (WMA), 738 ha (1823 acres).

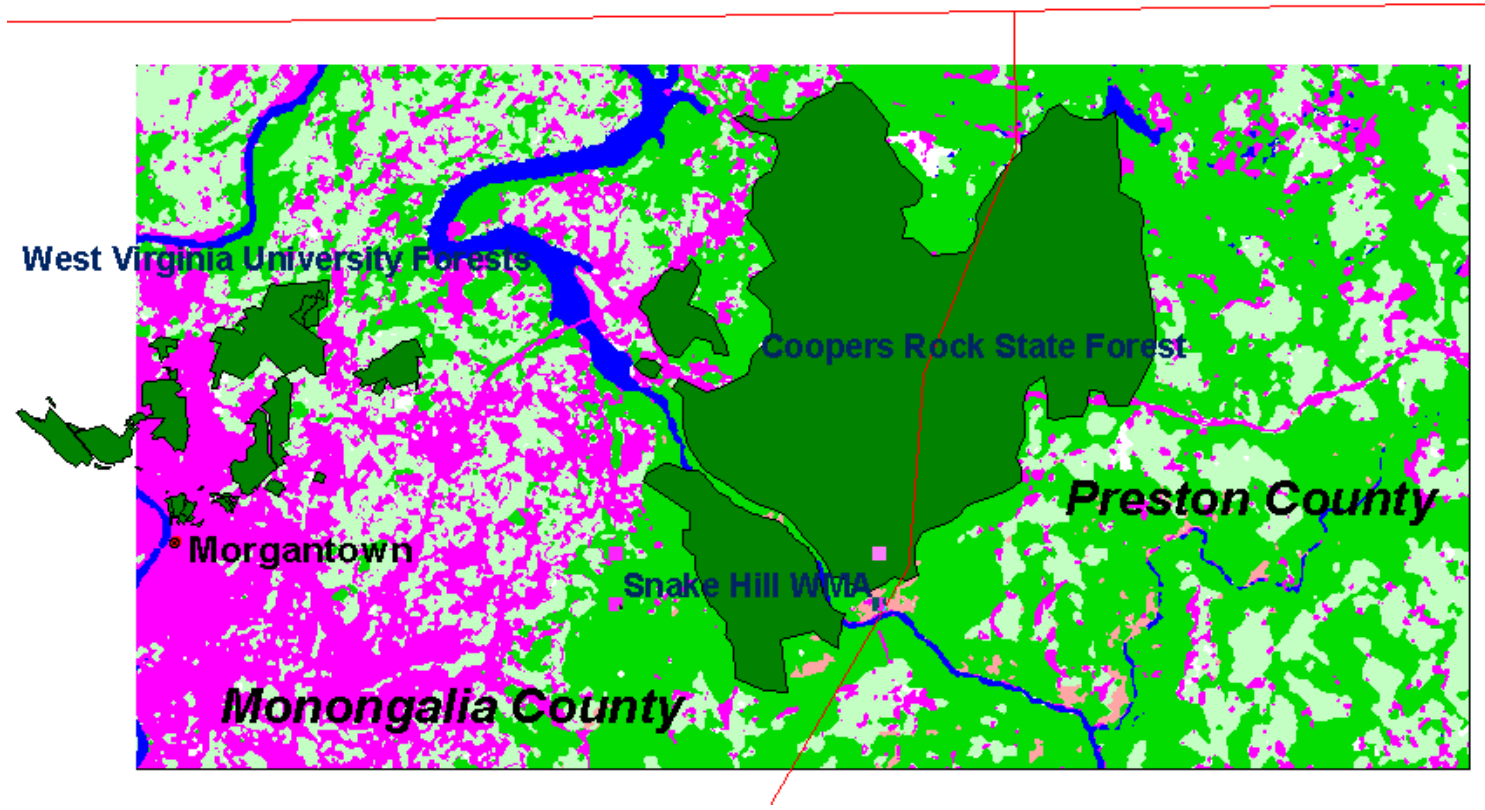

Figure 3.1 Three main forest management groups in the study area (data source: wvgis.wvu.edu).

In order to understand the context for this research, this chapter provides background related to the study area's general topography, drainage, climate, soils, vegetation, forest industry and harvesting activities, as well as some main forest landscape disturbance factors such as forest pests and forest fires.

\section{Topography and Drainage}

The Allegheny Plateau is the main topographic element in West Virginia, rising slowly from about $250 \mathrm{~m}$ (800 feet) above sea level in the west, and reaching dramatic relief along the Allegheny Front. The northern and western slopes of the Allegheny Plateau drain into the Ohio and the Gulf of Mexico, while the Ridge and Valley generally drains ultimately into Chesakeake Bay (West Virginia Network 2001). The study area is part of the Eastern Allegheny region (USDA Soil Conservation Service 1982, USADA Soil Conservation Service 1959), near the Pennsylvania state border. The study site 
covers parts of eastern and central Monongalia County, and the western end of Preston County, West Virginia. Monongalia County encompasses approximately 956 square kilometers (369 square miles) (West Virginia Association of Counties 2001a), and is characterized by mountain ranges oriented in a northeast-south-west direction, and by steep hillsides and narrow valleys. The study site in eastern Monongalia County is slightly more rugged than the rest of the county. The floodplain along the Monongahela River is generally narrow. Most of the remaining areas have rounded ridgetops and steep hillsides (USDA Soil Conservation Service 1982). Preston County is the eastern neighbor of Monongalia County, and has an area of 1694 square kilometers (654 square miles) (West Virginia Association of Counties 2001b). The overall topography of Preston County is that of a high, but strongly dissected, plateau sharply cut by the Cheat River gorge. Chestnut Ridge rises above the plateau level along the western boundary of the study area (U. S. Departments of Agriculture Soil Conservation Service 1959).

This study area is drained by the Cheat and Monongahela Rivers, Decker's Creek, and Dunkard Creek. All drainage from this area ultimately flows through the Monongahela River into the Ohio River. In the mountainous areas, only limited alluvial deposits occur along the larger streams. The Cheat River and most of its larger tributaries flow in deep, steep-sided gorges with a rapid fall (USDA Soil Conservation Service 1959).

\section{Climate}

In the study area of northern West Virginia, winters are long, and the growing season is comparatively short for the latitude. Differences in elevation and in exposure cause marked variations in temperature and precipitation. Winters are cold and snowy at high elevations, but in valleys long-lasting snow cover is not common (USDA Soil Conservation Service 1959, USDA Soil Conservation Service 1982). Summers are fairly warm on mountain slopes and very warm with occasional very hot days in the valleys. Annual precipitation usually falls in April through September, which covers the growing season for most crops (USDA Soil Conservation Service 1982). 


\section{Soils}

Soil types affect the potential productivity and suitability for supporting various forest species. Trees on the good soil sites grow more rapidly and require less management investment than on the poorer soil sites. The soils in most parts of this study area have developed under a cool, moist climate. Abundant rainfall, supplemented by heavy dew and fog during summer nights provides readily available moisture for plant growth. An excess of precipitation over evaporation has generally resulted in leaching and podzolic soil formation. The snow cover in higher elevation reduces the amount of freezing and the depth of the frost penetration (USDA Soil Conservation Service 1959). Most of the soils in this region are formed from weathered bedrock (USDA Soil Conservation Service 1982). The Conemaugh and Monongahela Groups are carbonate rich, and produce deeper, more productive soils than the soils of the resistant sandstones of Chestnut ridge. Alfisols, typical Forest soils of the deciduous forests of the eastern United States, are common through much of the upland region across the study site.

\section{Vegetation}

Appalachian hardwood forests dominate the vegetation types in this study area. The forest is deciduous, and is comprised of mixed oaks and mixed mesophytic types (Nellis et al. 2001). The main forest species include oaks, hickories, beech, maple, chestnut, and other hardwoods, as well as minor white pine and hemlock. Oak/hickory is the dominant forest-type group occupying about 77 percent of the timberland (USDA Forest Service 2001a, Table 3.1). The major commercial timber species include black cherry, sugar maple, red maple, black walnuts, oaks and pine (Raschka 1998). Several of these species have very high economic value (Nellis et al. 2001). 
Table 3.1 Area of timberland and forest types in Monongalia and Preston Counties in 1989 (in thousands of acres) (USDA Forest Service 2001a)

\begin{tabular}{|c|c|c|c|c|}
\hline \multirow{2}{*}{ County } & \multicolumn{4}{|c|}{ Forest type group (1,000's acres) } \\
\cline { 2 - 5 } & Total & $\begin{array}{l}\text { White-red } \\
\text { jack pine }\end{array}$ & Oak-hickory & $\begin{array}{l}\text { Maple/ beech } \\
\text { /birch }\end{array}$ \\
\hline Monongalia & 151.3 & 0.0 & 128.9 & 22.4 \\
\hline Preston & 299.8 & 6.6 & 219.5 & 73.7 \\
\hline Total & 451.1 & 6.6 & 348.4 & 96.1 \\
\hline
\end{tabular}

The forests of West Virginia provide habitat for many animals such as the hare, red squirrel, the endangered Virginia northern flying squirrel, and the threatened Cheat Mountain salamander. White-tailed deer, wild turkey, bobcat, and black bear are also among the wildlife found in the area.

\section{Forestry and forest harvesting}

Forest products have historically been an important industry in West Virginia. Before 1860, 80 percent of West Virginia was still covered by virgin forest. Between 1880 and 1925 most of the timber in West Virginia was harvested (Raschka 1998). The forests of West Virginia have now regenerated and once again support billions of board feet of mature hardwood timber. The latest statewide periodic forest inventory, which started in the year of 2000 is still not published (USDA Forest Service Northeastern Station, 2001). However, between 1975 and 1989 inventories of the area in forestland indicate an increase by 500,000 acres (Raschka 1998). The total volume increased by 37 percent over the 1975 inventory, and the saw timber volume increased by 60 percent to 57.8 billion board feet, an average of 4,847 board feet per acre, in 1989 (DiGiovanni 1990). The predominant species in terms of timber volume is yellow poplar. With three billion cubic feet ( 85 million cubic meters), yellow poplar accounts for over 16 percent of the growing-stock volume. Virginia pine is the top softwood species with 411 million cubic feet (11.64 million cubic meters), or two percent of growing-stock volume.

Sawtimber stands contain 76 percent of the growing-stock volume. Volume in hardwood sawtimber qualifying as log grade two or better represents more than 25 percent of the total hardwood sawtimber inventory in West Virginia (DiGiovanni 1990). 
With the regeneration of West Virginia forests, the forest industry has obviously increased. During the 1980s, and again during the period from 1990 to 1995, wood products created more new jobs than any other manufacturing industry in West Virginia (Greenstreet and Cardwell 1997). Not only has West Virginia's wood products industry grown, it also has become one of the larger industries in the state, has good prospects for continued growth, and has extensive links to the rest of the States' economy. Sawlogs are by far the most important logging product in West Virginia. The highest proportion of the state's production is in hardwoods, constituting constituted 91 percent of the total production, and nearly 99 percent of sawlog production (Greenstreet and Cardwell 1997). The most important species are red oak, yellow-poplar, white oak, chestnut oak, sugar maple, red maple, and black cherry.

Over the period from 1989 to 1995, average removal of hardwood sawtimber was 75 percent of net growth in volume (Greenstreet and Cardwell 1997). For some important species, including red oak, sawtimber removals exceeded net growth. Non-industrial private forests comprise 83 percent of the timberland in West Virginia. Even though the specific forest harvesting data for the study area is not available, the Timber Product Output (TPO) Database Retrieval System, developed in support of the 1997 Resources Planning Act (RPA) Assessment, suggests there are at least some harvesting activities in Monongalia County and Preston County (USDA Forest Service 2001b). These harvesting activities have the potential to change the forest landscape structure in the study area.

\section{Forest pests, diseases, and fires}

Gypsy moth fungus has spread rapidly since 1992 through areas previously severely impacted by the invasive moth. Since 1995 in particular, this fungus has dramatically reduced gypsy moth populations (USDA Forest Service Northeastern Forest Experiment Station 2000). Other main forest pests and diseases occurred in this area include periodical cicadas, hemlock woolly adelgid, dogwood Anthracnose, elm yellows, and chestnut blight. These forest pests and disease can stress and increase mortality of different forest species (USDA Forest Service Northeastern Forest Experiment Station 2000). For example, branch mortality from female cicada egg-laying mostly damages small shade and ornamental hardwood trees. Some diseases have a higher threat to the forest species in higher elevations, such as dogwood anthracnose epidemics which 
primarily affect dogwood above 2000 feet above sea level. The mortality caused by dogwood anthracnose has increased in recent years (USDA Forest Service Northeastern Forest Experiment Station 2000). The chestnut blight was an introduced fungal pathogen that kills chestnut trees. It moved rapidly through West Virginia in the 1930s, and resulted in a marked change in forest composition in many places (Nellis et al. 2001).

According to the Climate Prediction Center of National Oceanic and Atmospheric Administration, West Virginia fell into two drought categories on the Palmer Drought Index in 1999: severe drought and extreme drought (USDA Forest Service Northeastern Forest Experiment Station 2000). The majority of the severe drought occurred in the western part of the State, whereas the extreme drought occurred in the eastern part of the State. The drought encompassing West Virginia created increased levels of severe forest fires. Consequently, in 1999, there were 1,875 forest fires in West Virginia, nearly double that of the previous year, and fires burned 34169 ha (84,434 acres), four times the area burnt the previous year. Damage estimates totaled $\$ 25,330,200$ compared with $\$ 6,147,660$ the previous year. Suppression costs were estimated at $\$ 196,723$, more than double the estimated $\$ 99,884$ spent in 1998 . The number one cause of wildfires in West Virginia continues to be arson, with debris burning a distant second.

\section{Land Use Change}

As discussed in chapter1, the total area of forested land in West Virginia increased between 1982 and 1997 (USDA Natural Resources Conservation Service 1997). In 1982, 4,213,830 ha (10,412,600 acres) were classified as forest, while in 1997 , this number increased to 4,282,181 ha (10,581,500 acres). However, despite this net gain of about 68,351 ha (168,900 acres), 72,155 ha (178,300 acres) were lost to urban development. The increase of nearly 242,811 ha $(600,000$ acres $)$ of forestland converted from crop and pastureland was offset by a total loss of 128,811 ha $(318,300$ acres $)$ of forest converted to other uses. Table 3.2 shows the rates of land use conversion from or to forestland. 
Table 3.2 West Virginia forest land conversion from 1982 to 1997 (in thousands of acres) (Source: USDA Natural Resources Conservation Service 1997).

\begin{tabular}{|r|c|c|c|}
\hline & $\begin{array}{c}\text { Converted to Forest } \\
(1,000 \text { 's acres })\end{array}$ & $\begin{array}{c}\text { Converted From Forest } \\
(1,000 \text { 's acres })\end{array}$ & $\begin{array}{c}\text { Net Gain or Loss } \\
(1,000 \text { 's acres })\end{array}$ \\
\hline Cultivated Cropland & 25.80 & 0.00 & 25.80 \\
\hline Pon-cultivated Cropland & 50.10 & 13.40 & 36.70 \\
\hline Mastureland & 523.70 & 146.80 & -0.10 \\
\hline Urban land & 81.80 & 81.90 & -178.30 \\
\hline Rural Transportation & 0.00 & 178.30 & -5.90 \\
\hline Small Water & 6.00 & 11.90 & -3.80 \\
\hline Large Water & 1.50 & 5.30 & -0.30 \\
\hline Federal land & 3.00 & 0.30 & -82.10 \\
\hline Total & 692.1 & 85.30 & 168.90 \\
\hline
\end{tabular}

Urban and built-up lands showed a marked increase of 287,200 acres $(116,225.72$ ha.) from 1982 - 1997. Conversion of non-federal rural land to urban land between 1992 and 1997 outpaced the growth of the previous ten years. In 1997, urban lands amounted to 653,400 acres $(264,421.60$ ha.), an increase of 174,400 acres $(70,577.18$ ha.) from 1992. In the prior ten years, approximately 112,800 acres $(45,648.54$ ha.) were converted to urban uses. The following table illustrates trends in land conversion to urban uses (Table3.3).

Table 3.3 West Virginia urban land conversion from 1982 to 1997 (in thousands of acres) (Source: USDA Natural Resources Conservation Service 1997).

\begin{tabular}{|r|c|c|c|}
\hline & Converted to Urban & Converted From Urban & Net Gain or Loss \\
\hline Cultivated Cropland & 21.80 & 0.00 & 21.80 \\
\hline Fon-cultivated Cropland & 31.30 & 0.00 & 31.30 \\
\hline Forest & 46.60 & 0.00 & 46.60 \\
\hline Mastureland & 178.30 & 0.00 & 178.30 \\
\hline Rural land & 5.50 & 0.00 & 5.50 \\
\hline Smansportation & 3.80 & 0.00 & 3.80 \\
\hline Large Water & 0.00 & 0.00 & 0.00 \\
\hline Federal land & 0.00 & 0.00 & 0.00 \\
\hline Total & 0.00 & 0.10 & -0.10 \\
\hline
\end{tabular}


In the study area, forest is the main land cover type. According to the latest published 1989 forest inventory (DiGiovanni 1990), the total area of forest in Monongalia County and Preston County has stayed rather stable, with only a slight decrease. However, changes in the area size of average farm in the two counties from 1987 to 1997 suggested potential impacts on forest fragmentation caused by land use changes (Oregon State University 2001). Morgantown, on the east bank of the Monongahela River, is the main city and population area in the study site. It is growing rapidly, especially to the northeast towards Cheat Lake (Nellis et al. 2001). Even though the total population in this area has limited change, second home development and increasing human pressure from surrounding developed areas are effecting the land use change (Nellis et al. 2001).

\section{Summary}

Forest fragmentation is becoming a increasing concern throughout the state of West Virginia (The Charleston Gazette Online 2001). This chapter discussed natural events and human activities that are placing an ever-increasing strain on the West Virginia regional forest ecosystem, especially, through fragmentation of forest cover. The formation of forest patches and edges may reduce the sustainability of the regional ecosystem and be adverse for biodiversity. 


\section{Chapter 4 Methods}

As discussed in chapter 1, this study has two main objectives. The first objective of studying forest fragmentation changes between 1987 and 1999 in the study area was addressed with Landsat Thermal Mapping (TM) data, Gap data and Patch Analysis extension for ArcView. A demonstration project was implemented with a stand-alone GIS platform and Patch analysis tools. The second objective is to assess Internet mapping server and Web GIS for delivering forest fragmentation analysis functions and for supporting public participation in spatial decision making, collaborative forest fragmentation modeling, and representation from distributed spatial database. This latter objective therefore addresses potential solutions to the weaknesses of traditional standalone GIS.

\section{Analyzing forest fragmentation in a stand-alone computing environment}

The first objective of this thesis was addressed in four stages: (1) data acquisition, (2) data preprocessing, (3) land cover analysis, and, (4) land use classification and patch analysis for the study area in northern West Virginia.

\section{Data acquisition}

In general, Landsat TM data have proven to be very effective for land cover and land use detection (Stefanov et al. 2001, Yang et al. 2001, Steele 2000, Finder et al. 1999, Salajanu 2001, Franklin 1986). The nation-wide Gap Project, for example, which aimed to map land cover at a regional level, used Landsat TM data for landscape change analysis. In this study, two scenes of Landsat TM data were used as the main data source (Table 4.1). The first scene is a Landsat 5 TM image acquired in 1987. The second image is a Landsat 7 ETM image acquired in 1999. These two images were selected based on four criteria: (1) they were cloud free; (2) they were acquired in approximately the same time of the year; (3) they covered the study area; vi) and, they provided good spectral discrimination of forest cover. 
Table 4.1 Parameters of TM Images used in this study.

\begin{tabular}{|l|l|l|l|}
\hline Scene\# & Sensor & Path\#/Row\# & Acquisition Data \\
\hline 1 & $\begin{array}{l}\text { Landsat 5 } \\
\text { TM }\end{array}$ & $17 / 32$ & $10 / 05 / 1987$ \\
\hline 2 & $\begin{array}{l}\text { Landsat 7 } \\
\text { ETM+ }\end{array}$ & $17 / 32$ & $09 / 12 / 1999$ \\
\hline
\end{tabular}

Landsat 5 is a U.S. satellite launched in March 1984 and is still operational. The satellite carries the Thematic Mapper (TM) sensor, on which has six optical bands with $30 \mathrm{~m}$ IFOV and a thermal band with a $120 \mathrm{~m}$ IFOV (Table 4.2).

Table 4.2 Landsat5 TM Spectral and Spatial Resolution (from www.nasa.gov).

\begin{tabular}{|c|c|c|}
\hline Band & Spectral Resolution $(\mu \mathrm{m})$ & Spatial Resolution $(\mathrm{m})$ \\
\hline 1 & $0.45-0.52$ & 30 \\
\hline 2 & $0.52-0.60$ & 30 \\
\hline 3 & $0.63-0.69$ & 30 \\
\hline 4 & $0.76-0.90$ & 30 \\
\hline 5 & $1.55-1.75$ & 30 \\
\hline 6 & $10.4-12.4$ & 120 \\
\hline 7 & $2.09-2.35$ & 30 \\
\hline
\end{tabular}

Landsat 7 was launched on April 15, 1999. Thermal Mapper (ETM) sensor (Table 4.3), the ETM+ instrument is similar to the Tm instrument except the thermal band has a $60 \mathrm{~m} \mathrm{IFOV}$, and it also images in an eighth, panchromatic band, with a $15 \mathrm{~m}$ IFOV

Table 4.3 Landsat7 Spectral and Spatial Resolution (from www.nasa.gov).

\begin{tabular}{|c|c|c|}
\hline Band & Spectral Resolution $(\mu \mathrm{m})$ & Spatial Resolution $(\mathrm{m})$ \\
\hline 1 & $0.45-0.515$ & 30 \\
\hline 2 & $0.525-0.605$ & 30 \\
\hline 3 & $0.630-0.690$ & 30 \\
\hline 4 & $0.75-0.90$ & 30 \\
\hline 5 & $1.55-1.75$ & 30 \\
\hline 6 & $10.40-12.5$ & 60 \\
\hline 7 & $2.09-2.35$ & 30 \\
\hline Pan & $0.520-0.90$ & 15 \\
\hline
\end{tabular}

To evaluate the combination of TM data and other data for detecting forest fragmentation changes, the West Virginia Gap data was downloaded from the West Virginia GIS Technical Center (http://wvgis.wvu.edu/data/land_cover.html). The Gap data was used to add land cover and land use data for 1994 as an intermediate temporal period. 
The West Virginia Gap land cover data was produced as part of the West Virginia Gap Analysis Project, and was released in 2000. The source data were acquired from multiple 30-meter Landsat images obtained between 1992-1994. The results have not yet been subjected to accuracy assessment or testing. The land cover classification schema includes 26 classes as shown in the Table 4.4. West Virginia Gap Land Cover data was saved in a standard GRID format, with a UTM Zone 17 projection, on the North American Datum of 1927 (NAD27).

Other reference data used in this study include the West Virginia County boundary from the 1: 24000 digital line graph (DLG) of USGS, 1997 natural color photography of Monongalia County, West Virginia (with an original scale of 1:12,000 and spatial resolution 1.0 meter per pixel); and, the West Virginia Digital Orthophoto Quarter Quads (DOQQ) (part of the statewide color infrared (CIR) aerial orthophotography derived from 1996-99 color infrared NAPP photography), all of which were downloaded from the West Virginia GIS Technical Center (http://wvgis.wvu.edu).

\section{Data preprocessing:}

The data pre-processing was conducted in three steps: re-projection, clipping the study area, and, for the 1999 ETM+ images, geometric correction.

The 1987 TM data had a pixel size of 28x28 meter, and after visually confirming the accuracy of the geocoding by overlaying the DLG data for the same area, the 1987 TM data were chosen as the base image. The 1999 TM data were systematically corrected. 
Table 4.4 West Virginia Gap Land Cover Classification Schema (wvgis.wvu.edu).

\begin{tabular}{|l|l|}
\hline $\begin{array}{l}\text { Class } \\
\text { Code }\end{array}$ & Class Name \\
\hline 1 & Shrubland \\
\hline 2 & Woodland \\
\hline 3 & Surface water \\
\hline 4 & Major highways \\
\hline 5 & Major powerlines \\
\hline 6 & Populated area - mixed land cover \\
\hline 7 & Low intensity urban \\
\hline 8 & Moderate intensity urban \\
\hline 9 & Intensive urban \\
\hline 10 & Row crop agriculture \\
\hline 11 & Pasture/grassland \\
\hline 12 & Barren land - mining, construction \\
\hline 13 & Planted grassland \\
\hline 14 & Conifer plantation \\
\hline 15 & Floodplain forest \\
\hline 16 & Forested wetland \\
\hline 17 & Shrub wetland \\
\hline 18 & Herbaceous wetland \\
\hline 19 & Surface water (combine with class \#3) \\
\hline 20 & Cove hardwood forest \\
\hline 21 & Diverse/mesophytic hardwood forest \\
\hline 22 & Hardwood/conifer forest \\
\hline 23 & Oak dominant forest \\
\hline 24 & Mountain hardwood forest \\
\hline 25 & Mountain hardwood/conifer forest \\
\hline 26 & Mountain conifer forest \\
\hline & \\
\hline
\end{tabular}

\section{1) Re-projection}

The standard projection for this project was chosen to be the UTM, zone 17, with the 1997 North American Datum (NAD27) and 30 m pixel. Because the original projection of the 1987 TM image was $28 \mathrm{~m}$ pixels, the image was reprojected to a NAD 27 datum and $30 \mathrm{~m}$ pixels. The reproject model in ERDAS Geometric model (Figure 4.1) was used for carrying out reprojection. 


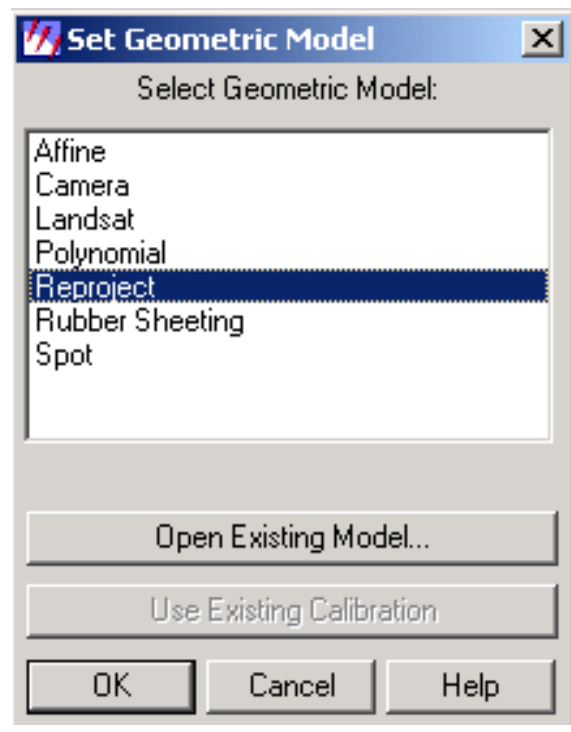

Figure 4.1 Interface of ERDAS Imagine ${ }^{\circledR}$ Geometric Model

Since the grid of pixels in the source image rarely matches the grid for the reference image, the pixels needed to be resampled to a new data file. In Imagine there are three kinds of resampling methods: nearest neighbor, bilinear interpolation, and cubic convolution (ERDAS, Inc. 1999). The nearest neighbor approach assigns the DN value of original pixel closest to the location of the center of the new pixel for the output pixel value. Bilinear interpolation uses the data file values of four pixels in a 2 x 2 window to calculate an output value with a bilinear function. Cubic convolution uses the data file values of sixteen pixels in a 4 x 4 window to calculate an output value with a cubic function. The nearest neighbor was chosen for this study because this method does no change the $\mathrm{DN}$ values.

\section{2) Study area clipping}

The ERDAS Subset Image function was used to clip the study area. First, a layer of 'area-of-interest' (AOL) was created as the study site boundary (Table 4.5). Then, the AOL boundary layer was used to clip Landsat TM image data and Gap data.

Table 4.5 Study sites boundaries

\begin{tabular}{|l|l|l|}
\hline & X (UTM) & Y (UTM) \\
\hline UL & 586091 meters & 4396389 meters \\
\hline LR & 609835 meters & 4382669 meters \\
\hline
\end{tabular}




\section{3) Geometric correction.}

The 1999 ETM+ data were systematically corrected by the EROS data center (EDC) and required more precise rectification. The rectification involved three steps: locating Ground Control Points (GCPs), computing and testing a transformation, and creating an output image file with resampled pixel values. GCPs are specific pixels in an image for which the output coordinates are known. GCPs consist of two X, Y pairs of coordinates, a source and reference. Source coordinates refer to data file coordinates in the image being rectified. Reference coordinates were obtained from the 1987 image to the coordinates of the map or reference image to which the source image is being registered.

In this study, the ERDAS imagine ${ }^{\circledR}$ image Raster |Geometric Correction function was used for rectification operations. First, the polynomial model was selected. The polynomial order was set as 1 , because the clipped image covers a relative small area. Then 18 GCPs were selected from both the 1987 TM image and 1999 ETM+ image. The final Transformation root mean square (RMS) was less than 0.5. Nearest neighbor resampling was used.

\section{Land Cover/ Land Use Classification}

The GAP data were recoded to a smaller number of more general classes, more appropriate for this study (Table 4.6). Because this research focused on a general forest class, all forest areas in the GAP classification were recoded as a single forest class.

The seven classes of the recoded Gap data were used in the classification of the TM and ETM+ data. Classification is the process of sorting pixels into a finite number of individual classes, or categories of data which are also called classification schema, based on their data file values (ERDAS, 1999). In order to classify the different land categories, the algorithm must be trained to recognize patterns in the data. Training is the process of defining the criteria by which these patterns are recognized (Hord 1982). The result of training is a set of signatures that defines a training sample or cluster. Each signature corresponds to a class, and is used with a decision rule to assign the pixels in the image file to a class (ERDAS, 1999). 
Table 4.6 The recoded Classification schema for TM image classification

\begin{tabular}{|c|c|c|c|}
\hline $\begin{array}{l}\text { Original Gap } \\
\text { Class Code }\end{array}$ & Class Name & $\begin{array}{l}\text { New } \\
\text { Class Code } \\
\end{array}$ & \begin{tabular}{|l} 
New \\
Class Name \\
\end{tabular} \\
\hline 1 & Shrubland & 4 & $\begin{array}{l}\text { Grassland / } \\
\text { Shrubland }\end{array}$ \\
\hline 2 & Woodland & 2 & Forest \\
\hline 3 & Surface water & 1 & Water \\
\hline 4 & Major highways & 5 & Road \\
\hline 5 & Major powerlines & 6 & Powerline \\
\hline 6 & $\begin{array}{l}\text { Populated area - mixed } \\
\text { land cover }\end{array}$ & 3 & Developed area \\
\hline 7 & Low intensity urban & 3 & Developed area \\
\hline 8 & Moderate intensity urban & 3 & Developed area \\
\hline 9 & Intensive urban & 3 & Developed area \\
\hline 10 & Row crop agriculture & 4 & $\begin{array}{l}\text { Grassland / } \\
\text { Shrubland }\end{array}$ \\
\hline 11 & Pasture/grassland & 4 & $\begin{array}{l}\text { Grassland / } \\
\text { Shrubland }\end{array}$ \\
\hline 12 & $\begin{array}{l}\text { Barren land - mining, } \\
\text { construction }\end{array}$ & 7 & Barren land \\
\hline 13 & Planted grassland & 4 & $\begin{array}{l}\text { Grassland / } \\
\text { Shrubland }\end{array}$ \\
\hline 14 & Conifer plantation & 2 & Forest \\
\hline 15 & Floodplain forest & 2 & Forest \\
\hline 16 & Forested wetland & 2 & Forest \\
\hline 17 & Shrub wetland & 4 & $\begin{array}{l}\text { Grassland / } \\
\text { Shrubland }\end{array}$ \\
\hline 18 & Herbaceous wetland & 4 & $\begin{array}{l}\text { Grassland / } \\
\text { Shrubland }\end{array}$ \\
\hline 19 & $\begin{array}{l}\text { Surface water (combine } \\
\text { with class \#3) }\end{array}$ & 1 & Water \\
\hline 20 & Cove hardwood forest & 2 & Forest \\
\hline 21 & $\begin{array}{l}\text { Diverse/mesophytic } \\
\text { hardwood forest }\end{array}$ & 2 & Forest \\
\hline 22 & Hardwood/conifer forest & 2 & Forest \\
\hline 23 & Oak dominant forest & 2 & Forest \\
\hline 24 & Mountain hardwood forest & 2 & Forest \\
\hline
\end{tabular}

There are two ways to train the pattern: one is unsupervised, and the other one is supervised (ERDAS, 1999). In the unsupervised classification, training is carried out through computer-automation. It enables us to uncover statistical patterns that are inherent in the data. Supervised training is closely controlled by an image analyst. In this process, the analyst select pixels that represent patterns or land cover features with help from other sources, such as aerial photos, ground truth data, or maps. Knowledge of the 
data, and of the classes desired, is required before such kind of classification. Supervised classification is usually appropriate to identify relatively few classes, or where selected training sites that can be verified with ground truth data, or to identify distinct, homogeneous regions that represent each class. Therefore, in this study, supervised classification was applied to identify the land cover and land use classes.

In this study, the reference data used for creating signatures includes natural color photography and color infrared DOQQs. The ERDAS IMAGINE Classifer|Signature Editor was used. First, the AOI tool was used to collect signatures. In order to identify more reliable signatures, several bands combination of TM data were used in defining the signature polygons.

a) Band 1(B), band $2(\mathrm{G})$ and band $3(\mathrm{R})$

This is the "natural color" band combination (Jensen, 1996). While the visible bands are used in this combination, ground features appear in colors similar to their appearance to the eyes. Rivers, roads and powerlines are very easy to distinguish from forests and grasses.

b) Band 2(B), band 3(G) and band 4(R)

This is the standard "false color" composite (Jensen, 1996). Vegetation appears in shades of red, developed areas such as urban areas or roads are cyan blue, and soils vary from dark to light browns. Coniferous trees will appear darker red than hardwoods. This is a very popular band combination and is useful for vegetation studies, monitoring drainage and soil patterns and various stages of crop growth. Generally, deep red hues indicate broad leaf vegetation, while lighter reds signify grasslands or sparsely vegetated areas. Densely populated urban areas are shown in light blue.

c) Band 1(B), band 5(G) and band 4(R)

With this combination, healthy vegetation appears in shades of reds, browns, oranges and yellows (Jensen, 1996). Urban features are white, cyan and gray, bright blue areas represent recently clearcut areas, and reddish areas show new vegetation growth, probably sparse grasslands. Clear, deep water will be very dark in this combination. If the water is shallow, or contains sediments, it would appear as shades of lighter blue. 
This is not a good band combination for studying cultural features such as roads and runways.

d) Band 3(B), band 5(G) and band 4(R)

This combination of near-IR (Band 4), mid-IR (Band 5) and red (Band 3) offers added definition of land-water boundaries and highlights subtle details not readily apparent in the visible bands alone. Inland lakes and streams can be located with greater precision when more infrared bands are used. This band combination is good for discriminating vegetation type and condition, in a variety of tones (brown, green and orange hues) (Jensen, 1995).

A total of 66 training signatures were identified for water, forest, developed areas, Grassland / Shrubland and Barren land (Figure 4.2). At this phase, the road and powerline features were classified as developed areas.

\begin{tabular}{|c|c|c|c|c|c|c|c|c|c|c|c|c|c|}
\hline Class \# & Siqnature Name & Color & Red & Green & Blue & Value & Order & Count & Prob. & $\mathrm{P}$ & $\mathrm{IH}$ & $\mathrm{A}$ & FS \\
\hline 31 & Class 12 & & 0.383 & 0.844 & 0.829 & 3 & 31 & 2518 & 1.000 & 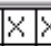 & $\begin{array}{l}x \\
x\end{array}$ & $x$ & \\
\hline 32 & Class 13 & & 0.479 & 1.000 & 1.000 & 3 & 32 & 723 & 1.000 & $x \mid x$ & & $x$ & \\
\hline 33 & Class 14 & & 0.313 & 1.000 & 1.000 & 3 & 33 & 262 & 1.000 & $x>$ & $x \times$ & $x$ & \\
\hline 34 & Class 15 & & 0.668 & 0.870 & 0.772 & 4 & 34 & 199 & 1.000 & $x$ & \begin{tabular}{l|l}
$x$ \\
$x$
\end{tabular} & $x$ & \\
\hline 35 & Class 16 & & 0.630 & 0.644 & 0.675 & 4 & 35 & 123 & 1.000 & $x>$ & $x \times$ & $x$ & \\
\hline 36 & Class 17 & & 0.803 & 0.676 & 0.740 & 4 & 36 & 426 & 1.000 & $x>$ & $x \times$ & $x$ & \\
\hline 37 & Class 18 & & 0.850 & 0.603 & 0.676 & 4 & 37 & 260 & 1.000 & $x$ & $x \times$ & $x$ & \\
\hline 38 & Class 19 & & 0.849 & 0.610 & 0.716 & 4 & 38 & 278 & 1.000 & $x \mid$ & $x \mid x$ & $x$ & \\
\hline 39 & Class 20 & & 0.676 & 0.670 & 0.705 & 4 & 39 & 376 & 1.000 & $x / 8$ & $x \times$ & $2 x$ & \\
\hline 40 & Class 21 & & 0.994 & 0.511 & 0.631 & 4 & 40 & 136 & 1.000 & $x / 8$ & $x \times$ & $2 x$ & \\
\hline 41 & Class 22 & & 0.799 & 0.605 & 0.708 & 4 & 41 & 1895 & 1.000 & $x>$ & $x \times$ & $5 x$ & \\
\hline 42 & Class 23 & & 0.774 & 0.638 & 0.721 & 4 & 42 & 690 & 1.000 & $x \mid$ & $x \times$ & $2 x$ & \\
\hline 43 & Class 24 & & 0.875 & 0.580 & 0.702 & 4 & 43 & 412 & 1.000 & $x$ & $x \times$ & $2 x$ & \\
\hline 44 & Class 25 & & 0.784 & 0.590 & 0.670 & 4 & 44 & 608 & 1.000 & $x>$ & \begin{tabular}{c|c}
$x$ \\
\end{tabular} & $3 x$ & \\
\hline 45 & Class 34 & & 0.267 & 1.000 & 1.000 & 7 & 53 & 188 & 1.000 & $x>$ & $x \times$ & $<x$ & \\
\hline 46 & Class 35 & & 0.360 & 1.000 & 1.000 & 7 & 54 & 257 & 1.000 & $x \mid$ & $x \times$ & $5 x$ & \\
\hline 47 & Class 26 & & 0.313 & 1.000 & 1.000 & 7 & 55 & 95 & 1.000 & $x>$ & $x \times$ & $5 x$ & \\
\hline 48 & Class 27 & & 0.220 & 1.000 & 1.000 & 7 & 56 & 205 & 1.000 & $|x|$ & $\bar{x} \mid x$ & $\langle x$ & \\
\hline
\end{tabular}

Figure 4.2 Selected supervised classification signatures from the imagine signature editor.

After the signatures were defined, the pixels of the image were sorted into classes based on the signatures using a classification decision rule. The decision rule is a mathematical algorithm that, using data contained in the signature, performs the actual sorting of pixels into distinct class values. A maximum likelihood decision rule was used for the classification. In a maximum likelihood classification, signatures are defined by the mean vector and covariance matrix of each class. 
After classification, the classified images that were derived from Landsat imagery were twice filtered with a 3x3 majority filter respectively. Then, an ERDAS spatial model (Figure 4.3) was employed to overlay roads and power lines from the GAP classification on the classified images.

Finally, this produces three classified land cover maps for 1987, 1994 (GAP), and 1999.

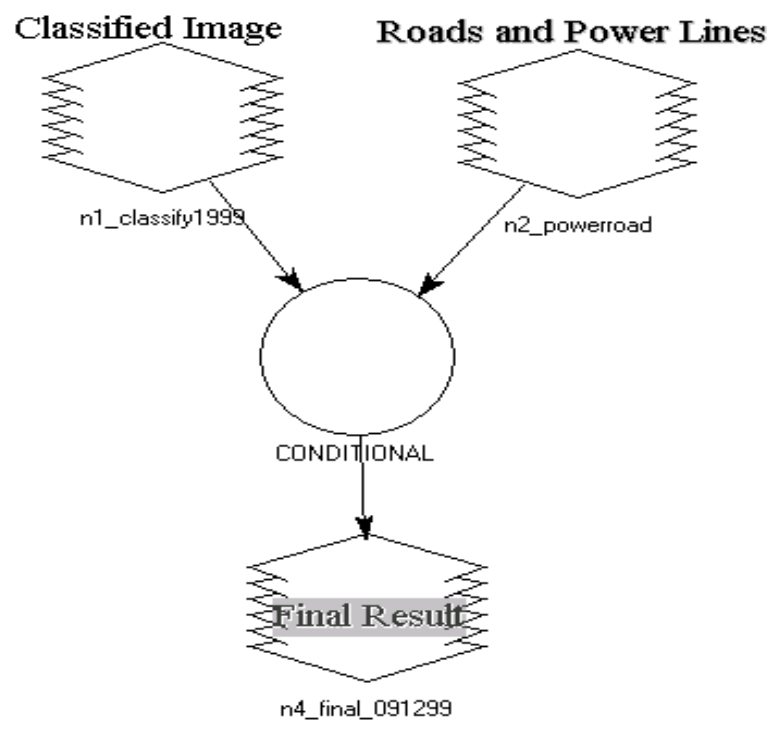

Figure 4.3 Spatial model for adding roads and power lines to the TM classification images

\section{Patch Analysis}

In this study, PATCH (GRID) ANALYST 2.0 (Rempel 2000) was used for the fragmentation metrics calculation and analysis. PATCH (GRID) ANALYST is an extension to the ArcView ${ }^{\circledR}$ GIS spatial analyst extension. PATCH (GRID) ANALYST calculates 28 patch metrics, including mean and median patch size, patch size coefficient of variance, edge density, mean shape index, fractal dimension, interspersion and juxtaposition, Shannon's diversity index, and the core area index. The program can also create a new shape with patch metric attributes attached. Summary statistics are reported at either the patch or landscape scale. The various patch metrics follow the definitions in FRAGSTATS ( McGarigal and Marks 1995).

For this study a selected number of landscape metrics was used: 1) Patch-per-Unit area (PPU), which measures the degree of fragmentation of patches on a landscape 
(Formula 4.1); 2) Square Pixel (SqP), which measures the shape complexity of patches on a landscape (Formula 4.2); 3 ) average forest patch area and average forest patch perimeter which are usually used for measuring the forest patch size change; 4) forest patch number; 5) percentage of landscape area occupied by forest patches which measure the forest patch abundance, 6) edge density, and 7) forest Patch core area.

\begin{tabular}{|l|}
\hline Formula 4.1 Formula of PPU \\
\hline $\mathrm{PPU}=\mathrm{m} /(\mathrm{n} * \lambda)$ \\
$\mathrm{N}$ is the total number of patches \\
$\lambda$ is a scaling constant equal to the area of a pixel. \\
Low PPU means less fragmentation \\
\hline
\end{tabular}

Formula 4.2 Formula of SqP

$\mathrm{Sqp}=1-\left(4 * \mathrm{~A}^{1 / 2} / \mathrm{P}\right)$

$\mathrm{A}$ is the total area of all pixels

$\mathrm{P}$ is the total perimeter of all pixels in the study area.

It is unitless.

Low SqP means less complexity

In order to calculate these metrics, ArcView3.2 $®$ was first opened with Imagine extension, spatial analyst extension and Patch (Grid) analysis 2.0 extension. Then the 1987 TM and 1999 TM classification images were converted to GRID files. After that, PatchGrid|Add Area/Perimeter was used to calculate the total area and perimeter for every land cover class. The PatchGrid|Spatial statistic (FragStats) were used to calculate 
total landscape area, number of patches, mean patch size edge density and other metrics (Figure 4.4).

In order to calculate PPU and SqP, the two new fields were added, and then the ArcView calculation function was used to get their values. Results were then summarized.

\section{ArcView GIS 3.2}

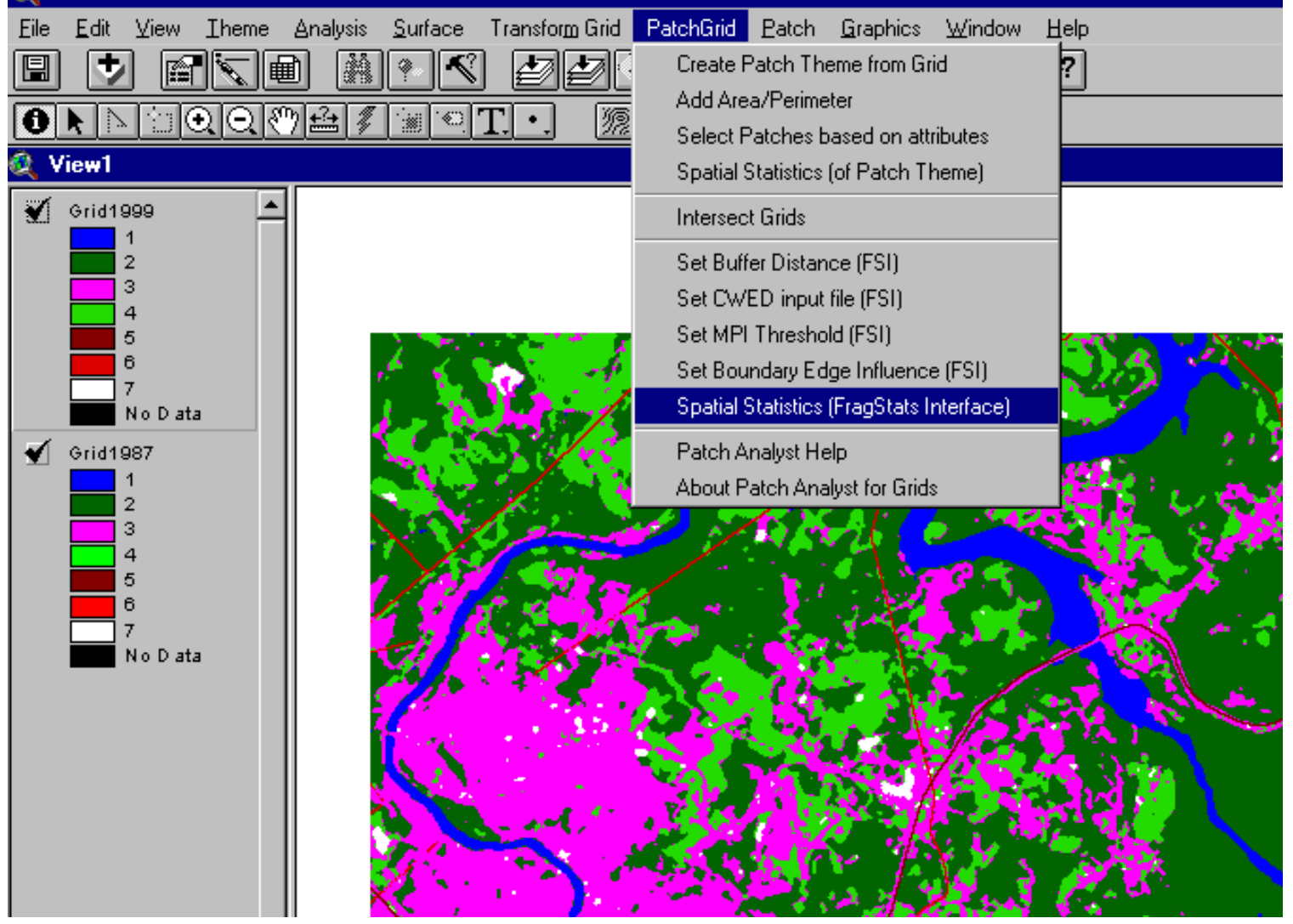

Figure 4.4 Interface of PATCH (GIRD). 


\section{The design and implementation of Forest Fragmentation Analysis Web site with ArcIMS}

The second objective of this study focused on assessing IMS and Web GIS as approaches to improve forest fragmentation information representation and delivery for the case study. First, four essential functions for web-based forest fragmentation analysis were identified. From those functions, some indicators were derived to assess the ability of different Web-GIS approaches for supporting data integration, spatial analysis, query and information representation. Then, ArcIMS HTML Viewer and JAVA viewer was used to explore the implementation of those proposed functions as it relates to forest fragmentation.

\section{Why ArcIMS?}

There are several ways to implement a Web-based GIS. The choice depends on application goals, time and cost requirements. For example, Internet application development languages and components such as Java, JavaScript, Perl, Vbscript and HTML could be used directly to design GIS servers. This approach is very flexible but time-consuming. A second approach would be to establish a Common Gateway Interface (CGI) by integrating common programming languages such as VisualBasic with commercial GIS component libraries such as MapObject or ArcObjects for processing web client-side requests. This approach has still higher requirements as to the developer's computer programming ability, and requires spending a significant amount of time on system design. The third approach would use a commercial Internet mapping server (IMS) package, such as ESRI's ArcView IMS, ArcIMS or Intergraph's GeoMedia Web Enterprise, to customize the application. Commercial IMS approaches allow developers to build web-based GIS in a quick and convenient way. In this research, ESRI's ArcIMS integrated environment was used.

ArcIMS provides a framework for distributing GIS services on the Internet. It is a toolset for authoring, designing, and administering Internet GIS sites. Compared with other commercial IMS solutions, ArcIMS has various special features for delivering Internet mapping services and GIS functionalities. For example, ArcIMS makes it possible to integrate data from multiple sources (ESRI 2001) including any number of ArcIMS Websites. It also enables the integration of local GIS data with ArcIMS layers. 
ArcIMS has a wide range of functionality. With the exception of editing tools, nearly all ArcMap ${ }^{\mathrm{TM}}$ tools that can be used with shapefiles, coverages, and geodatabases can also be used with ArcIMS feature layers. Users can potentially access and analyze data to the extent of an ArcGIS Desktop user. ArcIMS also provides access to GIS data and services. Web GIS service providers can determine how, and to whom, GIS data and services are delivered. ArcIMS provides a scalable system that can be configured to serve up to 10,000 map requests an hour.

ArcIMS includes a set of HTML and Java viewers that provides access to basic GIS services and tools. These viewers can provide options such as labeling features, creating map tips, selecting attributes spatially, determining distances, and even incorporating the user's own data with the feature service for further analysis. Users also can build new queries or run predefined queries to derive specific information about the distributed database (ESRI, 2001).

ArcIMS allows direct customization at both client and server levels. At the client level, custom HTML and JavaScript can be used to modify the look and feel of the viewer. At the server level, ArcIMS's XML language, ArcXML, can be used to modify map configuration files, for example, to project data and change the appearance of map features. It is also possible to incorporate custom and advanced services and tools (ESRI, 2001).

These features supported by ArcIMS provide the potential to develop a highly interactive Web GIS application for forest fragmentation information delivery and analysis.

\section{Components of ArcIMS}

ArcIMS consists of client-side components, server-side components and a data storage tier (Figure 4.5). 


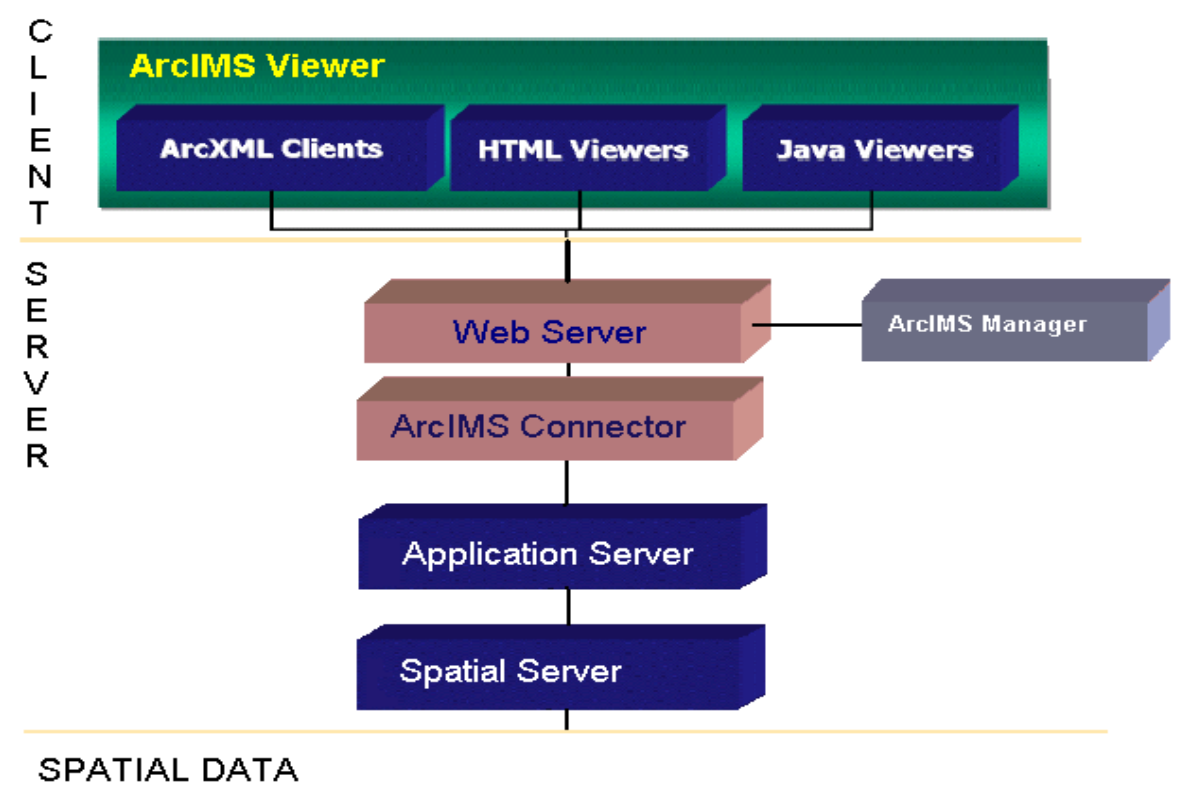

Figure 4.5 Components of ArcIMS (ESRI, 2001).

\section{(1) The server-side components}

The server-side components consist of a Web server, ArcIMS application Server Connectors, an ArcIMS Application Server, an ArcIMS Spatial Server, and an ArcIMS Manager. These components are used to process ArcIMS client-side requests, to create and run MapServices, and to manage the site (ESRI 2001).

A Web server provides standard web services, and communicates with one of the ArcIMS Application Server Connectors. The ArcIMS Application Server Connectors are used to connect the Web server to the ArcIMS Application Server.The ArcIMS Application Server handles the load balancing of incoming requests and tracks what MapServices are running on ArcIMS Spatial Servers. The ArcIMS Application Server passes a request to the appropriate spatial server.

The ArcIMS Spatial Server is the core component for processing requests for maps and related information. When a client request is received, the ArcIMS Spatial Server performs functions such as creating cartographic map image files, streaming map features, searching to query the database, geocoding for address matching operations, or "clipping" data to create a subset that can be sent back in shapefile format.

MapServices are major processes running on the ArcIMS Spatial Server. A MapService provides instructions to a spatial server on how to draw a map when a 
request is received. The input to a MapService is an ArcXML MapService configuration file (MCF). The same MCF file can be used as input to more than one MapService. ArcIMS supports two types of MapServices: Image and Feature. An Image MapService provides the client with a snapshot of the view of authored map by using the image rendering capabilities of the spatial server. When a request is received, a map is generated on the server, and the response is returned as a JPEG, PNG, or GIF image. A new map image is generated each time a client requests more information. Rather than rendering a map on the server, a Feature MapService uses the spatial server's feature streaming capabilities to bundle data and send the request to the client. Feature streams, in specially optimized compressed format, are processed by Java Applets embedded in the client-side Web browser. In this way, the communication traffic on Internet is reduced significantly. Therefore, the Feature MapService can potentially higher speed Web GIS application services.

The ArcIMS Manager is a suite of Web pages that provides access to all ArcIMS server-side functions and tools. Through the ArcIMS Manager, it is possible to author, design, and publish MapServices.

\section{(2) Client-side components: ArclMS Viewers}

The client-side components refer to the ArcIMS Viewers (ESRI, 2001), which are the interfaces for the users of ArcIMS applications. The main functions of ArcIMS viewers include supporting the viewing of maps and data, as well as sending users' requests to the ArcIMS server. Different types of ArcIMS viewers support different functionality sets and web site graphic displays. There are three kinds of viewers: HTML/DHTML Viewers, Java Viewers and ArcXML clients. The former two are most common viewers. The ArcXML client could be any client viewer which can send ArcXML requests and explain ArcXML responses (ESRI, 2001).

The HTML/DHTML Viewer is written using HTML, DHTML, and JavaScript. When a user clicks on a map or tool, a request is generated by the viewer and sent to an ArcIMS Spatial Server using the servlet connector. When a response is returned, the client processes the response for display instructions. In this environment only one Image MapService can be displayed at a time. The HTML/DHTML Viewer requires that 
browsers must be version 4.0 of Internet Explorer or higher to handle the communications for requests and responses (ESRI 2001).

Compared to HTML/DHTML Viewers, Java Viewers are thicker clients because they have higher requirements for the client environment for running this viewer. Java Run-time Environment and ArcIMS Java Viewer components must be installed on the client browser. Java Viewers support both Image and Feature MapServices. There are two types of Java Viewers: ArcIMS Java Custom Viewer and ArcIMS Java Standard Viewer. The Java Custom Viewer uses JavaScript to communicate with the applets. This viewer can be customized using methods in a Viewer Object Model application programming interface (API). The Java Standard Viewer does not use JavaScript. The tools and functions are predefined and cannot be customized using the Viewer Object Model (ESRI 2001).

In this study, only HTML viewers and Java Custom Viewers were used.

\section{Communications between ArcIMS components via ArcXML}

The basic relationships among ArcIMS components is that when an ArcIMS client makes a request for a map or data, the request travels first to the Web server, passes through one of ArcIMS Connectors, and then is handed to the ArcIMS application server. The application server hands the request to an ArcIMS Spatial Server. The responses follow the same path in reverse order. All requests and responses are written using ArcXML (ESRI 2001).

ArcXML is a kind of Extensible Markup Language designed by ESRI for describing and operating geographic features. ArcXML defines content for MapServices and is used for building requests and responses between clients, middleware, and the server. ArcXML files are similar to HTML pages. However, the difference is that HTML describes the page structure for display, while ArcXML provides the structure for describing the content. ArcXML tags and attributes provide the structure for the following: (1) MapService configuration files that describe how a map should be rendered, which including a list of layers used and how each layer should be symbolized; (2) requests to sets a filter on an existing MapService configuration file that specifies which part of a map and associated data will be acted upon; or (3) responses to send the information back to the client. 


\section{General steps for designing and implementing a Web-GIS website with ArcIMS}

ArcIMS not only provides internet mapping services, but also provides an integrated development environment (IDE) for designing and implementing a Web-GIS website. Usually, it takes four steps to develop a Web GIS application with ArcIMS: designing the maps, authoring the Map Services, creating a prototype of web site, and customizing the Web Site (ESRI 2000a, ESRI 2000b, ESRI 2000c).

\section{(1) Designing Maps}

A map can consist of several layers. In the map design phase, the designer should decide the map contents needed by the application. In general, it is need to consider which layers should be published, the spatial extent for which those layers should be displayed, the source of the data, the format of the data, color and symbols used for rendering, the scale of rendering and so on. The main tool for map design is ArcIMS Author that creates a MapService Configuration File(MCF) for each map. This MapService Configuration File is built in ArcXML format. MCF can also be edited directly in any text editor by following ArcXML syntax.

\section{(2) Authoring Map Services}

In ArcIMS, in order to publish a map, one needs to create a MapService that provides instructions to a Spatial Server on how to draw a map when a request is received. The tool used for creating Map Services is ArcIMS Manager/Author MapService. The input to a MapService is a MapService Configuration File.

An HTML approach is used when Image MapService is chosen. The available functionality based on Image MapService is limited to simple view and query, and data layers are used mainly for reference. Feature MapService provides a larger range of functionality, and therefore is an appropriate choice when extensive user interaction and analysis is required (ESRI, 2000a). Feature Mapservice is based on a client-side Java solution. 


\section{(3) Creating the Prototype Application Web Site}

After creating a MapService, a prototype web site was designed and built with ArcIMS web design templates by choosing suitable ArcIMS Viewer and function sets. The main tool used for the web site design is ArcIMS Designer.

a) Choosing A Viewer

The ArcIMS Viewers determines the functionality, graphic look of the site, and client browser burden. ArcIMS provides two kinds of Viewers: an HTML Viewer and a Java Viewer. The HTML viewer can be opened in any Internet Browser such as Microsoft IE and Netscape. The HTML Viewer employs JavaScript and Dynamic HTML (DHTML) to enhance its capabilities. Java Viewers are only compatible with web browsers that support Java plug-in functionalities, and require a onetime web download to a user's computer (ESRI, 2000b).

The HTML viewer is approprite when the application is viewed with a variety of browsers, when the plug-ins are not allowed, when less client-side processing is preferred, and when only view and query functionalities are needed. If these requirements are not met, Java Viewers are an effective alternative (ESRI, 2000b).

b) Defining the GIS functions

The functionality in a Web GIS system is driven by the goals and requirements of the application. Applications can range from the most simple, requiring only viewing functions, to more sophisticated applications, requiring extensive user expertise and analytical processing. A suite of pre-defined functions has been provided in ArcIMS, including: zooming and panning the map, identifying and finding features, searching spatial features, querying data, displaying Maptips, selecting and buffering features, working with measures and scales, adding MapNotes, using EditNotes, operating layer properties, integrate data locally or from the internet, printing web maps, and so on. Different Web GIS approaches support different function sets (ESRI, 2000b). During the creation of the prototype of Application Web Site, predefined functions are specified after the viewer is chosen. Complex functions needed in the application can be added by later customization. 


\section{(4) Customization}

The prototype of the web site is not always ideal for the final application. For example, a specific application may need a special style of interface for the web site with special logo, help files and other interface elements. In addition, special functions may be needed. Therefore, after building the prototype of the web site, customization is usually required. HTML and JavaScript is used customizing interface and functionalities, and ArcXML is used for customizing spatial query and map contents (ESRI, 2000b; ESRI, 2000c).

\section{Proposed Functions in Forest Fragmentation Analysis Web Site}

The first step of the web site creation was to identify the essential functions for delivering forest fragmentation information.

From the literature review, it was determined that land cover data input and display, as well as forest fragmentation metrics calculation are the basic operations for forest fragmentation analysis. An additional important issue is the quantification of changes of forest fragmentation over time. A function to query a specific patch is needed to assess the forest fragmentation impacts on different species, because individual species tend to have different requirements for forest habitat extents. In addition, it may be necessary to assess impacts caused by individual disturbances such as new roads, forest harvesting, or fire. Based on these requirements, five essential functions for delivering forest fragmentation information and interactive analysis features were identified: (1) forest fragmentation metrics calculation; (2) a forest fragmentation viewer (3) a forest fragmentation change viewer; (4) patch query; and (5) disturbance assessment.

\section{(1) The forest fragmentation metrics calculation function}

The metrics calculation function allows users to choose a classified data set on the Web, and then to define a spatial extent for forest fragmentation calculations. Finally, the results of the metrics calculations, including those for area of forest, the total area of Area of Interest (AOI) specified, Pixel-Per-Unit, Square Pixel, number of patches, and Mean Patch Size are displayed. 


\section{(2) Forest fragmentation viewer}

The viewer displays distributed spatial data such as Landsat TM, and classified data, as well as the associated fragmentation metrics. Multi-temporal Landsat TM data and classification data should be organized as separate map layers. The forest fragmentation metrics should be shown as tabular data.

\section{(3) Patch query}

The patch query function allows users to identify forest patch as of specified size and type which may be suitable for specific species.

\section{(4) Disturbance assessment}

This function would allow users to add a disturbance polygon or line, for example a logging polygon, or a propose road corridor, and then associated changes of the forest fragmentation metrics should be reported.

\section{Steps for implementing the forest fragmentation web site}

The first step of the web site construction was to design the web site structure. The first page of the web site was designed as the entrance of the whole application. ArcIMS IDE was used to design the maps, create the associated map services, and build the prototypes of the application web pages. Finally, HTML, JavaScript and ArcXML were used to customize the application interfaces and functions.

\section{(1) Web Site Structure Design}

Generally, a web site has an introduction page which plays the role of introduction, and overall link to the web site functions. The more detailed content is linked with this page through the hyperlinks. Following this approach, one introduction web page, and nine independent functional web sites, representing five different forest fragmentation representation and analysis functions, were deployed with HTML or Java approach (Figure 4.6). The functional web sites are:

a) Forest fragmentation metrics calculation in an HTML Viewer;

b) Forest fragmentation metrics calculation in a JAVA Viewer with Image Service;

c) Forest fragmentation viewer in an HTML Viewer; 
d) Forest fragmentation viewer in a JAVA Viewer with Image Service;

e) Forest fragmentation viewer in a JAVA Viewer with Feature Service;

f) Forest fragmentation change viewer in an HTML Viewer;

g) Patch query using HTML;

h) Patch query using JAVA; and,

i) Disturbance assessment using JAVA.

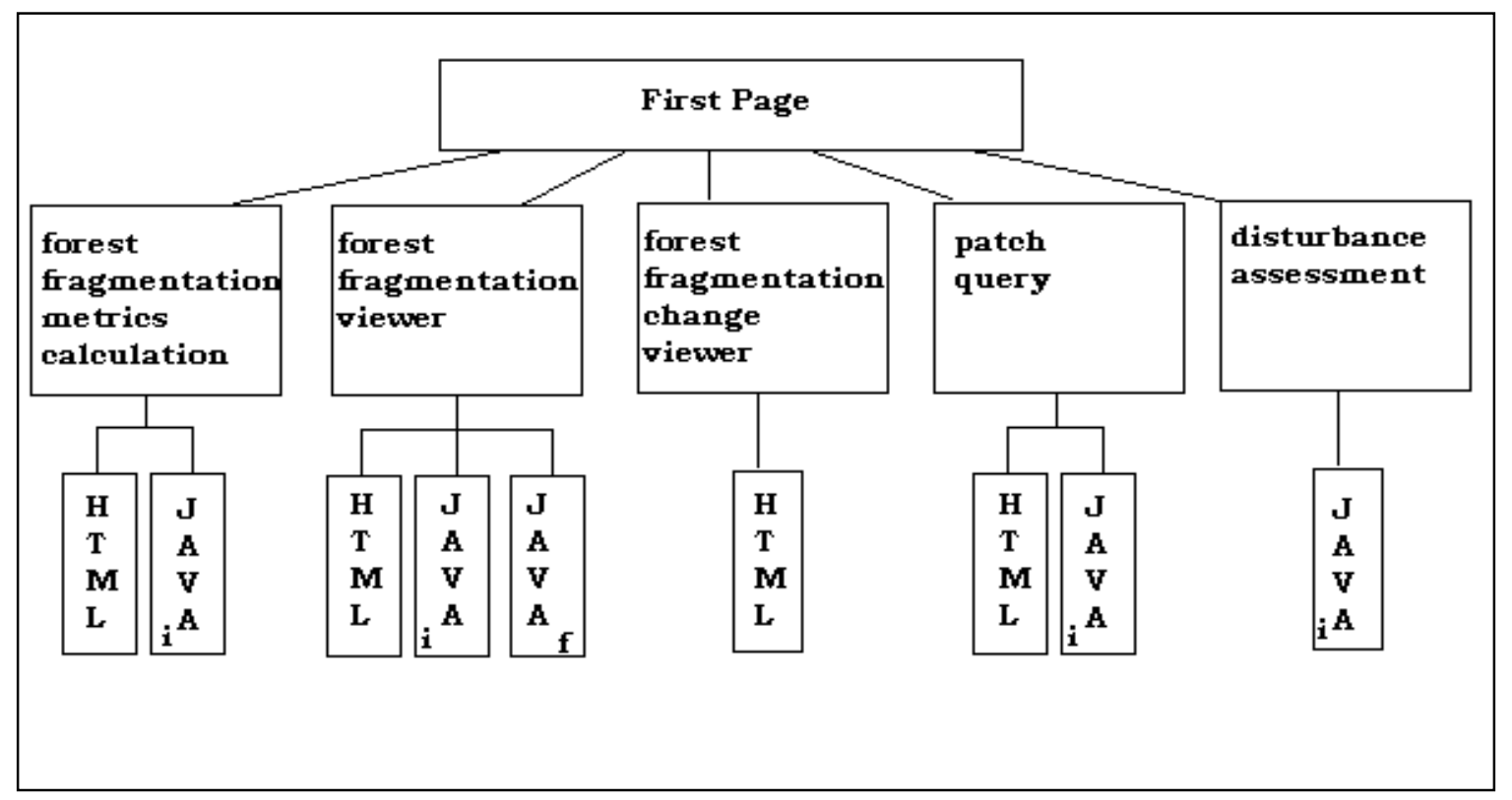

Figure 4.6 WFFA system Web Site Structure (I= image service, $F=$ feature service).

\section{(2) First Page Design}

The first page is the entrance to the whole application. It lists the system functionality, and contain project background information. The main method employed to create the first page was the HTML frame. With frames, multiple HTML document can be displayed in the same browser window. Each HTML document is called a frame, and each frame is independent of the others but can communicate with others. The first page consists of five HTML frames: TopFrame, TopicFrame, MainFrame, ModeFrame and BottomFrame.

In the TopFrame, the web page title, help link, and home link are shown in figure 4.7. In the TopicFrame, forest fragmentation analysis functions and related data, 
documents, other forest-fragmentation associated hyperlinks are listed. The MainFrame shows project introduction information, functionality description and associated web pages.

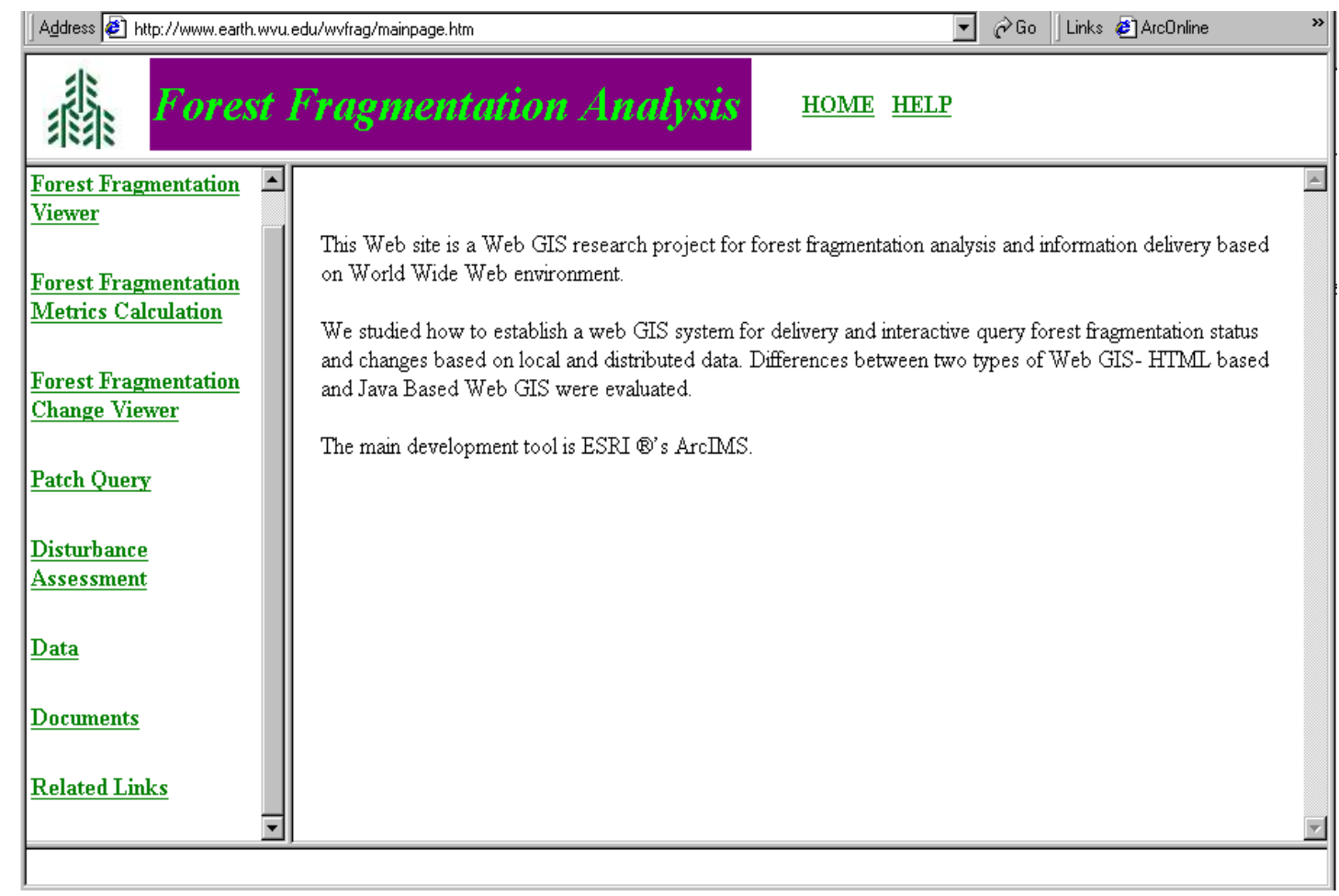

Figure 4.7 Interface of WFFA first page of the forest fragmentation Analysis web site.

\section{(3) Map Design and Data preparation}

The web site was designed with the case study data, including one Landsat 51987 TM image, and one Landsat 71999 ETM+ image. West Virginia county boundary data and GAP land cover and land use data were incorporated additional layers for enhancing the forest fragmentation representation.

The basis of serving the above data is to create maps which consist of one or more layers. In order to serve maps on the Web, ArcIMS requires a map configuration file (MCF) in ArcXML format for each map. MCFs are used to create different MapServices for different forest fragmentation functions. In this study, an aim was to test ArcIMS's capability of supporting integration of different format vector data and raster data. The proposed the functions require that main maps, overview maps and distributed maps are shown separately. Therefore, three main MCFs for the three maps were created. The first MCF is for map that consists of West Virginia county boundary layer, 1987 and 1999 
Landsat TM images layers, 1987 and 1999 land cover/land use classification data with unique symbols for each class, and 1987 and 1999 land cover/land use classification data with transparent symbols. The reason for using transparent symbols in the classification polygon file is to provide an alternative approach to link land classes with TM images. The second map is an overview map which only consists of a West Virginia county boundary layer. This map would be used for creating an overview mapservice for all forest fragmentation analysis ArcIMS web sites. The third map is a Landsat imagery map which consists of all Landsat TM images. It is used to create a specific map service for assessing the ArcIMS ability for supporting integrating multiple web data and multiple map services.

The following is an example of the MCF for the overview map file:

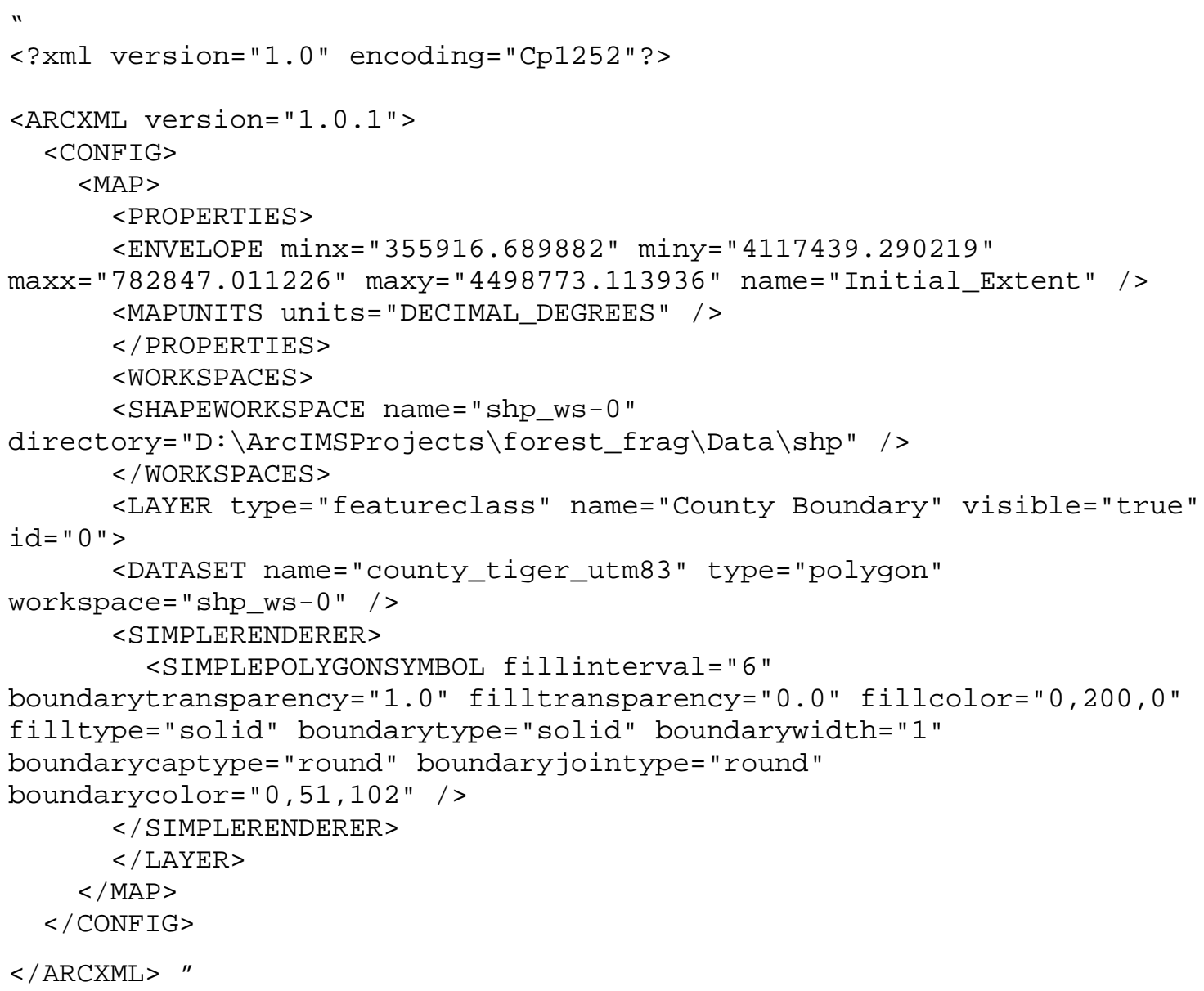

In ArcIMS author, image files cannot be shown (Figure 4.8), although they are displayed in the final web page (Figure 4.9). 


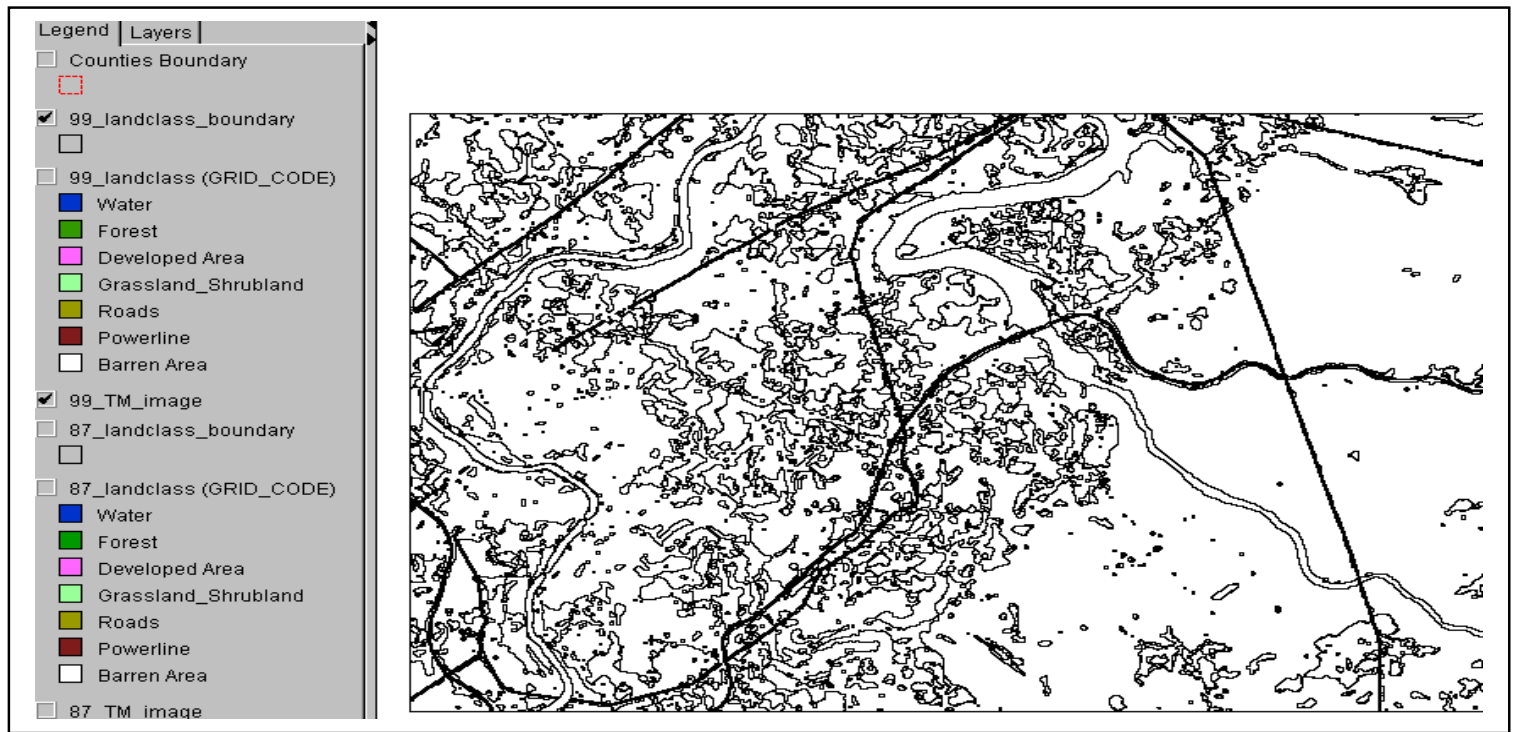

Figure 4.8 The result of adding image file with ArcIMS Author.

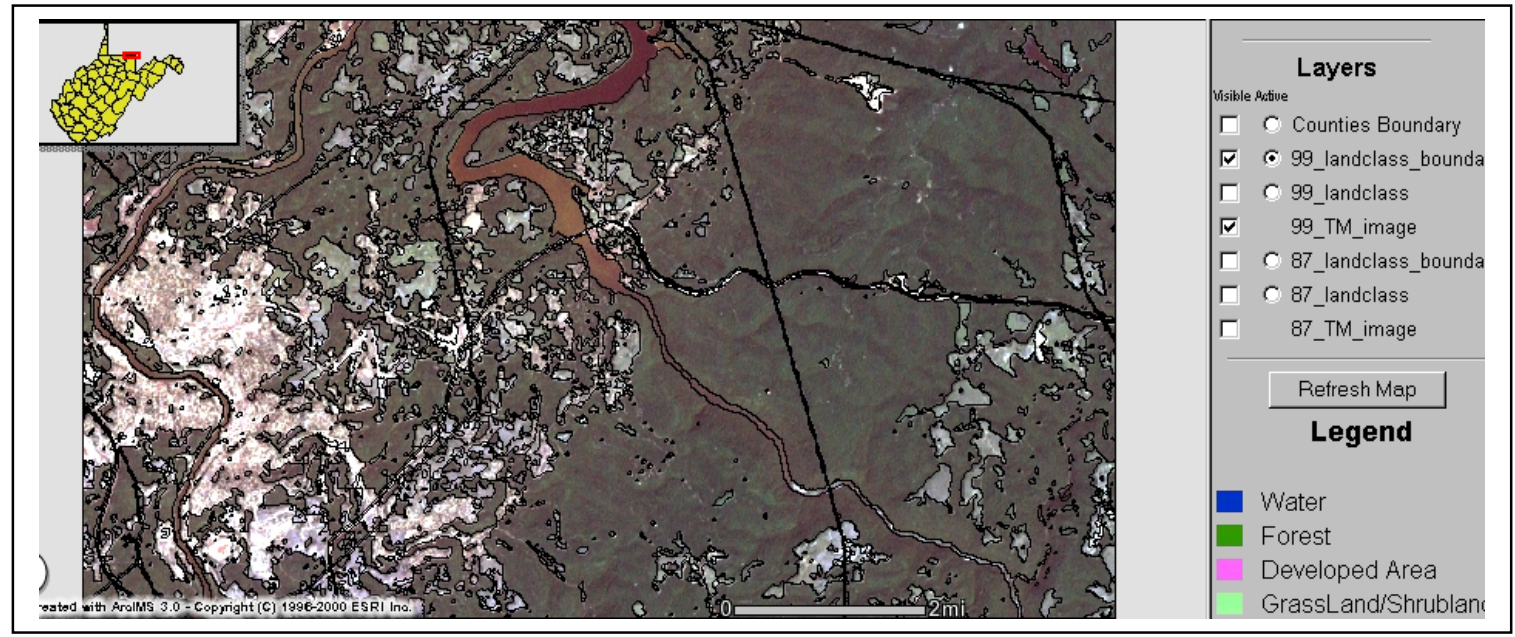

Figure 4.9 The result of displaying image file in the client side web browser.

\section{(4) Map Services Design}

In this study, map services design considered the needs of users interactively operating local data and server data in a standard web browser. The extent and content of MapServices were determined by the proposed functions in the forest fragmentation analysis web site. Two kinds of MapService, functions, Image MapService and Feature Mapservice, were used to define six application map services. These MapServices are a) Image MapService of main map for HTML Viewer and Java Viewer; b) Feature Mapservice of main map for Java Viewer; c) Image MapService for Overview map; d) Feature Mapservice and Image MapService for GAP map services; and e) Image MapService for the TM image. The tool used for creating these application Map Services 
was ArcIMS Manager/Author MapServics. Any MapService link with a Map

Configuration File builds during the phase of map design (Figure 4.10 and Table 4.7).

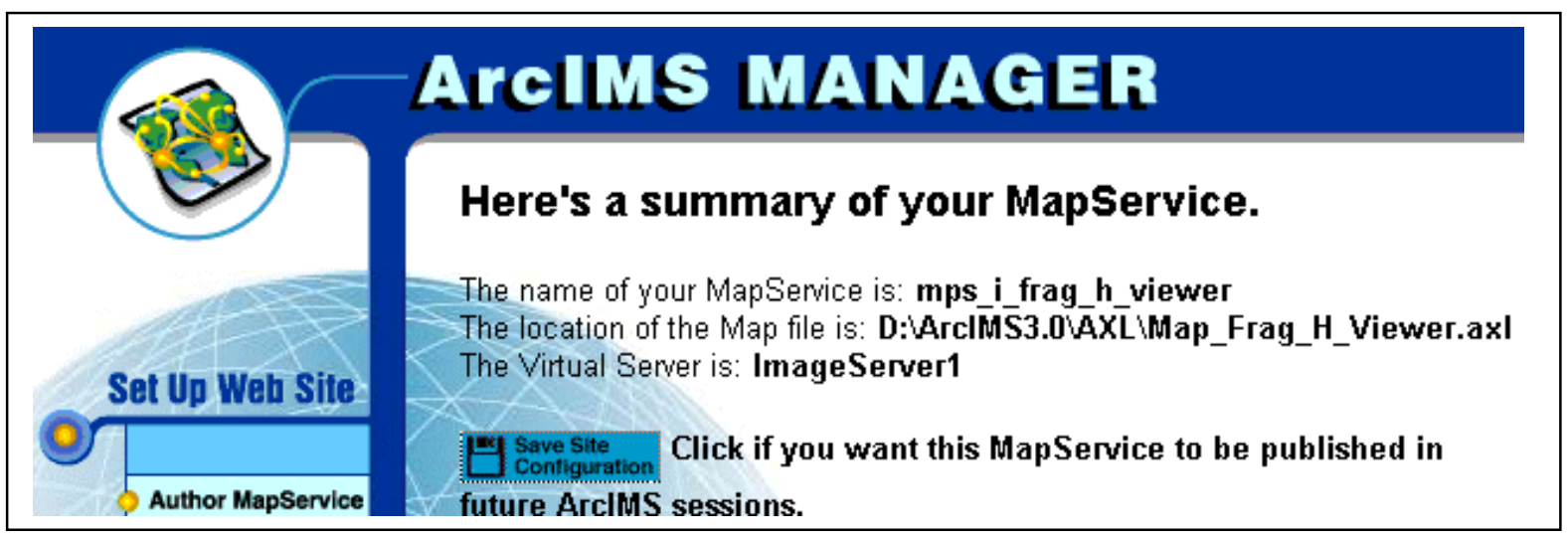

Figure 4.10 The interface of a summary of a Mapservice.

Table 4.7 MapServices in the Forest Fragmentation Analysis web sites.

\begin{tabular}{|l|l|l|}
\hline Map Service & Type & Map Configuration File \\
\hline mpsi_fraghviewer & Image MapService & map_fragviewer.axl \\
\hline mpsf_fragjviewer & Feature MapService & map_fragviewer.axl \\
\hline mpsi_wvcounties & Image MapService & map_wvcounties.axl \\
\hline mpsi_gap & Image MapService & Map_gap.axl \\
\hline mpsf_gap & Feature MapService & Map_gap.axl \\
\hline mpsi_tmimages & Image MapService & Map_TMimages.axl \\
\hline
\end{tabular}

\section{(5) The Design of Web site Prototypes}

Creating a web site prototype is carried out with ArcIMS web site templates and associated Mapservices. The nine prototypes of functional web sites in this study were built with ArcIMS Designer following similar procedures.

First, a name of web site entry directory and a title for the web site is specified (Figure 4.11).

\section{Type a name for the Web site directory.}

Fragiviewer_i_HTML

Type a title for the Web page and browser window:

Forest Fragmentation HTML Viewer

Figure 4.11 The interface for setting up the entry directory and title for the web site with ArcIMS 
Then, the MapServices used in the MapFrame is chosen (Figure 4.12). The MapFrame is the specific frame for displaying map data in an ArcIMS viewer.

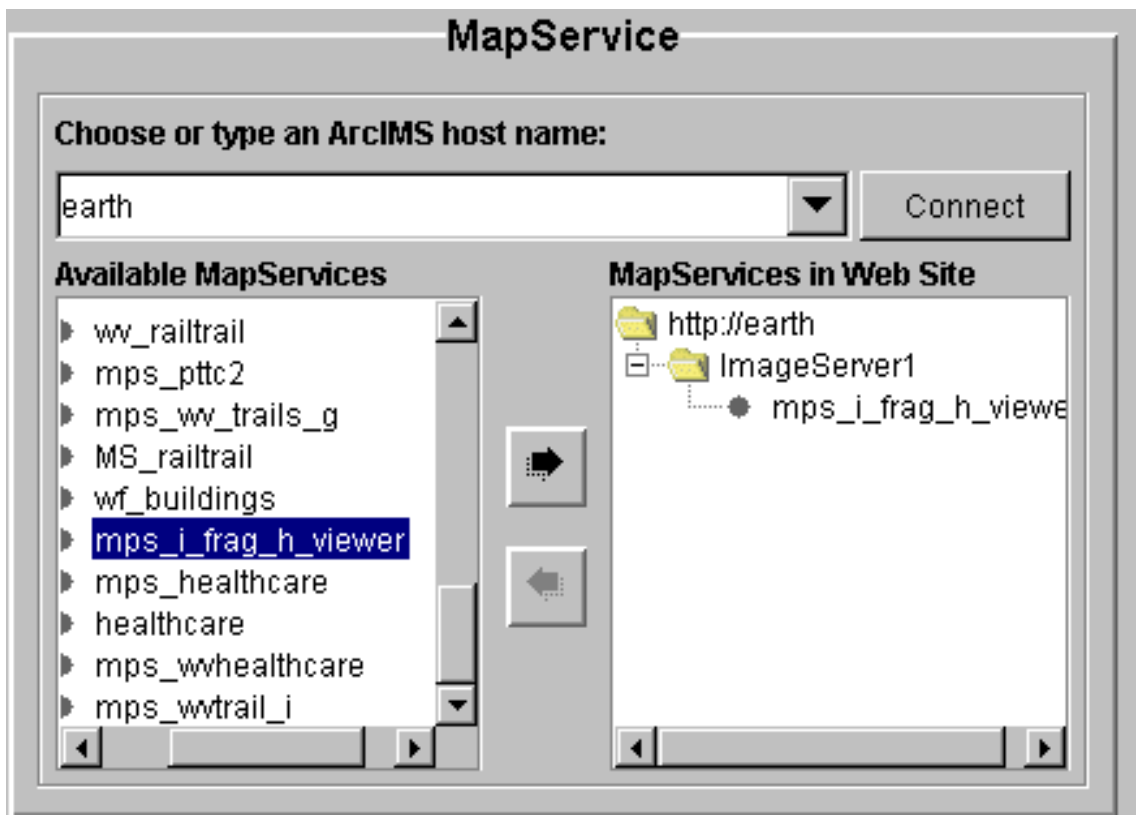

Figure 4.12 The interface for setting up MapService for the Web GIS application

After defining MapServices, an ArcIMS viewer, HTML viewer, or Java viewer, is selected. If an HTML viewer is selected, then the HTML web site template is used to create the web site prototype (Figure 4.13). If a Java viewer is selected, either Java custom or Java standard web site templates can be used. In this study, all Java web site templates used Java custom web site templates to facilitate further customization.

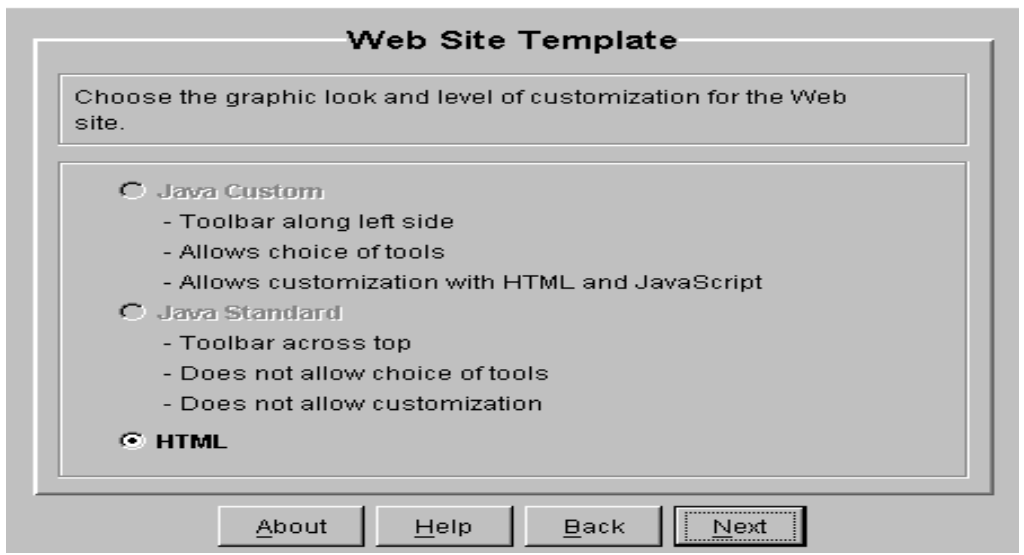

Figure 4.13 The interface for setting up the web site template 
The corresponding relationships among nine functional web sites, viewers and associate MapServices are listed in Table 4.8.

Table 4.8 Web sites and their associated Viewer types and MapServices in WFFA system.

\begin{tabular}{|l|l|l|}
\hline Web sites & Functions \& Viewer & MapServices \\
\hline FragCalculator_i_HTML & $\begin{array}{l}\text { forest fragmentation metrics } \\
\text { calculation in HTML Viewer }\end{array}$ & $\begin{array}{l}\text { mpsi_fraghviewer } \\
\text { mpsi_wvcounties }\end{array}$ \\
\hline FragCalculator_f_JAVA & $\begin{array}{l}\text { forest fragmentation metrics } \\
\text { calculation in JAVA Viewer }\end{array}$ & $\begin{array}{l}\text { mpsf_fragjviewer } \\
\text { mpsi_tmimages }\end{array}$ \\
\hline FragViewer_i_HTML & $\begin{array}{l}\text { forest fragmentation viewer in } \\
\text { HTML Viewer }\end{array}$ & $\begin{array}{l}\text { mpsi_fraghviewer } \\
\text { mpsi_wvcounties }\end{array}$ \\
\hline FragViewer_i_JAVA & $\begin{array}{l}\text { forest fragmentation viewer in } \\
\text { JAVA Viewer with Image } \\
\text { Service }\end{array}$ & $\begin{array}{l}\text { mpsi_fraghviewer } \\
\text { mpsi_wvcounties } \\
\text { mpsi_gap }\end{array}$ \\
\hline FragViewer_f_JAVA & $\begin{array}{l}\text { forest fragmentation viewer in } \\
\text { JAVA Viewer with Feature } \\
\text { Service }\end{array}$ & $\begin{array}{l}\text { mpsf_fragjviewer } \\
\text { mpsi_wvcounties } \\
\text { mpsf_gap } \\
\text { mpsi_tmimages }\end{array}$ \\
\hline FragPatch_i_HTML & patch query in HTML & $\begin{array}{l}\text { mpsi_fraghviewer } \\
\text { mpsi_wvcounties }\end{array}$ \\
\hline FragPatch_f_JAVA & $\begin{array}{l}\text { Patch query in JAVA with } \\
\text { Feature Service }\end{array}$ & $\begin{array}{l}\text { mpsf_fragjviewer } \\
\text { mpsi_wvcounties }\end{array}$ \\
\hline FragDisturb_f_JAVA & $\begin{array}{l}\text { Disturbance assessment in } \\
\text { JAVA }\end{array}$ & $\begin{array}{l}\text { mpsf_fragjviewer } \\
\text { mpsi_wvcounties } \\
\text { mpsi_tmimages }\end{array}$ \\
\hline
\end{tabular}

In the HTML web site template, map extents are defined. The initial extent is the area that the user first sees in the browser, and the extent limit is the area the user cannot view beyond (ESRI, 2000b). In this study, the extent of MapService of mpsi_fraghviewer was used as the initial extent, and extent of all MapServices was used as the extent limit in all HTML viewers (Figure 4.14).

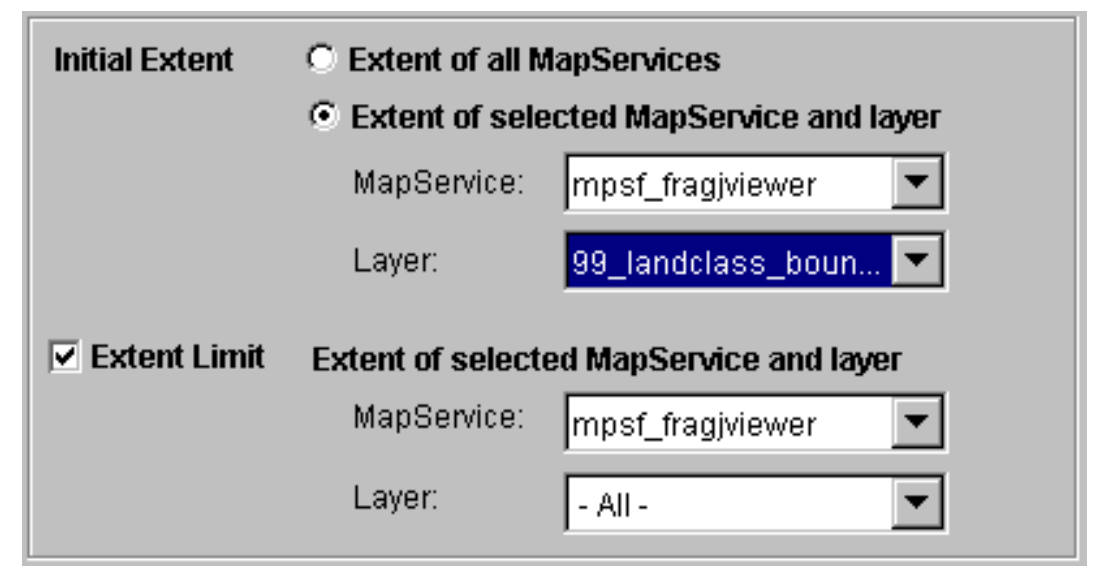

Figure 4.14 The interface of setting up initial Map Extent with ArcIMS. 
MapSevice, mpsi_wvcounties, was set up as the overview map. After that, meters were set up as the data source units and miles as the scale bar units. The next step is to select pre-defined toolbar functions from the list of functions supported by ArcIMS HTML viewers (Figure 4.15).

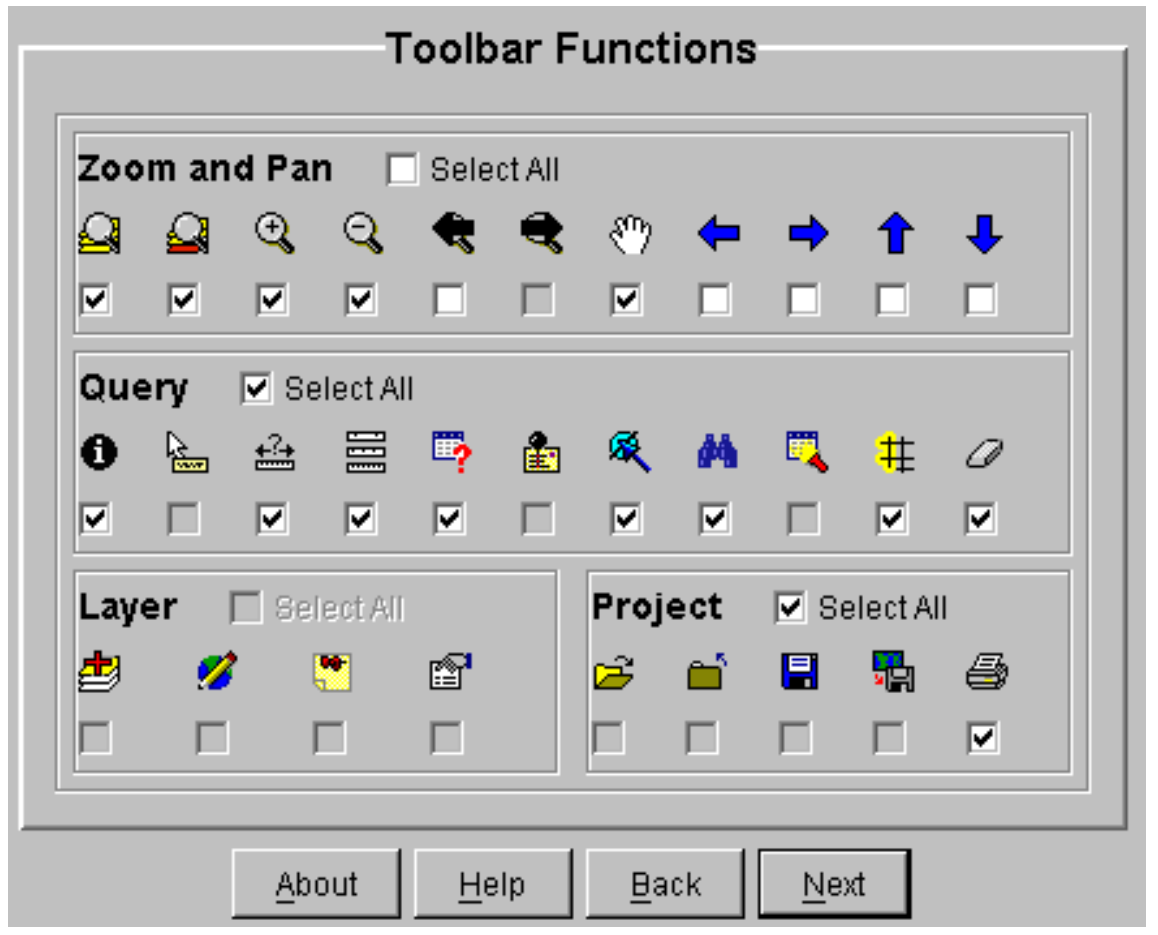

Figure 4.15 The interface for setting up pre-defined interactive mapping functions.

Finally, the web site location is defined. In this study, the system web site directory that had been established at the time of web server installation was used. After all the above steps, a web site with HTML viewer is built automatically.

The procedures for setting up a web prototype with a Java custom web site template are broadly similar those establishing HTML viewer web site, except that they are more complex because Java Viewer provided web GIS designers and users more feature to interact with spatial data and mapping elements.

At first, the Java custom web site template asks the designer to choose the look of mapping elements such as the colors for background, foreground and outline of maps, legend, scale and the overview map (Figure 4.16). In this study, the default values were used. 


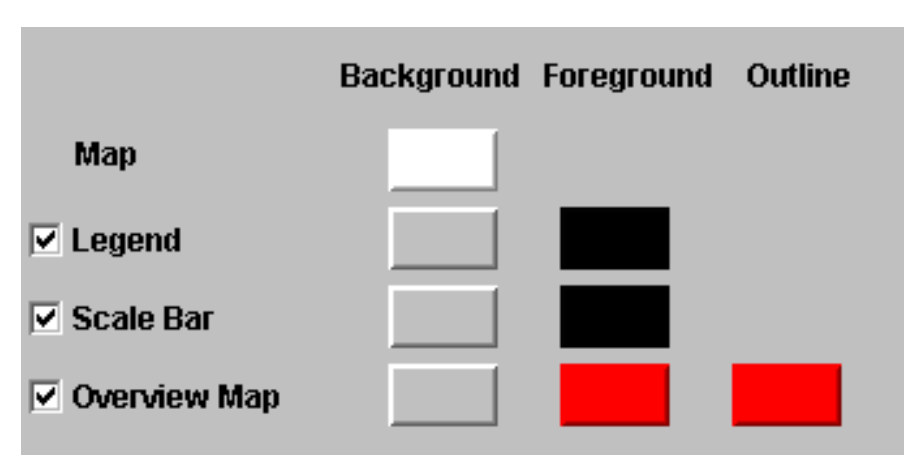

Figure 4.16 The interface for setting up the look of mapping elements, including the colors of the background, foreground and outlines of maps.

In the same manner as the HTML template setup, the map extent is defined. Then the visible layers in corresponding MapServices and content of overview map are set up.

Predefined functions are chosen via the interface of Toolbar functions. Almost all layer control and project control functions are used in Java Viewers. These new functions provide a unique potential to operate local and server spatial data on the Web. For example, the function tool of $\operatorname{EditNotes}(\mathscr{Z})$ allows simple editing of features. The MapNotes function ( ) allows Web GIS users to add descriptive text and graphics to the map. Add New Layer function (当) allows the user to open a local map layer or layers in a MapService on the Web. The only difference between setting up an Image MapService-based Java viewer and a Feature MapService-based Java viewer is that the EditNotes tool can only be used in the former.

Two features unique to the Java Viewer, MapTips and Identify Results, were then set up (Figure 4.17). MapTips displays a field of information about features on a map layer, and Identify Results displays fields when the tool is used on a map layer. 


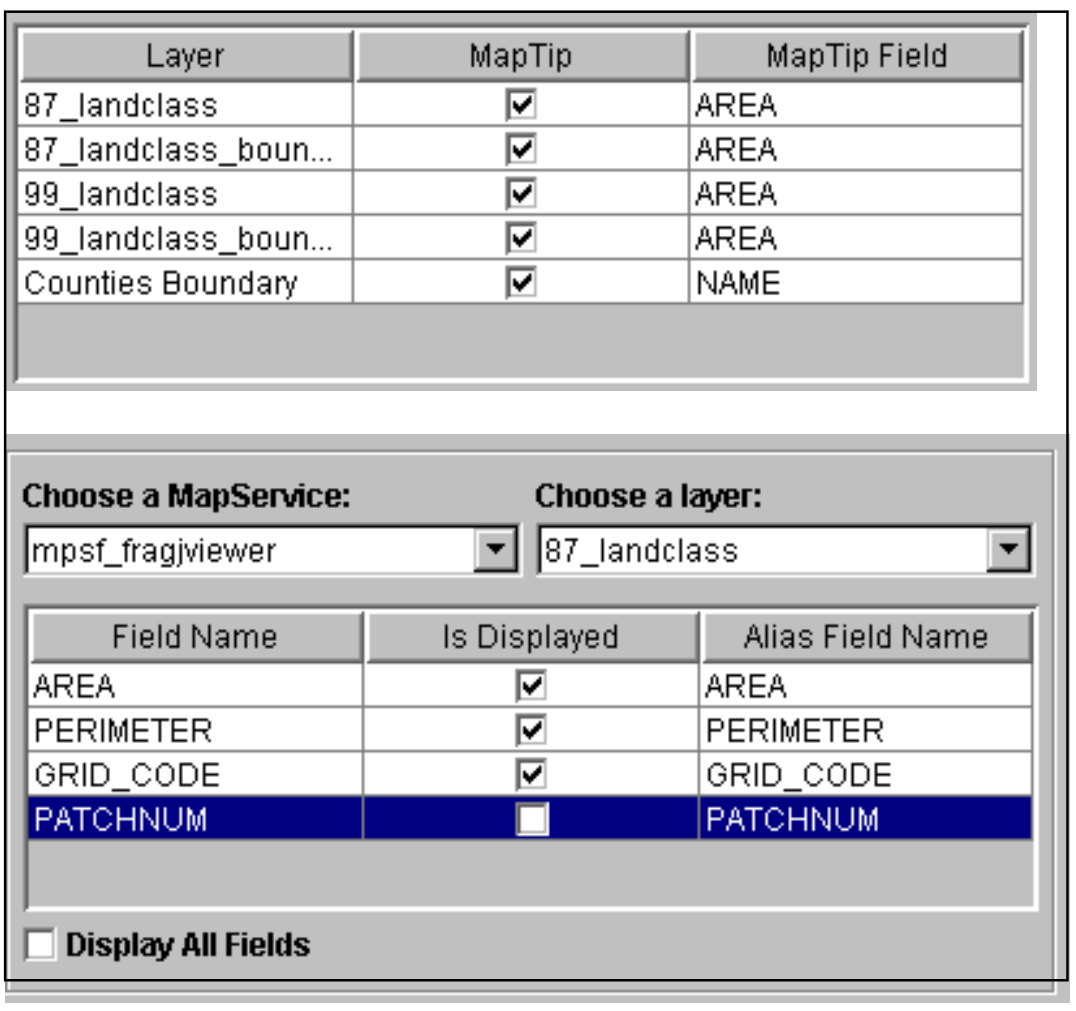

Figure 4.17 Interface of setting up MapTips and Identify results

The final step is to set up folders where new features added by MapNotes tool or EditNotes are saved and to specify the web site location directory. In this study, the setup employed the system default values. Finally, the introductory web site and the eight ArcIMS functional web sites prototypes were established with six MapServices.

\section{(6) Customization of interfaces and functionalities}

After establishing the application prototypes, the next step is to customize the interfaces and the applications functions. By customizing the interfaces, a web GIS system can provide users with a more understandable guide to the system, and provide spaces to show application results for example from a customized query or a special analysis. This modification of the pre-defined functions and addition do new functions allows the development of more specific or complicate functions. In this study, eight functional web sites were customized respectively. 


\section{Customization of the forest fragmentation viewer web site in HTML Viewer} (FragViewer_i_HTML)

The main interface changes are a newly designed legend, which was inserted in a Layer Frame and a FragMetrics Title Frame, which was added between the Map Frame and the FragMetrics Frame (Figure 4.18).

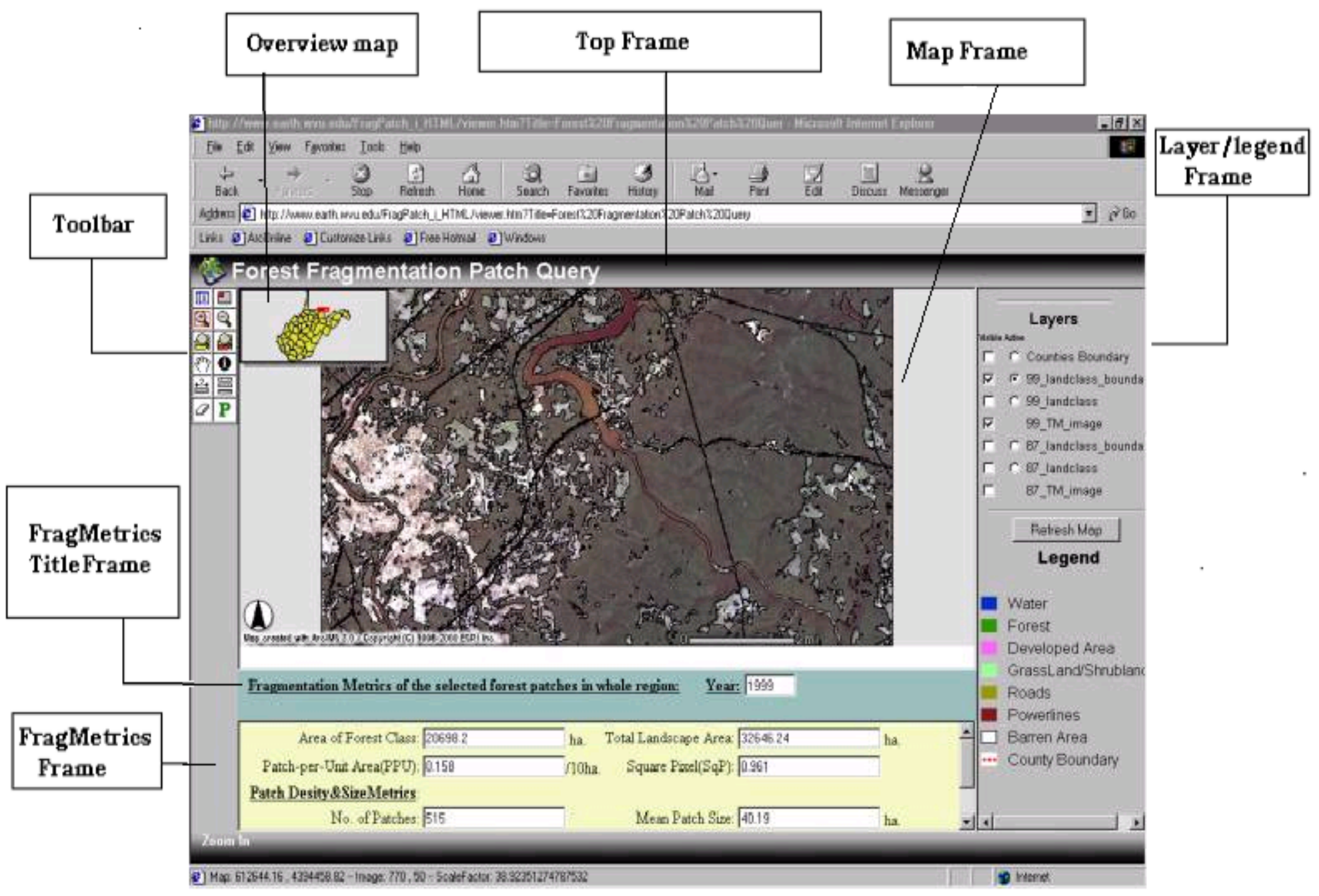

Figure 4.18 Forest fragmentation viewer HTML Viewer interface

The legend icons were created in Microsoft Paint and were added into the Layer Frame by editing the toc.htm file. In the Layer Frame, the legend was constructed with a HTML table that defined the legend frame, a set of images of symbols representing the geographic features on the map, and text labels that specify the meaning of each symbol. 
The FragMetrics Title Frame was designed using HTML (Figure 4.19). This frame used a HTML form with one text field to show the year of current active layer.

\section{Forest Fragmentation Metrics in the Year of 1999}

\section{Figure 4.19 FragMetrics Title Frame}

The form is named Form_FragMetricsYear. In a Web page, a form is an area that can contain form elements that allow users to enter or show information such as text fields, textarea fields, drop-down menus, radio buttons, and checkboxes. A form can be operated by related functions or action programs such as a CGI program. The text field in form of Form_FragMetricsYear was controlled by a segment of a JavaScript program, SetFragMetricsYear. Each time the current active layer is changed, the year of the newly displayed data will be shown.

An additional new function was added in the prototype for showing the fragmentation metrics of the current active layer. The values of these metrics are derived from the implementation of the fragmentation analysis, as described under the first objective of the research. Therefore, the links between the fragmentation metrics and the corresponding layer are static links. The values of the metrics will change when a new active map layer is chosen in the Layer Frame. In order to show the forest fragmentation metrics, the original Text Frame in the Web site prototype was converted to the FragMetrics Frame.

The FragMetrics Frame contained a HTML Form which consists of ten read-only text fields for displaying the values of the calculated metrics including area of forest, total landscape area, Patch-per-Unit Area of forest patches, Square Pixel of forest, total number of patches, mean forest patch size, mean shape index, mean patch fractal dimension, total edge of forest patches, and edge density of forest patches (Figure 4.20). 


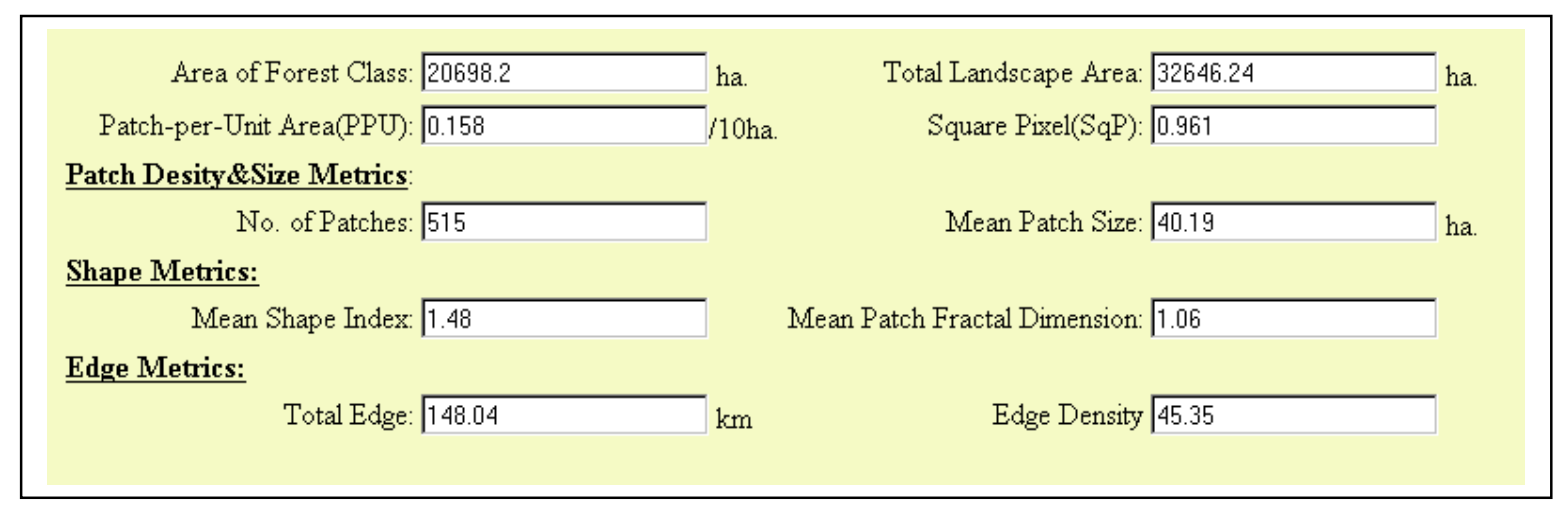

\section{Figure 4.20 FragMetrics Frame}

The operation functions for this form were included in the same HTML file as the FragMetrics Frame. When a new active layer in Layer Frame is specified, a JavaScript program will call the processing function in FragMetrics Frame to change the values of the forest fragmentation metrics.

\section{Customization of the Forest fragmentation metrics calculation function web site in HTML_(FragCalculator_i_HTML)}

This web site used the same methods as the former web site to customize the application interface. FragMetrics Title Frame and FragMetrics Frame were also created in the same way as that in former web site but in FragMetrics frame, only eight metrics were used. The mean shape index and mean patch fractal dimension metrics were not used because they required more complex calculations that are not supported by JavaScript Math object.

A function for dynamic calculation of forest fragmentation was added to this web site. Users can define a region with selection tools such as select by rectangle ( select by line/polygon ( tool, over which forest fragmentation metrics are calculated (Figure 4.21). 


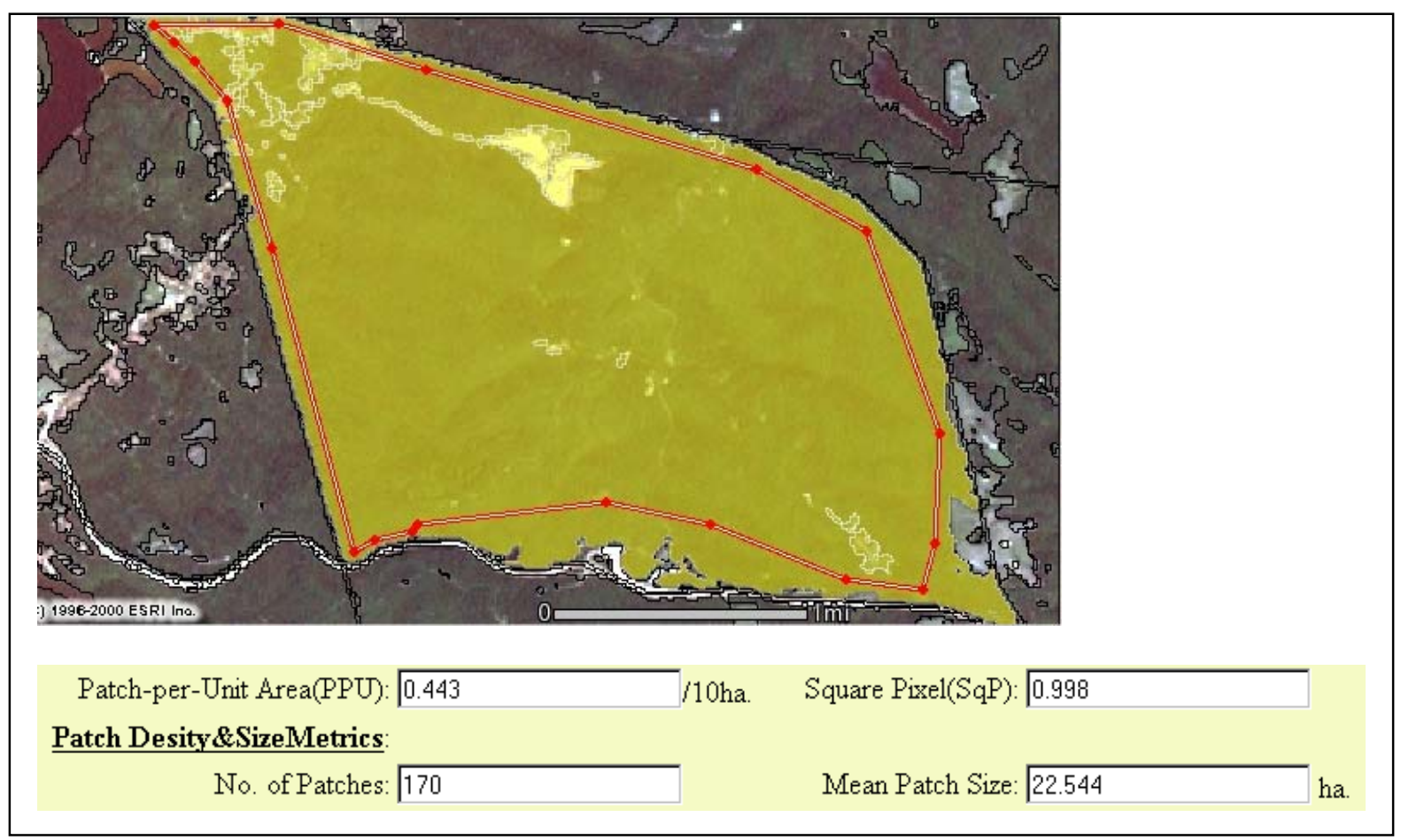

Figure 4.21 forest fragmentation index results from a defined polygon.

In order to implement this function, the identify tool program named aimsIdentify.js was customized to run the following processes: (1) count the total number of selected features; (2) to count the total area and perimeter in the selected area; (3) calculate the forest fragmentation metrics.

For counting the total number of selected features, an ArcIMS pre-defined function named justGetFeatureCount () was used (Figure 4.22).

JustGetFeatureCount is used for returning the number of features returned in ArcXML query response.

\section{Syntax:}

justGetFeatureCount(theReply)

\section{Arguments:}

theReply String containing returned ArcXML response.

\section{Returned Value:}

Numeric Number of features returned.

\section{Figure 4.22 ArcIMS justGetFeatureCount function}

The next step is to get the values of area and perimeter of the selected features by using an ArcIMS pre-defined function named getAllfieldValues(), and save those 
values to two javaScript defined arrays separately. The syntax of getAllFieldValues() is shown in figure 4.23 .

GetAllFieldValues is used for parsing out the values of one field from an ArcXML query response.

\section{Syntax:}

getAllFieldValues(theReply, theField, recCount)

Arguments:

theReply String containing ArcXML query response to be parsed. theField String containing name of field to be used.

recCount Numeric representing number of records to be parsed.

\section{Returned Value:}

Array List of values parsed.

\section{Figure 4.23 ArcIMS getAllFieldValues function.}

JavaScript objects and associate methods were used to calculate forest fragmentation metrics. The main JavaScript objects, the related properties and the methods used for the metrics calculation are listed in Table 4.9.

After calculating forest fragmentation metrics, a series of form updating statements were used to update the values in FragMetrics Frame. The forest fragmentation viewer web site established with a Java Viewer with Image Service, the Java Viewer with Feature Service and the Java based metrics calculation web sites, all used similar procedures to develop forest fragmentation viewers. However, the ArcIMS Java approaches used Java Viewer Object Model combined with JavaScript, to create an application interface. 
Table 4.9 JavaScript objects, related properties and methods for calculating forest fragmentation metrics (www.w3c.org)

\begin{tabular}{|l|l|l|}
\hline $\begin{array}{l}\text { JavaScript } \\
\text { Object }\end{array}$ & Properties/Method & Function \\
\hline Array & & $\begin{array}{l}\text { An Array object is used to store a set of } \\
\text { values in a single variable name. Each value } \\
\text { is an element of the array and has an } \\
\text { associated index number. }\end{array}$ \\
\cline { 2 - 3 } Math & Length & $\begin{array}{l}\text { This property returns the number of elements } \\
\text { in an array. }\end{array}$ \\
\hline Number & $\begin{array}{l}\text { The Math object includes mathematical } \\
\text { constants and functions. It is used for } \\
\text { mathematic calculation. }\end{array}$ \\
\cline { 2 - 3 } & Sqrt(a) & $\begin{array}{l}\text { Returns the square root of a. } \\
\text { The Number object is an object wrapper for } \\
\text { primitive numeric values, allowing for their } \\
\text { manipulation. }\end{array}$ \\
\hline String & To convert a value to a string. \\
\cline { 2 - 3 } & ToString() & The String object is used to work with text. \\
\cline { 2 - 3 } & ValueOf() & $\begin{array}{l}\text { Returns the primitive value of a String object } \\
\text { separator character. The substrings are saved } \\
\text { into an array. }\end{array}$ \\
\cline { 2 - 3 } & Split(separator) & $\begin{array}{l}\text { Returns the string starting at the "start" index } \\
\text { of the string and ending at "end" index } \\
\text { location, less one. }\end{array}$ \\
\cline { 2 - 3 } & Substring(start, end \\
\cline { 2 - 3 } & &
\end{tabular}

\section{Customization of patch query web site in HTML Viewer (FragPatch_i_HTML)}

The patch query web site allows users to define the minimum size of forest patches that are to e shown and then calculates the associated forest fragmentation metrics using these patches within the region.

This web site used forest fragmentation metrics calculation web site as a template. All files in the web site of forest fragmentation metrics calculation function were copied to patch query HTML Viewer web site. Then five steps were taken to customize the interfaces and functionality.

First, a new variable named usePatch was added to ArcIMSparam.js. ArcIMSparam.js is the main parameter file for initializing an ArcIMS-based web site. 
The usePatch variable controls the display of the toolbar named PatchQuery, which is represented by $\mathbf{P}$.

Second, the toolbar frame was customized by turning off selected pre-defined tools, and adding two new tool icons ( $\mathbf{P}$ and $\mathbb{P}$ ) (Figure 4.24). The PatchQuery tool icon and the call to the related event-processing programs were added in the Toolbar.htm file by adding HTML and JavaScript statements. The tools deleted were the selection, query and print tools, because these functions were not needed, or conflict with the implementation of the patch query function.

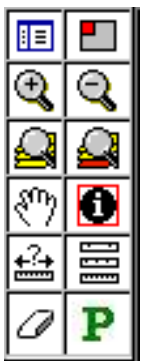

Figure 4.24 Toolbar of Patch Query Web site

The third step was to edit the function clickFunction() in the aimsClick.js file by adding a processing program segment (Figure 4.25) to call the patch query process function queryPatchForm() which in turn was defined in a new file named CustomizedQuery.js.

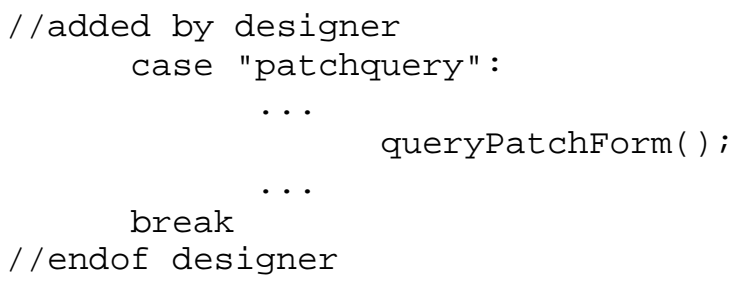

Figure 4.25 Program segment of calling the function queryPatchForm().

CustomizedQuery.js consists of a set of new functions implemented with HTML, JavaScript and ArcXML. An interface(Figure 4.26) was created to allow the user to enter the minimum size of forest patch, to generate the related ArcXML requests, and to send the ArcXML requests to the ArcIMS server. 


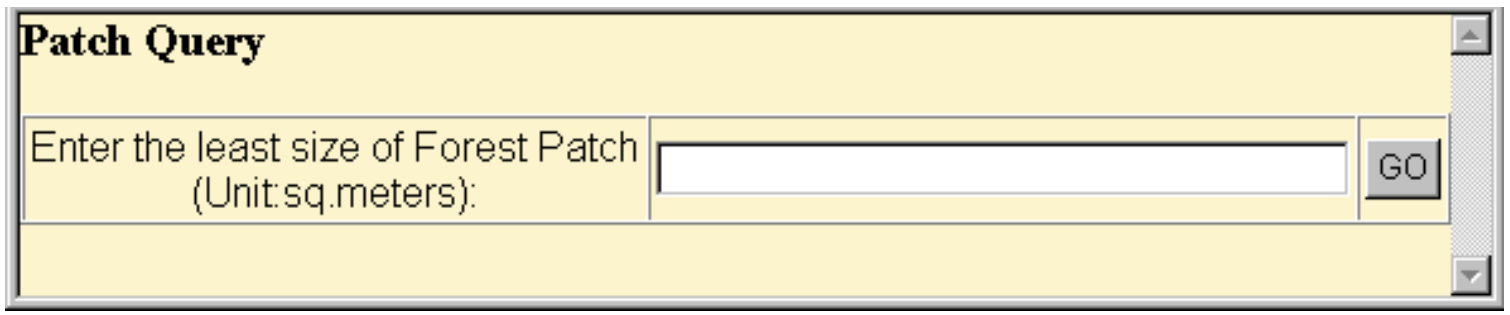

Figure 4.26 Interface for specifying the minimum patch size.

The new functions include queryPatchForm(), writeForestPatchSizeQueryForm(), writePatchQueryXML(queryString), and sendPatchQueryString(newString).

QueryPatchForm() was designed with JavaScript. It begins patch processing by initializing system variables and calling the function writeForestPatchSizeQueryForm() to open a new window, and show the interface for entering the minimum forest patch size. The function writeForestPatchSizeQueryForm() was written with JavaScript and HTML.

After the user enters the patch size and clicks the 'GO' button, the function writePatchQueryXML() writes an ArcXML request, which is sent out by the function sendPatchQueryString().

The fourth step was to modify the functions for calculating the forest fragmentation metric in aimsIdentify.js. The total landscape area is based on the spatial extend of whole image. The area of forest class metrics is calculated from the total areas of queried patches.

The final step was to make the patch query tool work, employed HTML $<$ SCRIPT $>$ tags for adding CustomizedQuery.js to the mapframe file (MapFrame.htm), so that functions in CustomizedQuery.js could be integrated into the whole system.

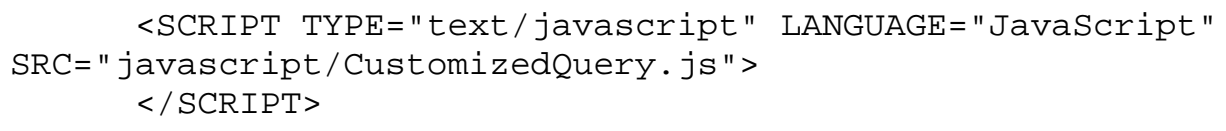

After customization, a test was run by entering an area of 4,000,000 square meters as the minimum forest patch area (Figure 4.27, Figure 4.28). Ten patches were found, and a set of new forest fragmentation metrics was calculated from these patches. 


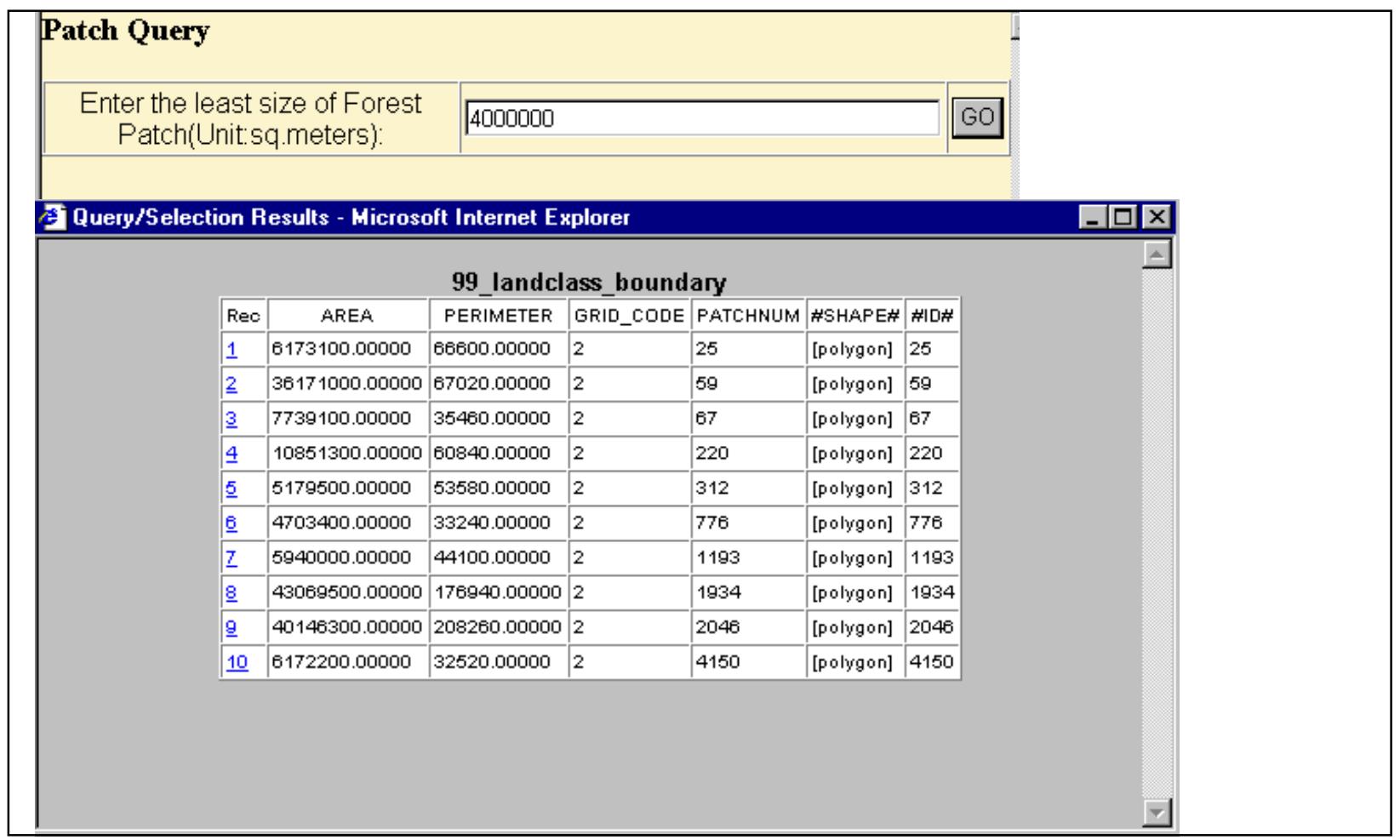

Figure 4.27 Patch list for patches $>4,000,000$ sq. meters in size.

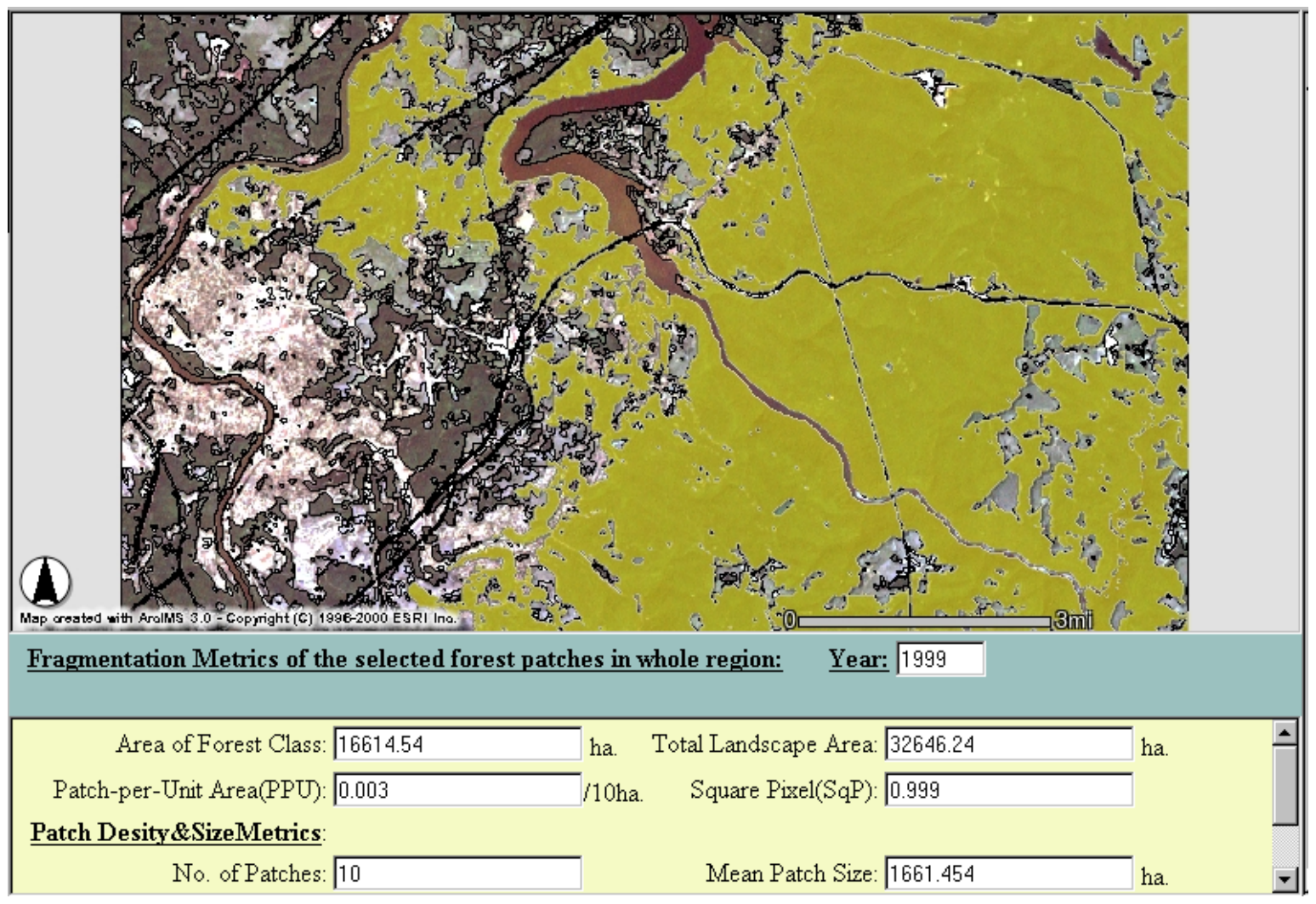

Figure4.28 Patches $>$ 4,000,000 sq. meters shown in grayish yellow color. 


\section{Chapter 5 Results and Discussion}

In this Chapter, results from the two research objectives are presented. The main results from the forest fragmentation analysis include the outcomes of land cover and land use classification, patch statistic results, and forest fragmentation metrics changes from 1987 to 1999 . For the second research objective, the main results focus on the forest fragmentation analysis Web pages, including the serving of the maps, the user interfaces, and system functionalities. The HTML and Java approaches in ArcIMS were assessed in accessibility, navigation ability, interactive digital cartography ability, data integration ability, and implementation of proposed functionalities for supporting forest patch query, forest fragmentation metrics calculations, and disturbance analysis.

\section{Land cover and land use maps}

As mentioned in Chapter 4, the land cover/land use categories were grouped into seven classes: water, forest, developed areas, Grassland/Shrubland, road, powerline and Barren land. The 1987 maps (Figure 5.1) and 1999 maps (Figure 5.2) were classified directly from the TM and ETM+ data, respectively. The 1994 map (Figure 5.3) was obtained by recoding the GAP data, originally produced by classification of TM data. 


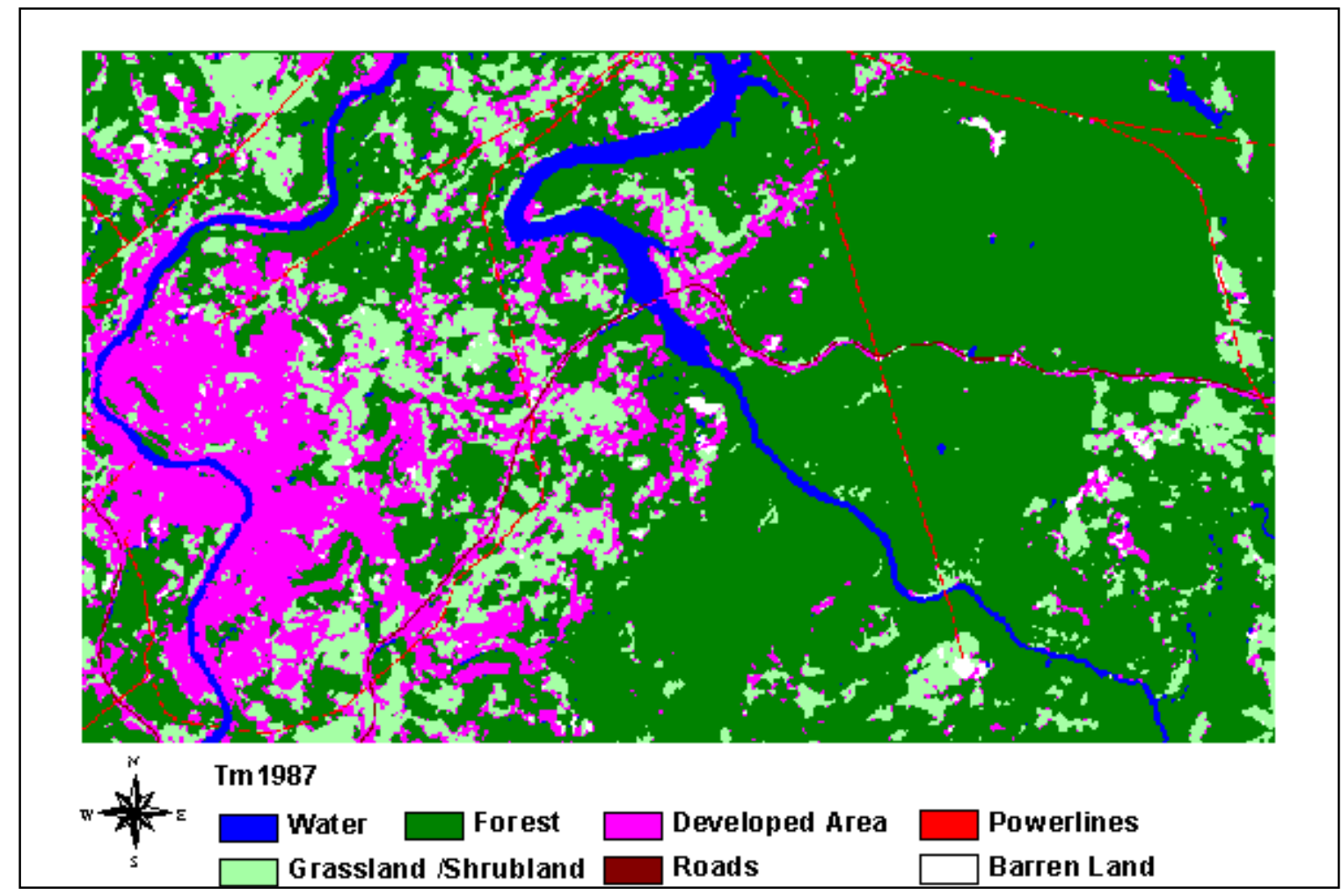

Figure 5.1 1987 Land Cover/Land Use
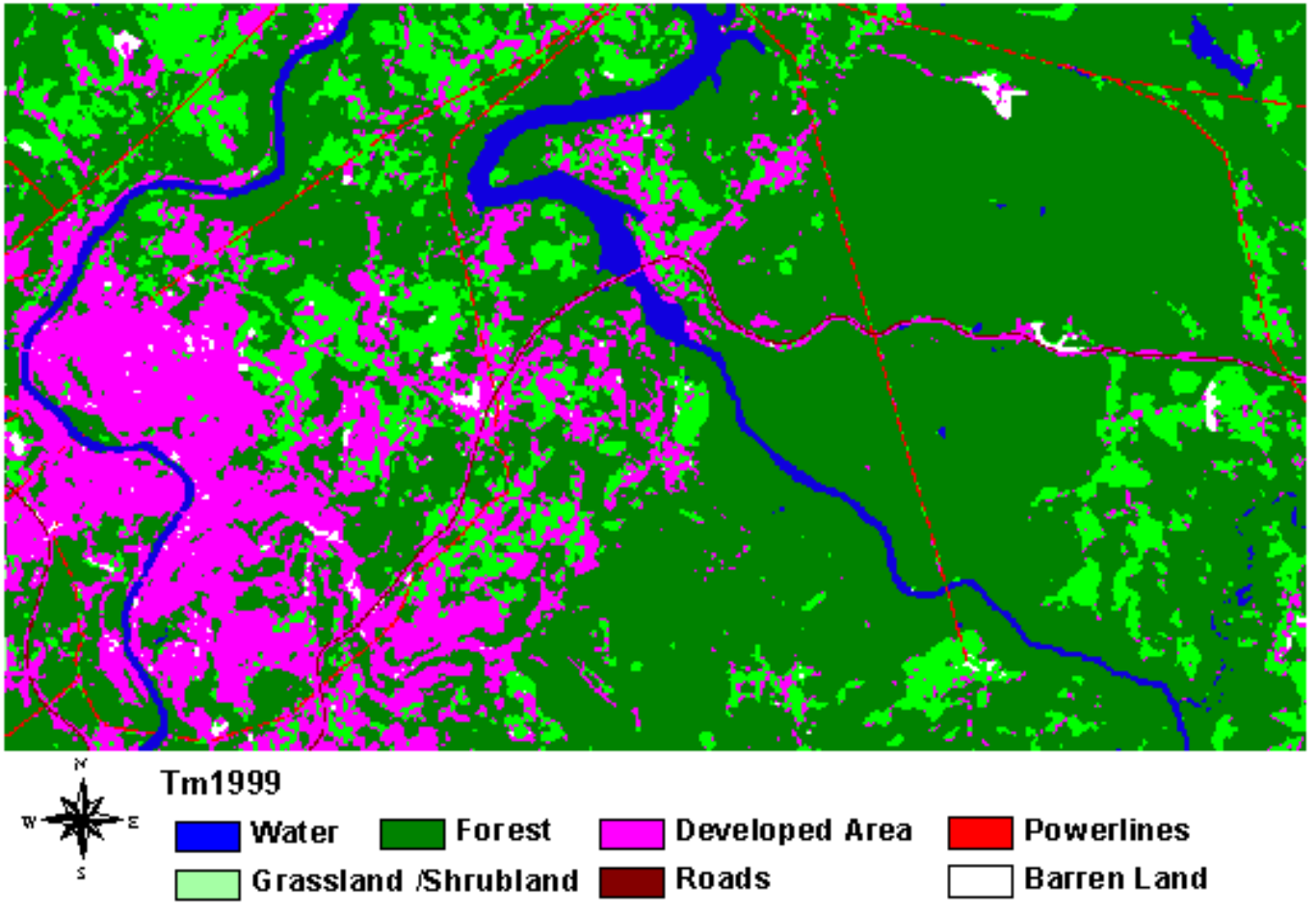

Figure 5.2 1999 Land Cover/Land Use 


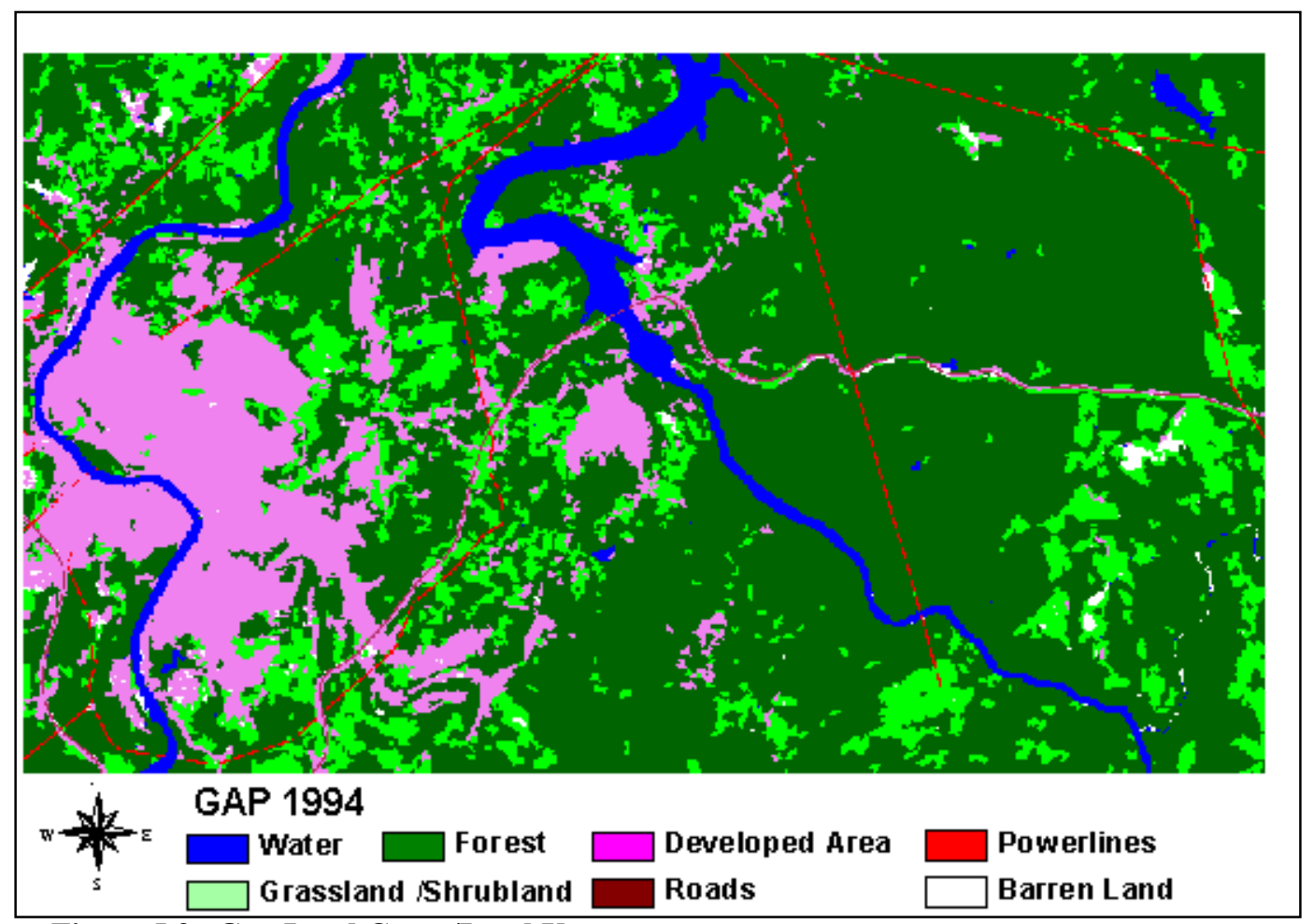

Figure 5.3 Gap Land Cover/Land Use

\section{Results of Forest fragmentation metrics from Patch analysis}

Patch Analysis (GRID) was used for calculating the forest fragmentation metrics for the three dates data(Table 5.1). The results show that GAP data give different spatial patterns compared to the direct classification of the TM data. After overlaying the Landsat TM 1999 image, Landsat TM 1999 classification data, and GAP recoded data, obvious differences can be found. For example, from the Figure5.4, 5.5, 5.6, 5.7, some areas which are classified as forest land in 1987 and 1999 is classified as other kinds of land use. Therefore, in the discussion of trends, the GAP data will not be discussed simultaneously with the 1987 and 1999 data, exempt to point out that the Square Pixel Metric ( $\mathrm{SqP})$ is the only measure that appears to be consistent between the two data sets. 

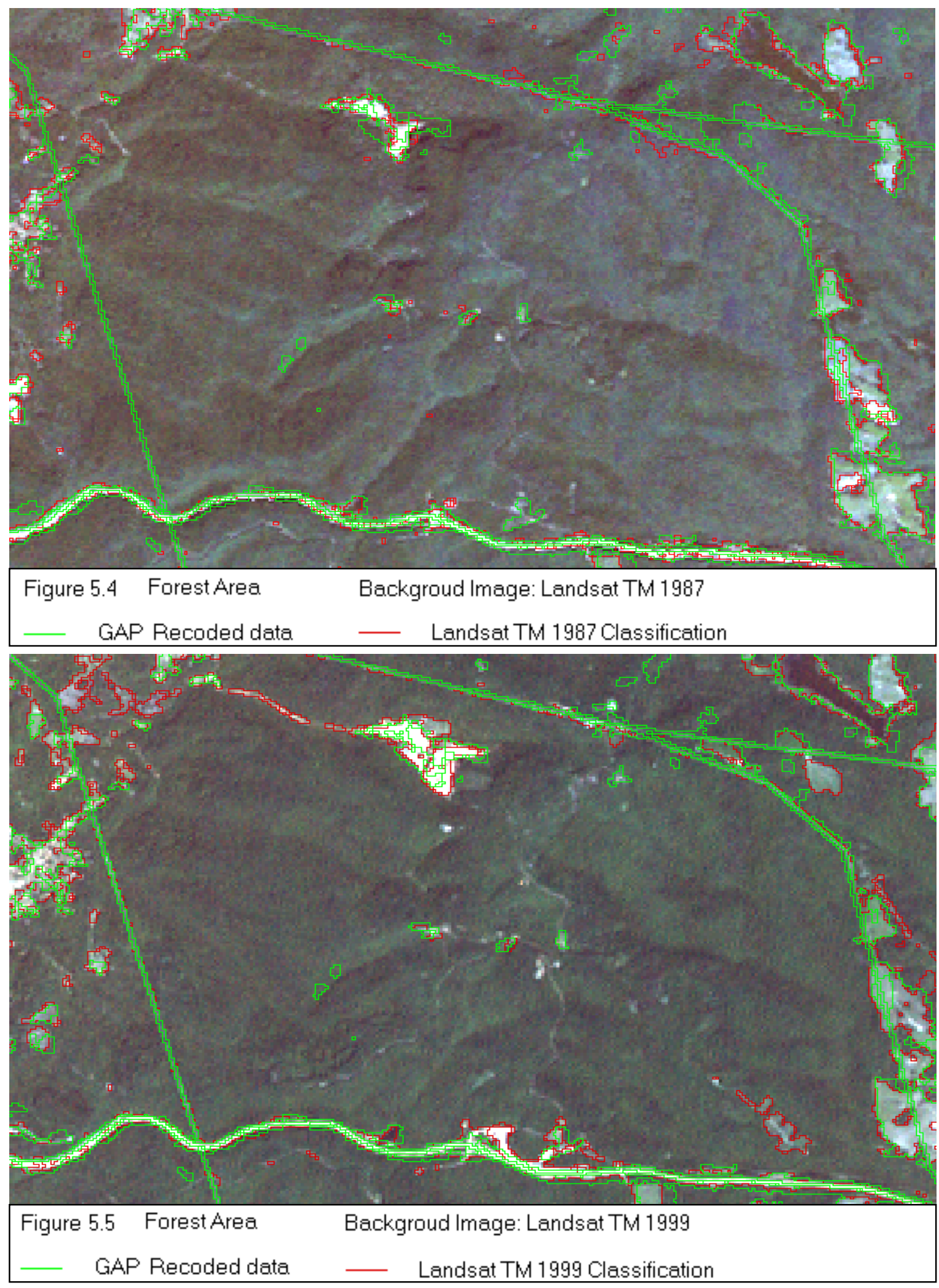

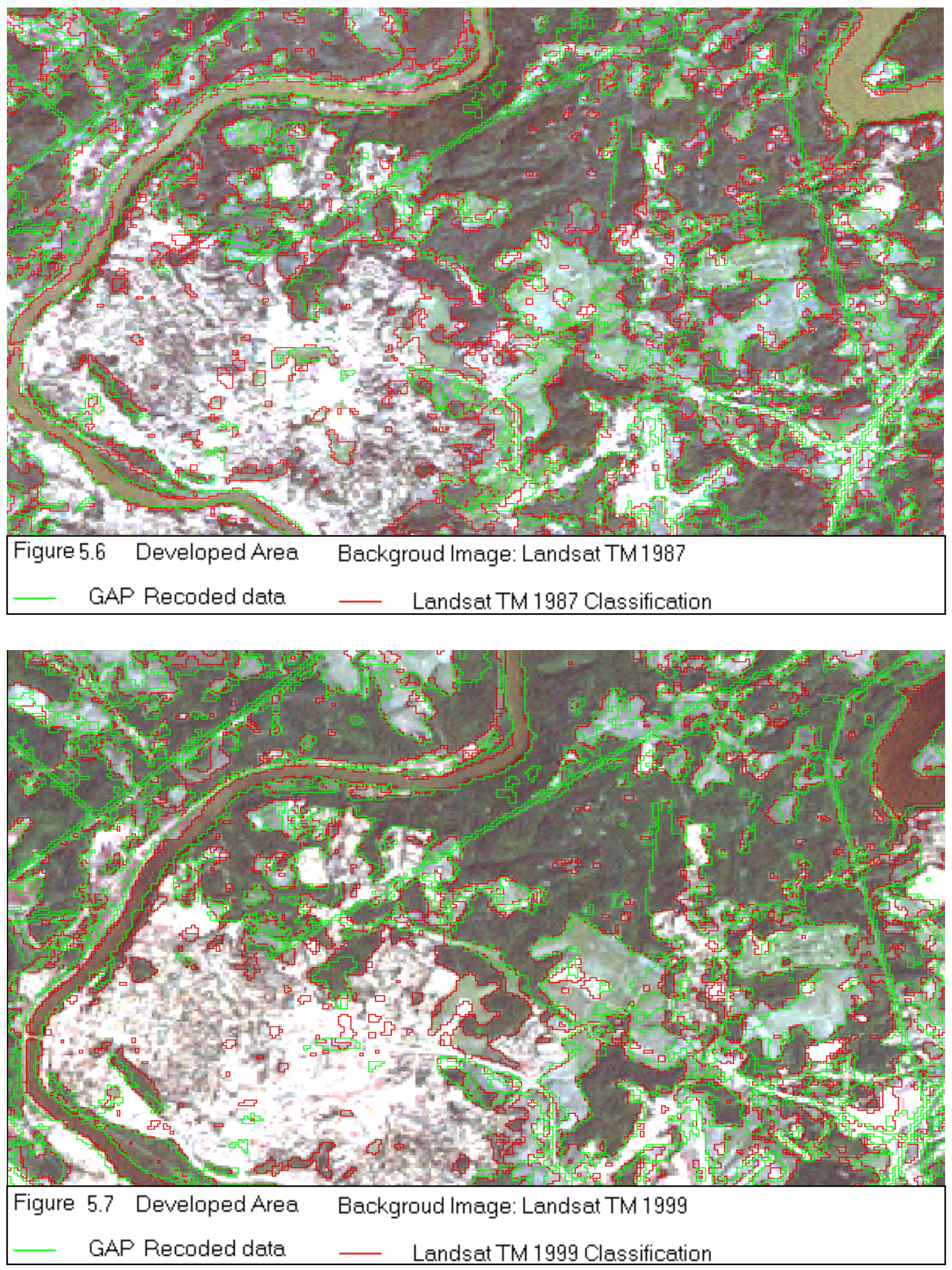
Table 5.1 Forest fragmentation metrics results derived from 1987 TM, 1999 ETM+ data and the Gap data.

\begin{tabular}{|l|l|l|l|}
\hline \multicolumn{1}{|c|}{ Year } & \multicolumn{1}{|c|}{1987} & & 1999 \\
\hline $\begin{array}{l}\text { Average forest patch area } \\
\text { (area/NUMP) }\left[\mathrm{m}^{2}\right]\end{array}$ & 569,454 & 401,907 & 896,059 \\
\hline Number of Forest Patches & 366 & 515 & 240 \\
\hline Forest Area $\left[\mathrm{m}^{2}\right]$ & $208,420,192$ & $206,982,000$ & $215,054,096$ \\
\hline Forest Perimeter $[\mathrm{m}]$ & $1,318,740$ & $1,480,380$ & $1,492,560$ \\
\hline Patch-per-Unit area (PPU) & 0.112 & 0.158 & 0.074 \\
\hline Square Pixel (SqP) & 0.956 & 0.961 & 0.961 \\
\hline Edge density & 40.39 & 45.35 & 45.72 \\
\hline
\end{tabular}

Table 5.1 shows that the total forest area of the study site has only slightly changed, with a 0.7 percent decrease from 1987 to 1999 . The average forest patch area has decreased by almost one third, associated with a large increase in the number of forest patches. The edge density increased by approximately 12 percent. These changes imply increasing forest fragmentation, which is confirmed by the 41 percent increase in PPU.

The increased forest fragmentation may have an impact on the habitats of local species. The increase in the edge density may be particularly important in influencing species diversity and the distribution of species. Certain butterflies and birds prefer edges habitat, as do white-tailed deer. Other birds and mammals may decrease because fragmentation may segment their traditional habitats, allow increase predation, and cause an increase in mortality from crossing the human-made barriers.

The observed increase in forest fragmentation in the study area may be associated with changes in the local agricultural economy, the increase in population and numbers of households. USDA national agricultural statistics (USDA National Agricultural Statistics Service 2000) indicate that, during the ten years from 1987 to 1997, the number of farms 
in Monongalia County and Preston County increased by 17.4 percent, from 1,104 to 1,296. The total area of land in farms has increased by 11.5 percent from 76,127 ha $(188,113$ acres $)$ to 84,891 ha $(209,771$ acres $)$. The average size of farms was relatively stable. These new farms may occupy former forestlands, and fragment large forests.

The 1990 and 2000 Census results (Table 5.2) (US Census Bureau 2000) show that the total households in eastern Monongalia County and Western Preston County has increased by 20.3 percent and 65.1 percent respectively. The total population has increased by about 12.6 percent and 49.1 percent, respectively. This increase in local population and number of households has likely fueled construction growth relatively undevelop areas, which in turn probably increased fragmentation.

Table 5.2 Household and population statistics for the eastern portion of Monongalia County and western Preston County for 1990 and 2000 (from http://factfinder.census.gov)

\begin{tabular}{|l|l|l|l|l|}
\hline District & Index & $\mathbf{1 9 9 0}$ & $\mathbf{2 0 0 0}$ & changes \\
\hline \multirow{2}{*}{$\begin{array}{l}\text { Morgantown } \\
\text { city }\end{array}$} & $\begin{array}{l}\text { Total } \\
\text { households }\end{array}$ & 9,588 & 10,782 & $12.45 \%$ \\
\cline { 2 - 5 } & Population & 25,879 & 26,809 & $3.6 \%$ \\
\hline $\begin{array}{l}\text { Cheat Lake } \\
\text { CDP }\end{array}$ & $\begin{array}{l}\text { Total } \\
\text { households }\end{array}$ & 1,489 & 2,511 & $68.64 \%$ \\
\cline { 2 - 5 } & Population & 3,992 & 6,396 & $60.22 \%$ \\
\hline \multirow{2}{*}{$\begin{array}{l}\text { Brookhaven } \\
\text { CDP }\end{array}$} & $\begin{array}{l}\text { Total } \\
\text { households }\end{array}$ & 1,506 & 1,838 & $21.85 \%$ \\
\cline { 2 - 5 } & Population & 3,836 & 4,734 & $23.40 \%$ \\
\hline \multirow{2}{*}{$\begin{array}{l}\text { First district, } \\
\text { Preston County }\end{array}$} & $\begin{array}{l}\text { Total } \\
\text { households }\end{array}$ & 1,439 & 2,375 & $65.05 \%$ \\
\cline { 2 - 5 } & Population & 3,943 & 5,879 & $49.1 \%$ \\
\hline
\end{tabular}




\section{Web design results}

The Web based forest fragmentation information and analysis web site (WFFA) consists of an introduction page, and nine independent functional web sites. All functional web sites use the same map sets which consist of West Virginia county boundary layer, 1987 and 1999 Landsat TM images layers, 1987 and 1999 land cover/land use classification data with unique symbols for each class, and 1987 and 1999 land cover/land use classification data with transparent symbols.

In order to compare the efficiency of delivering forest fragmentation data and analysis functionalities with ArcIMS HTML and Java approaches, the accessibility, navigation, interactive digital cartography, data integration, and the success of the implementation of the proposed functionalities were assessed.

\section{Accessibility}

The main difference between a stand-alone GIS system and a Web GIS is that the web GIS provides GIS users a higher level of accessibility. A web GIS is usually accessed by a standard web browser such as Netscape Navigator or Microsoft Internet Explorer. ArcIMS (Version 3.0) supports the developments of Web GIS application on standard Web browsers. ArcIMS Java viewers require users to download Java applets and install plug-ins on the users' browser. Therefore, the user who tries to access the Forest Fragmentation Analysis web site through a public computer that does not allow download privileges, may not get all the forest fragmentation analysis functions which were implemented with Java approaches.

The target users of the forest fragmentation Web GIS include forest researchers, owners, managers and the public. Many people access the Internet through a specific Internet browser system such as DELL online and AOL online. Therefore, the accessibility of the forest fragmentation web site through DELL online and AOL online was tested. The results showed that both the HTML and Java viewers could not be supported in these two browsers.

The accessibility of the WFFA web site is influenced not only by the limitation of the ArcIMS HTML and Java approaches themselves, but also by the customization strategies employed. The main tool used in this study was JavaScript. Because the 
different Web browsers have no standardized support for JavaScript syntax, different implementations for different Web browsers should be developed. In this study, the patch query function will only run in the Microsoft Internet Explorer. The process fails in Netscape Navigator.

\section{Navigation}

The navigation ability of a Web GIS application can be assessed in two main aspects: Web page navigation ability and Map navigation ability.

For the WFFA web site, Web page navigation was implemented mainly by HTML and JavaScript functions. HTML provides navigation at a number of levels from page to page and from site to site. The mechanisms used to implement this navigation can be hypertext links and buttons. JavaScript can provide a greater range of navigation commands. With the ArcIMS web site design template, most web page navigation functions can be created automatically. However, after implementation of the forest fragmentation web site, it was found that the BACK button in Internet Explorer would not work. This constrains the system's navigation ability, and also reduces system efficiency because it may require the system to run the duplicate mapping processing that are time consuming for the Web GIS server.

With ArcIMS HTML and Java approaches, the map navigation ability is clearly enhanced. End users can pan the map in any direction with a simple mouse movement. They can change the zoom to get a better perspective of the area of interest. The overview map gives end users a larger spatial extent so that end users can get a better understanding of the spatial relationship of the current map to the entire region. When end users pan the map, the location of the area covered in map window will be shown as a red rectangle in the overview map window. In WFFA web site, a West Virginia county map was used for the overview map.

\section{Interactive digital cartography}

The essential part of a Web GIS application is digital cartography which consists of digital map organization and display, map rendering, labeling, symbolization, and other elements such as a scale bar, north arrow and legend. 
In an ArcIMS application, the digital map was organized by one or several themes which represent thematic information layers. For example, in WFFA, the map consists of five themes that are West Virginia County, 1987 Landsat TM image, 1987 land cover, 1999 Landsat TM image and 1999 land cover. End users can turn on or off the display of each theme, and can specify a vector theme as an active layer. These controls for themes allow end users to analyze selected themes and geographic features. However, there is no support for selecting a group of themes at one time. This function would be especially helpful in displaying multi-temporal forest fragmentation information, because it would allow end users to switch from one temporal window (for example, 1987 data) to another (for example, 1999 data) more conveniently.

ArcIMS supports scale-based map display and symbolization. When the scale of map changes, themes can be hidden or increased in visibility. The symbols of a geographic feature can also be changed when the scale changes. This provides the potential to represent multi-resolution forest fragmentation information. However, in the WFFA system, the scale based map display and symbolization was not tested, because the scale changes of the main data sets have no direct association with data symbols.

Both ArcIMS HTML and Java approaches support the creation of cartographic elements such as a scale bar, north arrow, and legend on the web page map, and support digital map rendering and symbolization. In particular, ArcIMS supports the building of dynamic legend that is updated when the displayed themes change, or new spatial operations such as selection or identify are run. In the WFFA project, when the current themes change, the dynamic legend automatically removes the appropriate elements. A dynamic legend makes the digital map looks more intuitive, and also saves the limited map representation space of the screen.

In the WFFA project, the data sets are mainly of two types: vector land use and land cover classification polygons, and raster Landsat Images. The vector data are used for patch selection and forest fragmentation metric calculation, and the raster data are used as a background. Therefore, the requirements for map rendering and symbolization are relatively simple. There are four main requirements: rendering the land cover polygons, rendering selected polygons, creating user-defined Landsat TM Image color 
composites, and creating a transparent overlay of vector classification polygons on the raster Landsat Image. In the WFFA system, the first three requirements were implemented successfully. The fourth requirement, that of an overlay, failed because there is no direct indirect data structure that supports the representation of multi-band remote sensing images on the Web. The rendering result also looks vaguely in Web browser. The transparent overlay was implemented by rendering polygons in a semitransparent color. Rendering polygons in a semi-transparent or transparent fashion could help forest fragmentation analyst in linking land cover classification results with remote sensing images for verification. In addition, the transparent rendering of polygon features can be supported directly in ArcIMS Map Author, but semi-transparent rendering requires ArcXML to integrate transparent rendering and other rendering symbols (Figure $5.8)$.

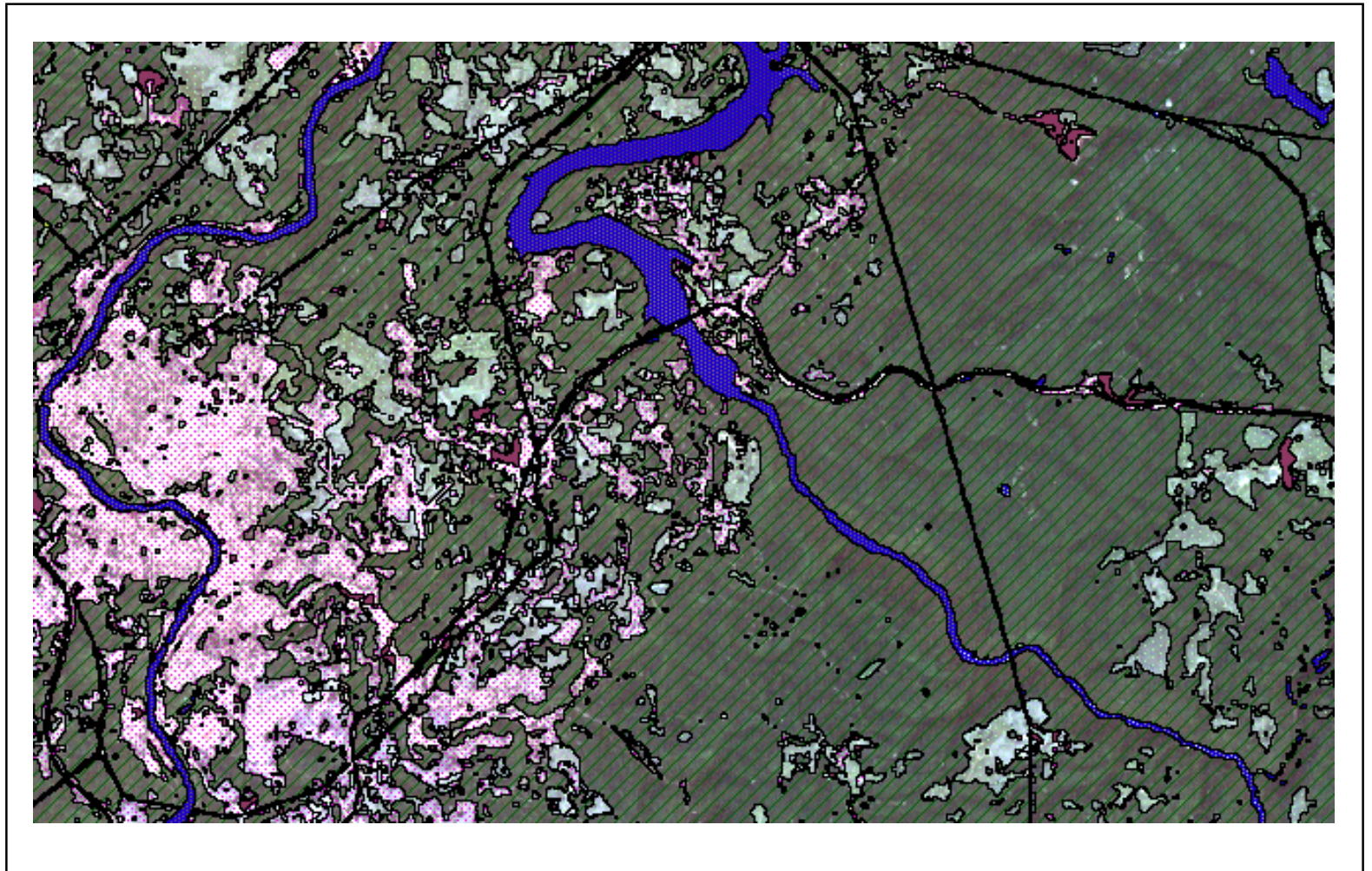

Figure 5.8 Semi-transparent rendering land use/cover classes on the Landsat image

Comparing the ArcIMS HTML and Java approaches, the latter provides more support for interactive map rendering and symbolization. With the Java approach, users can change color and symbols used to render land covers. This makes it possible for a user to build a preferred rendering schema. With the HTML approach, all themes are 
displayed according to a schema defined by the system itself at the time of the development of the web site.

\section{Data integration}

The construction of the WFFA web site showed that ArcIMS provides wide support for integrating spatial data with a variety of formats, including shapefiles, images, and ArcSDE data (ESRI 2000a, ESRI 2000b). In this study, Landsat TM data in ERDAS IMG format land cover/land use classification data in Shape File format were integrated in the system successfully. However, when IMG data were added with ArcIMS Map Author, the IMG data could not be shown in the map design phase. Therefore, ArcView had to be used to check whether the Landsat TM data and the classification data matched.

Delivery of the forest fragmentation analysis tool also required support for the integration of local user data for metrics calculation. The ArcIMS HTML approach only supports server side land cover data for forest fragmentation analysis; The ArcIMS Java approach allows users to include their own land cover/land use themes for the forest fragmentation metrics calculation. In the WFFA system, with Forest Fragmentation Metrics Calculator Java Viewer, user can calculate indices on local data sets.

This flexibility of the ArcIMS Java approach extends to the delivery of distributed spatial data on the Web. In the WFFA system, end users can draw on distributed land cover data, remote sensing images, and other remote ArcIMS web map services, for forest fragmentation spatial analysis.

\section{Functionalities}

In WFFA system, four proposed functions were implemented with ArcIMS (Table 5.3). Only the fifth proposed function, forest fragmentation disturbance assessment, could not be supported directly with the ArcIMS existing modeling language and approaches. In order to develop a web-based forest fragmentation disturbance assessment tool, there are three essential requirements. The first requirement is to allow users input disturbance geographic features in the web browser. The geographic feature could be a buffered line of a new road or a polygon representing a proposed logging 
ooperation. The second requirement is that the added geographic features can be uploaded to the server. The third requirement is that the server can automatically combine the uploaded geographic features with existing geographic data sets for spatial analysis. In the ArcIMS Java approach, with Edit Note, users can add polygon features in Web browser. The polygon features then can be uploaded to the server side. However, the ArcIMS mapping server cannot combine uploaded data with server side data. ArcIMS HTML is even more limited because it has no support to add new features on the client side. Therefore forest fragmentation disturbance assessment cannot be implemented successfully using existing ArcIMS approaches.

Table 5.3 The implementation of forest fragmentation analysis functionalities

\begin{tabular}{|l|l|l|}
\hline & HTML & JAVA \\
\hline Forest fragmentation viewer & $\mathrm{X}$ & $\mathrm{X}$ \\
\hline $\begin{array}{l}\text { Forest fragmentation } \\
\text { metrics calculation }\end{array}$ & $\mathrm{X}$ & Unimplemented \\
\hline $\begin{array}{l}\text { Forest fragmentation } \\
\text { change viewer }\end{array}$ & $\mathrm{X}$ & Unimplemented \\
\hline Patch query & $\mathrm{X}$ & $\mathrm{X}$ \\
\hline Disturbance assessment & Unimplemented & Unimplemented \\
\hline
\end{tabular}

\section{X: implemented successfully Unimplemented: not be implemented}

The first step in calculating forest fragmentation metrics is to define a spatial extent of the study area on a land cover vector theme. Theoretically, it should be possible to implement this function with the ArcIMS rectangle selection tool or polygon selection tool. However, in ArcIMS, there is no support for allowing a user to define a spatial extent on a polygon theme. For example, when the rectangle selection tool was used with the land cover layer for defining a rectangle region filter (the red rectangle in Figure 5.9), the tool selects all polygons that intersect with the defined rectangle (the yellow area in Figure 5.10). This unexpected result comes from an existing limitation in the ArcXML 
spatial filter. A spatial filter defines the envelope for a spatial query in ArcXML. A spatial filter has just two options: area_intersection and envelop_intersection. If the area_intersection option is used, all features whose areas overlap the area of the polygon filter are identified. When the envelope_intersection option is used, all features whose bounding box overlap with the bounding box of the polygon filter are selected (ESRI, 2000d). Obviously, there is no support for clipping polygons with a rectangle filter. This means some forest fragmentation analysis cannot be implemented correctly.

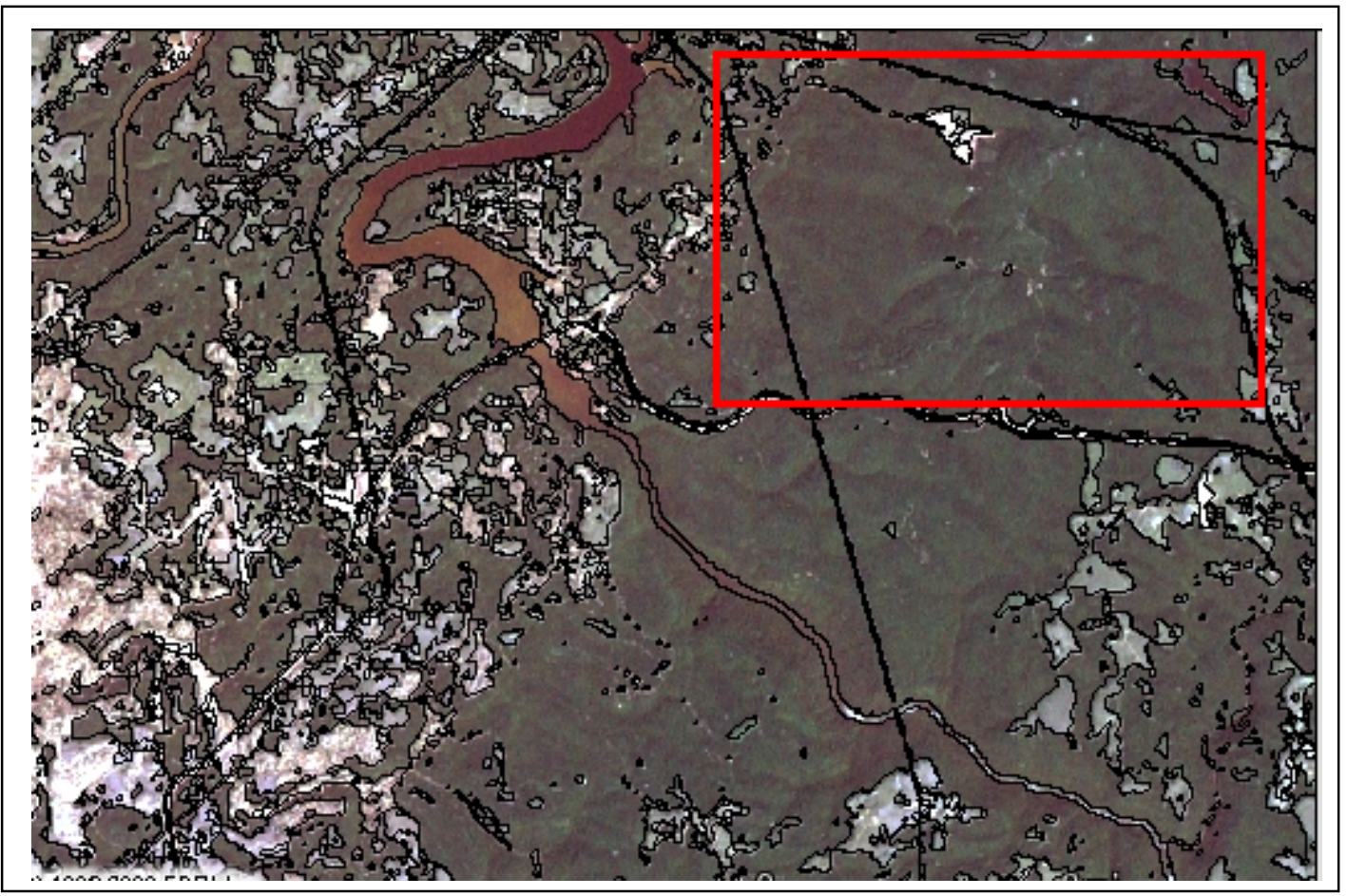

Figure 5.9 Define a study area with a rectangle. 


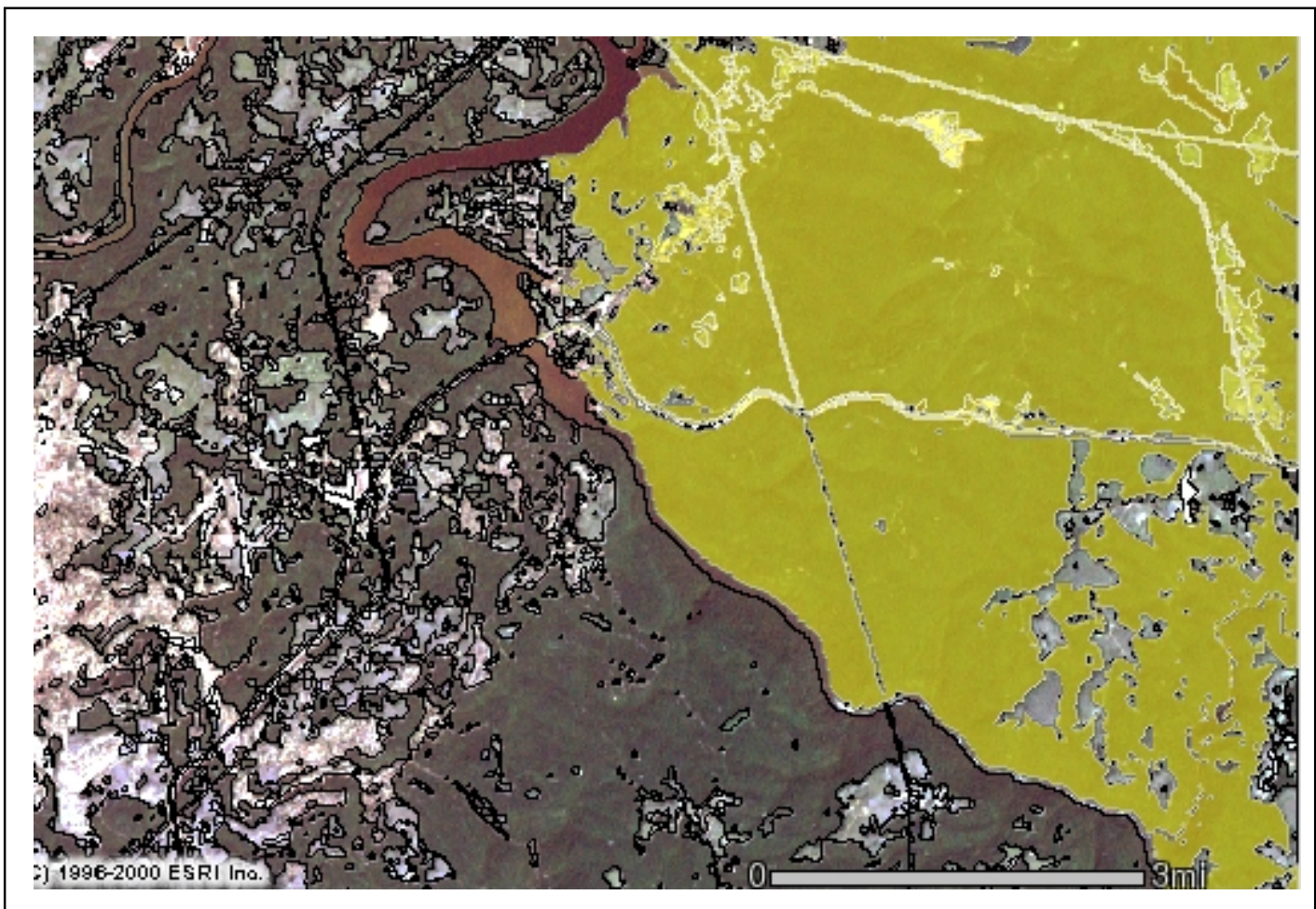

Figure 5.10 the result of defining a study area with the rectangle selection tool. 


\section{Chapter 6 Summary and Conclusion}

In the earlier chapters, research on forest fragmentation, web-based spatial information delivery and forest information delivery was reviewed. In addition, the forest fragmentation status and changes in the study site of northern West Virginia was analyzed. A Web-based forest fragmentation analysis system was developed with ESRI ArcIMS for assessing delivery elements of the same area's forest fragmentation information, as well as analysis tools for the public.

The literature review of forest fragmentation showed that current landscape-scale forest fragmentation studies focus on assessing the status of forest fragmentation, identifying the extent and location of forest fragmentation, modeling changes of forest fragmentation, identifying the cause of forest fragmentation and predicting fragmentation trends, identifying the impacts of forest fragmentation on specific species, and developing forest fragmentation analysis and representation tools. The base data for measuring the status and changes of forest fragmentation at landscape scale is land cover and land use data. In most of studies, the status of forest fragmentation usually was measured by calculating the absolute amount of fragmented patches. Assessing the pattern of those patches is usually done with various landscape metrics. In order to identify the extent or location of forest fragmentation, a common method is to calculate landscape metrics in user-defined independent study units (such as terrain facets, watersheds or management units, or continuous units) and then to compare or rank the values in those units. Forest fragmentation metrics have three basic characteristics: sensitivity, diversity and correlativity. No single index can define or describe directly all pattern or structures of forest fragmentation at the landscape scale. As an alternative, various combinations of measures are used.

At present, the impacts of forest fragmentation in West Virginia have not been widely studied. This study used land cover classification data derived from Landsat TM and ETM+ image captured in 1987 and 1999 for analysis of forest fragmentation. Forest fragmentation metrics in the northern West Virginia were calculated with Patch Analyst. The results show that even though the total forest area in study area has only slightly 
changed, with a 0.7 percent decrease from 1987 to 1999, the average forest patch area has clearly decreased, and the number of forest patches has increased by approximately 40 percent. This implies an increase in forest fragmentation, which may have impacts on the habitat of local species. The 41 percent increasing in PPU values mirror this change. The recoded GAP data were found to show a different spatial pattern regarding the number and average size of patches. However, the SqP metrics was very similar for the recoded GAP and directly classified imagery. This suggests the SqP metric is less sensitive to classification accuracy than other metrics. Similar land classification methods and image processing procedures are essential for integrating multi-temporal remote sensing data for forest fragmentation analysis.

The Web-based forest fragmentation analysis tools used in this study were developed with ESRI ArcIMS HTML and Java approaches. The results show that Web GIS could improve the public's interaction with, and accessibility to, forest fragmentation information. The current HTML approach can be used to deliver forest fragmentation information more widely, with fewer requirements for the client-side computing environment. The Java approach supports the integration of distributed spatial data, and the addition of local data into system by users. The main drawback in the current Web GIS is weak support for spatial query, especially query based on polygon boundaries. 


\section{References}

1000 Friends of Wisconsin and The Land Use Institute, 2001. Fragmentation? What is it really? URL: http://www.1000friendsofwisconsin.com/landuse/forestfrag_what.shtml

Alig, R. J., 1986. Econometric analysis of the factors influencing forest acreage trends in the southeast. Forest Science 32: 119-134.

Anderson, G. S., and B. J. Danielson, 1997. The effects of landscape composition and physiognomy on metapopulation size: the role of corridors. Landscape Ecology 12: 261-271.

Andren, H., 1994 Effects of habitat fragmentation on birds and mammals in landscapes with different proportions of suitable habitat: A review. Oikos 71(3): 355-366.

Automata, 2001. Imagemap authoring guide and tutorial sites.

URL: http://www.cris.com/ automata/tutorial.shtml

Berry, L., 2001. Edge effects on the distribution and abundance of birds in a southern Victorian forest. Wildlife Research 28(3): 239-245.

Birch, T.W., D. A. Ganser, S. L. Arner, and R. H.Widmann, 1992. Cutting activity on West Virginia timberlands. North Journal of Applied Forestry 9(4): 146-148.

Burnham, B. O., 1973. Markov intertemporal land use simulation model. Southern Journal of Agricultural Economics 5: 253-8.

Cantwell, M. D., and R. T. T. Forman, 1993 Landscape graphs: Ecological modeling with graph theory to detect configuration common to diverse landscape. Landscape Ecology 8: 239-255.

Chalifoux, S., F. Cavayas, and J. T. Gray, 1998. Map-Guided approach for the automatic detection on Landsat TM Images of forest stands damaged by the Spruce Budworm. Photogrammetric Engineering and Remote Sensing 64(6): 629-635.

Chavez, P. S., Jr., and D. J. MacKinnon, 1994. Automatic detection of vegetation changes in the southwestern United States using remotely senses images. Photogrammetric Engineering and Remote Sensing 60(5): 571-583.

Dale, V. H., R. V. O'Nell, M. Pedlowski, and F. Southworth, 1993. Causes and effects of land-use change in central Rondônia, Brazil. Photogrametry Engineering \& Remote Sensing 59(6): 997-1005.

DeGraaf, R. M. and M. H. Williams, 1988. Is forest fragmentation a management issue in the Northeast? Paper Collection of Wildlife and fish ecology working group, Society of American Forests' annual Convention Oct. 19,1988 USDA Forest Service.

DeMeo, T. E., 1999. Forest songbird abundance and viability at multiple scales on the Monongahela national forest, West Virginia. West Virginia University Ph.D. Thesis.

DiGiovanni, D. M., 1990. Forest statistics for West Virginia--1975 and 1989. Resour. Bull. NE-114. Radnor, PA: U.S. Department of Agriculture, Forest Service, Northeastern Forest Experiment Station.

Donovan, T. M., J. Faaborg, R. H. Lamberson, A. Kimber, and F. R. Thompson, 1995. Modeling the effects of habitat fragmentation on source and sink demography of Neotropical migrant birds. Conservation Biology 9(6): 1396-1407. 
ERDAS, Inc., 1999. ERDAS Field Guide, Fifth edition, p365-373.

ESRI, 2001. Mapping and GIS for the Internet. An ESRI White Paper from Environmental Systems Research Institute, Inc. Redlands CA.

ESRI, 2000a. ArcIMS Features and functions An ESRI White Paper, Environmental Systems Research Institute, Inc. Redlands CA.

ESRI, 2000b. Using ArcIMS ArcIMS 3. Environmental Systems Research Institute, Inc. Redlands CA.

ESRI, 2000c. Customizing ArcIMS HTML viewer. Environmental Systems Research Institute, Inc. Redlands CA.

ESRI, 2000d. ArcXML programmer's Reference Guide Environmental Systems Research Institute, Inc. Redlands $C A$.

Esseen, P. A., and K. E. Renhorn, 1998. Edge effects on an epiphytic lichen in fragmented forests. Conservation Biology 12(6): 1307-1317.

Fang, T., 1990. An assessment of TM imagery for landcover change detection. IEEE Transactions on Geoscience and Remote sensing 28(4): 681-684.

Finder, R.A., J. L. Roseberry, and A. Woolf, 1999. Site and landscape conditions at white-tailed deer/vehicle collision locations in Illinois. Landscape and Urban Planning 44(2-3): 77-85.

Forests.org Inc., 2001. Forest Conservation Maps. URL:http://forests.org/maps/makemap.htm

Forman, R. T. T., and M. Godron, 1986. Landscape ecology. Wiley, New York.

Fournier, R. A., F. Raulier, L. Guindon, P. Y. Bernier, and C. -H. Ung, 2000. Spatial implementation of models in forestry. Forestry Chronicle 76(6): 929-940.

Franklin, J., 1986. Thematic Mapper analysis of coniferous forest structure and composition. International Journal of Remote sensing 7: 1287-1301.

Fried, J.S. 2000. Geospatially Enabled Information Systems Supporting Forest Decisions at the Millennium: a U.S. Perspective. URL: http://www.metsa.fi/eng/tat/jointweek/pdf/fis2000_fried.pdf

Frohn, R. C., 1998. Remote sensing for landscape ecology: new metric indicators for monitoring, modeling, and assessment of ecosystems. Boca Raton: Lewis Publishers.

Gardner, R.H., W. H. Romme, and M. G. Turner, 1999. Predicting forest fire effects at landscape scales spatial modeling of forest Landscape change. Cambridge University Press: 163-185.

Greenstreet, D., Jr. R. Cardwell, 1997. Economic Impact of the wood products Industry, West Virginia 1995. Bereau of Business and economic Research.

Hansen, A. J., T. A. Spies, F. J. Swanson, and J. L. Ohmann, 1991. Conserving biodiversity in managed forests. Bioscience 41: 382-392.

Harris, L. D., 1984. The fragmented forest. University of Chicago Press, Chicago, IL.

Harris, L. D. and G. Silva-Lopez, 1992. Forest fragmentation and the conservation of biological diversity. Chapman and Hall, NY. 
He, H. S., D. J. Mladenoff, T. A. Sickley, and G. G. Guntenspergen, 2000. GIS interpolations of witness tree records (1839-1866) for northern Wisconsin at multiple scales. Journal of Biogeography 27(4): 10311042.

Hewison, A. J. M., B. Cargnelutti, C. Cibien, J. P. Vincent, J. Joachim, and J. M. Angibault, 2001. The effects of woodland fragmentation and human activity on roe deer distribution in agricultural landscapes. Canadian Journal of Zoology 79(4): 679-689.

Hill, L. R., C. J. McConnell, K. O'Connell, J. Michaels, D. Raimo, J. Garner, J. Grace, and J. Mallow, 1998. Forest Fragmentationin the ChesapeakeBay watershed: Ecological, Economic, Policy and Law Impacts. URL:www.safnet.org/policy/frag6.htm

Holmes, D. E., 1995. Counties in West Virginia Blue Book Chapman Printing 77: 731-846.

Hord, R. M., 1982. Digital Image Processing of Remotely Sensed Data. New York: Academic Press.

Hsu, L., 2000. Modeling Landscape changes using Logit Models.

URL: http://www.gisdevelopment.net/aars/acrs/2000/ts6/fore0005.shtml

Integraph, 2001. GeoMedia Web Applications - GIS For The Web.

URL: http: //www.intergraph.com/gis/newsroom/gwe_white.asp

Jensen, J. R., 1996. Introductory digital image processing: a remote sensing perspective. Englewood Cliffs, New Jersey: Prentice-Hall.

Johnsson, K., 1995. Fragmentation index as a region based GIS operator International Journal of Geographical Information Systems 9(2): 211-220.

Johnston, J. J., D. R. Weigel, and J. C. Randolph, 1997. Satellite remote sensing: an inexpensive tool for pine plantation management. Journal of Forestry 95(6): 16-20.

Jorge, L.A.B., and G.J. Garcia, 1997. A study of habitat fragmentation in Southeastern Brazil using remote sensing and geographic information systems (GIS) Forest Ecology and Management 98(1): 35-47.

Kozakiewicz, M., 1993. Habitat isolation and ecological barriers - the effect on small mammal populations and communities. Acta Theriologica 38(1): 1-30.

Kruess, A., and T. Tscharntke, 1994. Habitat fragmentation, species loss, and biological control Science 264(5165): 1581-1584.

Lefsky, M. A., W. B. Cohen, and T. A. Spies, 2001. An evaluation of alternate remote sensing products for forest inventory, monitoring, and mapping of Douglas forests in western Oregon. Canada Journal of Forest Resource 31: 78-87.

Lindsay, B. E., and D. L. Dunn, 1979. Land use projections under alternative policies: a transition matrix approach. Journal of Northeastern Agricultural Economic Council 8(2): 87-99.

Lord, J.M., 1990. Scale and the spatial concept of fragmentation. Conservation Biology 4(2): 197-202.

Lynch, J. F., and D. F. Whigham, 1984. Effects of forest fragmentation on breeding bird communities in Maryland, USA. Biological Conservation 28(4): 287-324.

Mallawaarachchi, T., H. S. Lynch, G. Dudgeon, P. A. Walker, M. D. Young, R. E. Smyth, 1996. GIS-based integrated modelling systems for natural resource management Agricultural Systems 50(2): 169-189. 
Mark, D. M., 1999. Geographic information science: critical issues in an emerging cross-disciplinary reseach domain. URL: http://www.geog.buffalo.edu/ncgia/GIScienceReport.html

McGarigal, K., and B. J. Marks, 1995. FRAGSTATS: spatial pattern analysis program for quantifying landscape structure. USDA Forest Services General Technical Report:PNW-351.

Mertens, B., and E. F. Lambin, 1997. Spatial modelling of deforestation in southern Cameroon: spatial disaggregation of diverse deforestation processes. Applied Geography 17(2): 143-162.

Messina, J. P., K. A. Crews-Meyer, and S. J. Walsh, 2000. Scale dependent pattern metrics and panel data analysis as applied in a Multiphase hybrid land cover classification scheme.

URL: http://www.unc.edu/ messina/asprs2000.html

Mid-Atlantic Regional Earth Science Application Center, 2001. Analyzing patterns of forest fragmentation in Montgomery County, MD and Fairfax County, VA.

URL: http://www.geog.umd.edu/resac/forest-frag.htm

Miler, G. W., and H.C. Smith, 1991. Comparing partical sutting practices in Central Appalachian hardwoods. In Eighth Central Hardwood Forest Conference.

Miller, G. W., and J. N. Kochenderfer, 1998. Maintaining species diversity in the Central Applalachians Journal of Forestry 96(7): 28-33.

Minnesota Department of Natural Resources, 2001. ForNet Applications.

URL: http://www.ra.dnr.state.mn.us

Mladenoff, D.J., and W. Baker, 1999. Spatial modeling of forest landscape change-approaches and applications. Cambridge University Press.

Muller, M. R., and J. Middleton, 1994. A Markov model of land-use change dynamics in the Niagara Region, Ontario, Canada. Landscape Ecology 9(2):151-157.

National Climatic Data Center, 2001. West Virginia Climate Summary.

URL: http://lwf.ncdc.noaa.gov/oa/climate/research/cag3/WV.html

Nellis, M. D., T. A. Warner, R. Landenberger, J. McGraw, J. S. Kite and F. Wang, 2000. The Chestnut Ridge Anticline: The first major ridge of the Appalachian Mountains. Geocarto International 15(4): 73-78.

Nielsen, N. C., and M. L. Paracchini, 2000. Remote sensing based estimates of structural diversity and sustainability for forest ecology. Proceedings to IUFRO Conference on Remote Sensing and Forest Monitoring, June 1-3, 1999, Rogow, Poland.

O'Neill, R. V., J. R. Krummel, R. H. Gardner, G. B. S. Jackson, D.L. DeAngelis, B.T. Milne, M.G. Turner, B. Zygmunt, S. W. Christenser, V. H. Dale, and R. L. Graham, 1988. Indices of landscape pattern. Landscape Ecology 1:153-162.

Oregon State University, 2001. Government information sharing project: Agriculture Census for Monongalia County, West Virginia. URL: http://govinfo.library.orst.edu/cgi-bin/ag-state?West+Virginia

Pennsylvania spatial data access, 2001. Access Data: Search by County.

URL: http://www.pasda.psu.edu/access/county.shtml

Peters, T., and J. Nichols, 1998. Development and implementation of a Graphical User Interface to examine land-use planning efforts in Licking County, Ohio. Ohio Journal of Science 98 (4-5): 69-74. 
Ranta, P., M. Siitonen, T. Blom, J. Niemela, and E. Joensuu, 1998. The fragmented Atlantic rain forest of Brazil: Size, shape and distribution of forest fragments. Biodiversity and Conservation 7(3): 385-403.

Rasch, H., 1994. Mapping of vegetation, land cover, and land use by satellite-experience and conclusions for future project applications. Photogrammetric Engineering and Remote Sensing 60: 265-271.

Raschka J. S., 1998. Timber harvesting in West Virginia: a statewide study of some effects and landowner attributes. WestVirginia University Master Thesis.

Reed, R. A., J. Johnson-Barnard, and W. A. Baker, 1996. Contribution of roads to forest fragmentation in the Rocky Mountains Conservation Biology 10: 1098-1106.

Rempel, R., 2000. Patch Analyst 2.2 and Patch Analyst (Grid) 2.1.

URL: http://flash.lakeheadu.ca/ rrempel/patch/

Rempel, R. S., A. Carr, and P. Elkie, 1999. Patch analyst and patch analyst (grid) function reference. Centre for Northern Forest Ecosystem Research, Ontario Ministry of Natural Resources, Lakehead University, Thunder Bay, Ontario.

Riemann, R., and K. Tillman, 1999. FIA photointerpretation in Southern New England: a tool to determine forest fragmantation and proximity to human development. USDA Forest Service, Northeastern Research Station. URL: http://www.fs.fed.us/ne/fia/studies/FRAG/main.html

Richmond, A., 2001. Accessibility and Usability. URL: http://www.wdvl.com/Authoring/Design/Design/design2-1.html

Riiters, K.H., 1995. A factor analysis of landscape pattern and structure metrics. Landscape Ecology 10(1): 23-39.

Riitters, K., J. Wickham, R. O'Neill, B. Jones, and E. Smith, 2000. Global-scale patterns of forest fragmentation. Conservation Ecology 4(2): 3 URL: http:/www.consecol.org/vol4/iss2/art3

Ripple, W. J., 1994. Remote sensing and GIS applications for forest ecosystem analysis. Web document URL: http://www.odyssey.maine.edu/gisweb/spatdb/acsm/ac94061.html

Roberts, S.A., G.B. Hall, and P.H. Calamai, 2000. Analysis forest fragmentation using spatial autocorrelation, graphs and GIS International Journal of Geographical Information Science 14(2): 185204.

Rolstad, J., 1991. Consequences of forest fragmentation for the dynamics of bird populations: conceptual issues and the evidence. Biological Journal - Linnean Society 42(1-2): 149-163.

Rudis, V. A. 1995. Regional forest fragmentation effects on bottomland hardwood community types and resource values. Landscape Ecology 10(5): 291-307

Russ, A., 2000. Forest Fragmentation in Central Massachusetts 1951-1991.

URL: http://earth.clarku.edu/hero/abel/forest_fragmentation.html

Sachs, D. L., P. Sollins, and W. B. Cohen, 1998. Detecting landscape changes in the interior of British Columbia from 1975 to 1992 using satellite imagery. Canadian Journal of Forest Research 28(1): 23-36.

Sader, S. A., 1995. Spatial characteristics of forest clearing and vegetation regrowth as detected by Landsat Thematic Mapper imagery. Photogrammetric Engineering \& Remote Sensing 61(9): 1145-1151.

Salajanu, D., and C. E. Jr. Olson, 2001. The significance of spatial resolution: identifying forest cover from satellite data Journal of Forestry 99(6): 32-38. 
Saunders, D. A., R. H. Hobbs, and C. R. Margules, 1991. Biological consequences of ecosystem fragmentation: A review. Conservation Biology 5:18-32.

Saura, S., and J. Martinez-millan, 2001. Sensitivity of landscape pattern metrics to map spatial extent Photogrammetric Engineering and Remote Sensing 67(9): 1027-1036.

Scott, J. M., F. Davis, B. Csuti, R. Noss, B. Butterfield, C. Groves, J. Anderson, S. Caicco, F. D'Erchia, T. C. Edwards, J. Ulliman, and R. G. Wright, 1993. Gap analysis: A geographical appraoch for protection of Biological Diversity. Wildlife Monograph 123: 1- 41.

Sharma, S., and L. M. S. Palni, 2000. Analysis of fragmentation and anthropogenic disturbances in the Himalayan forests: use of remote sensing and GIS.

URL: http://www.gisdevelopment.net/aars/acrs/2000/ts6/fore0004.shtml

Steele, B. M., 2000. Combining multiple classifiers: An application using spatial and remotely sensed information for land cover type mapping. Remote Sensing of Environment 74(3): 545-556.

Stefanov, W. L., M. S. Ramsey, and P. R. Christensen, 2001. Monitoring urban land cover change: An expert system approach to land cover classification of semiarid to arid urban centers. Remote Sensing of Environment 77(2): 173-185.

Stenback, J.M., and R.G. Congalton, 1990. Using Thematic Mapper imagery to examine forest understory. Photogrammetric Engineering and Remote Sensing 56(9): 1285-1290.

The Charleston Gazette Online, 2001. The Forest for the Trees.

URL: http://www.wvgazette.com/static/series/timber/

The School of Natural Resources University of Missouri-Columbia, 2001. Sustaining private forests in the Central Hardwood Region. URL: http://www.snr.missouri.edu/SPF/fragment.html

Theobald, M. D.,1998. Tools Available for Measuring Habitat Fragmentation.

URL: http://ndis.nrel.colostate.edu/davet/pubs/fragtools.htm

Tinker, D.B., C. I. Fernandes, W. L. Baker, C. A. C. Resor, G. P. Beauvais, and K. F. Kipfmueller, 1998. Watershed analysis of forest fragmentation by clearcuts and roads in a Wyoming forest. Landscape Ecology 13(3): 149-165.

Turner, M. G., 1989. Landscape ecology: the effect of pattern on process. Annual review of ecology and systematics 20: 171-197.

Turner, M. G., 1990. Spatial and temporal analysis of landscape patterns. Landscape Ecology 4:21-30.

Turner, M. G., and R. H. Gardner, 1991. Quantitative methods in landscape ecology. Ecological Studies 82: 536.

Tyrrell, M., and G. Dunning, 2000. Forestland conversion, fragmentation, and parcelization: a summary of a forum exploring the loss of forestland and the future of working family forests. A Yale Forest Forum Series Publication 3(6).

University of Connecticut, College of Agriculture \& Natural Resources, 2001 Forest Fragmentation Research. URL: http://resac.uconn.edu/research/forest_frag/index.html

US Census Bureau, 2000. URL: http://factfinder.census.gov/servlet/BasicFactsServlet

USDA Forest Service, 2001a. Forest Inventory and Analysis Data Base Retrieval System.

URL: http://www.srsfia.usfs.msstate.edu/scripts/ew.htm 
USDA Forest Service, 2001b. Timber Product Output Database Retrieval System.

URL: http://srsfia.usfs.msstate.edu/rpa/tpo/

USDA Forest Service, 2001c. Forest Stewardship Program.

URL: http://www.fs.fed.us/spf/coop/fsp.htm

USDA Forest Service, 2001d. Forest Inventory Mapmaker program.

URL: http://www.ncrs.fs.fed.us/4801/FIADB/index.htm

USDA Forest Service Northeastern Station, 2000. West Virginia Forest Health Highlights - 1999.

URL: http://www.fs.fed.us/na/morgantown/fhp/fhh/fhh99a/wv/wv99.htm

USDA Forest Service Northeastern Station, 2001. Status of Statewide Inventories, West Virginia.

URL:http://www.fs.fed.us/ne/fia/news/status/wv.html

USDA National Agricultural Statistics Service, 2000. http://www.usda.gov/nass

USDA Natural Resources Conservation Service, 1997. National Resources Inventory - West Virginia

Results (Revised December 2000). URL: http://www.wv.nrcs.usda.gov/nri/bclutrends.htm

USDA Soil Conservation Service, 1959. Soil Survey Preston County West Virginia Series 1954 N0.3.

USDA Soil Conservation Service, 1982. Soil Survey Marion and Monongalia Counties West Virginia.

US Environmental Protection Agency, 2000. Mid-Atlantic integrated assessment.

URL: http://www.epa.gov/ceisweb1/ceishome/atlas/maiaatlas/forest_fragmentation.html

USGS Biological Resources Division, 1999. The state of the nation's ecosystem.

URL: http://www.us-ecosystems.org/forests/index.html

USGS Biological Resources Division, 2000. USGS Gap Analysis Program.

URL: http://www.gap.uidaho.edu/

Verboom, B., and R. Van Apeldoorn, 1990. Effects of habitat fragmentation on the red squirrel, Sciurus vulgaris L. Landscape Ecology 4(2-3): 171-176.

Vogelmann, J. E., 1995. Assessment of forest fragmentation in Southern New England Using Remote sensing and Geographic Information System Technology. Conservation Biology 9(2): 439-449.

W3Schools, 2001. The World Wide Web. URL: http://www.w3schools.com/site/site_www.asp

Weakland, C. A., 2000. Effects of diameter-limit and two-age timber harvesting on songbird populations on an industrial forest in central West Virginia. West Virginia University Ph.D. Dissertation.

West Virginia Association of Counties, 2001a Monongalia County.

URL: http://www.wvcounties.org/map-frameset.html

West Virginia Association of Counties, 2001b Preston County.

URL: http://www.wvcounties.org/map-frameset.html

West Virginia Network, 2001. The Mountains of West Virginia.

URL: http://wvnvm.wvnet.edu/ rlanden/mts.htm

West Virginia Geological and Economic Survey, 2001. County at a Glance - Preston.

URL: http://www.wvgs.wvnet.edu/www/geology/geolpres.htm 
West Virginia State Technical Center, 2001. Forest Service Land Cover.

URL: http://wvgis.wvu.edu/dataset.php?action=search\&ID $=64$

Wickham, J.D., K. B. Jones, R. V. O'Neill, K. H. Riitters, and T. G. Wade, 1997. Sensitivity of selected landscape pattern metrics to land-cover misclassification and differences in land-cover composition. Photogrammetric Engineering and Remote Sensing 63(4): 397-402.

Wickham, J. D. and K. H. Ritters, 1995. Sensitivity of landscape pattern metrics to pixel size. International Journal of remote sensing 16:3585-3594.

Wiens, J. A., 1989. Spatial scaling in ecology. Functional Ecology 3: 385-397.

World Wide Web Consortium, 2001. HyperText markup language. URL: http://www.w3.org/MarkUp

Yang, L., J. D. Wickham, S. V. Stehman, and J. H. Smith, 2001. Short communication: thematic accuracy of MRLC land cover for the eastern United States. Remote Sensing of Environment 76(3): 418-422.

Yoakum, J., and W. Dasmann, 1971. Habitat manipulation practices. Wildlife management techniques Third edition, The Wildlife Society, Washington, D.C.: 173-231. 